University of Louisville

ThinkIR: The University of Louisville's Institutional Repository

Electronic Theses and Dissertations

8-2020

\title{
Identification and structural characterization functional motifs in the Porphyromonas gingivalis MFA1 short fimbria.
}

\author{
Mohammad K. Roky \\ University of Louisville
}

Follow this and additional works at: https://ir.library.louisville.edu/etd

Part of the Bacteriology Commons, Organic Chemicals Commons, and the Pathogenic Microbiology Commons

\section{Recommended Citation}

Roky, Mohammad K., "Identification and structural characterization functional motifs in the Porphyromonas gingivalis MFA1 short fimbria." (2020). Electronic Theses and Dissertations. Paper 3517. https://doi.org/10.18297/etd/3517

This Doctoral Dissertation is brought to you for free and open access by ThinkIR: The University of Louisville's Institutional Repository. It has been accepted for inclusion in Electronic Theses and Dissertations by an authorized administrator of ThinkIR: The University of Louisville's Institutional Repository. This title appears here courtesy of the author, who has retained all other copyrights. For more information, please contact thinkir@louisville.edu. 


\title{
IDENTIFICATION AND STRUCTURAL CHARACTERIZATION FUNCTIONAL MOTIFS IN THE PORPHYROMONAS GINGIVALIS MFA1 SHORT FIMBRIA
}

\author{
Mohammad K. Roky
}

A dissertation submitted to the faculty of the School of Medicine of the University of Louisville in partial fulfillment of the requirements for the degree of

\author{
Doctor of Philosophy \\ in Microbiology and Immunology \\ Department of Microbiology and Immunology \\ University of Louisville
}

August 2020 



\title{
IDENTIFICATION AND STRUCTURAL CHARACTERIZATION FUNCTIONAL MOTIFS IN THE PORPHYROMONAS GINGIVALIS MFA1 SHORT FIMBRIA
}

\author{
By \\ Mohammd K. Roky \\ A Dissertation Approved on \\ $23^{\text {rd }}$ July, 2020 \\ By the following committee \\ Dissertation Chair ,Dr. Donald R. Demuth \\ Dissertation Co-chair, Dr. Matthew B. Lawrenz \\ Dr. Pascale Alard \\ Dr. Jan S. Potempa \\ Dr. James E. Graham
}




\section{ACKNOWLEDGMENT}

I would like to express my gratitude to all those who gave me the possibility to complete this Dissertation. I have the honor to express my heartfelt thanks and earnest gratitude to my honorable supervisor Dr. Donald R. Demuth, for his enthusiastic guidance, affectionate inspiration, passionate supervision and endearing company. I am very indebted to learn not only how to think critically like scientists but also how to improve myself as a person. Your calmness and supportiveness, even in my difficult time, are truly appreciative. The positive experience that I had under your supervision simply amazing which I will miss.

I am deeply indebted to my committee members whose help, stimulating suggestions and encouragement helped me in all the time of research. My special thanks to Dr. Matthew B. Lawrenz. When I approached to have you as my Co-mentor, you happily accepted without a second thought. You always asked thought-provoking research questions that suggested to me how to solve them. It was always interesting to discuss the research topics with you, also thanks for the guidance for further career development. Dr. Pascale Alard, you are a fantastic personality and I am very fortunate to have you in my committee even though my research is not your immediate interest. Your encouragement to think outside of the box helped me to be a better scientist. Thanks to Dr. James E. Graham for the endless congenial conversation and discussion. 
Alsothanks to Dr. Jan S. Potempa for allowing me to use of lab equipment and reagents and also valuable suggestion to address the research question.

My special thanks goes to Dr. John O. Trent. It's a beautiful experience to team up with Dr. Trent and learning various bioinformatics tools for protein analysis and drug discovery. Without the help of Dr. Trent and the molecular modeling facility, it was nearly impossible to finish up my projects. I also would like to extend my gratitude to the animal care facility for allowing me to perform the mice experiments.

I would like to express my gratitude to all the past and present members of Dr. Demuth's Lab. Especially Julie, who took the time to teach me a lot of techniques and helped with managing all the reagents and equipment. It was fun to brainstorming with Dr. Blair, Dr. Weigel, Dr. Sztukowska, Hazel and Julie to troubleshoot an experiment. Thanks, Hazel, Julie and Hetal for continuous support and the lots of laughs at the end of the tiresome days.

Without the support of family and friends, it was nearly impossible to make it possible. My parents encouraged me to pursue higher studies. Today I am standing here because of their dedication and sacrifice. I would like to thank all of my friends, especially Reza, Dhruba, Mamun and Opu, Chris, Irina, Jim, Hassan and Hazel, for their warm welcome and support to adapt to the new environment in the early days of being here.

Finally, I would like to thank all the faculties, staff and students of the Department of Microbiology and Immunology and Department of Oral Immunology and Infectious diseases for their appraisals, support, encouragement and assessments towards achieving this goal. 


\title{
ABSTRACT \\ IDENTIFICATION AND STRUCTURAL CHARACTERIZATION OF \\ FUNCTIONAL MOTIFS IN THE PORPHYROMONAS GINGIVALIS \\ MFA1 SHORT FIMBRIA
}

\author{
By \\ Mohammad K. Roky

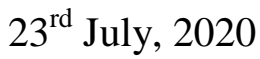

Porphyromonas gingivalis is a causative agent of periodontal disease, initially colonizes the oral cavity by adhering to commensal streptococci. Adherence requires the interaction of the minor fimbrial protein (Mfa1) of P. gingivalis with streptococcal antigen I/II (Ag I/II). A peptide derived from Ag I/II peptide has been well characterized and shown to significantly reduce $P$. gingivalis colonization and bone loss in vivo, suggesting that this interaction represents a potential target for therapeutic intervention. However, the functional motifs of Mfa1 involved in the interaction with $\mathrm{Ag}$ I/II remain uncharacterized. A series of $\mathrm{N}$ - and C-terminal peptide fragments of Mfal were expressed and tested for inhibition of $P$. gingivalis adherence to $S$. gordonii. Residues 225-400 of Mfa1 was identified as essential for $P$. gingivalis adherence. Using the three- 
dimensional structure of Mfa1, a putative binding cleft was identified and five smallmolecule peptidomimetics based on the AgI/II peptide could be docked in this site. Sitespecific mutation of amino acids in the predicted cleft, specifically, R240A, W275A, D321A and A357P inhibited the interaction of Mfa1 with streptococci. Additionally, complementation of an Mfa1-deficient $P$. gingivalis strain with wild-type $m f a l$ restored adherence to streptococci, whereas complementation with the site-specific mfal mutants resulted in significantly reduced levels of adherence.

To develop targeted small molecule inhibitors of this protein-protein interaction, virtual screening was performed to identify compounds that exhibit structural similarity with the two functional motifs (NITVK and VQDLL) of the AgI/II peptide. Thirtythree compounds were tested for in vitro inhibition of $P$. gingivalis adherence, and the three most potent compounds, N7, N17 and V8, were further characterized. In vivo efficacy of these compounds was evaluated in a murine model of periodontitis. Treatment of mice with each of the compounds reduced $P$. gingivalis-mediated gingival inflammation as determined by IL-17 expression and significantly reduced maxillary alveolar bone resorption in infected animals. Finally, a series of cytotoxicity tests were performed with human and murine cell lines. N17 and V8 did not show any cytotoxic activity. In summary, we successfully characterized the Mfa1 binding site and identified compounds N17 and V8 as potential lead compounds that will provide the platform to design more potent therapeutic agents that may function to limit or prevent P. gingivalis colonization of the oral cavity. 


\section{TABLE OF CONTENT}

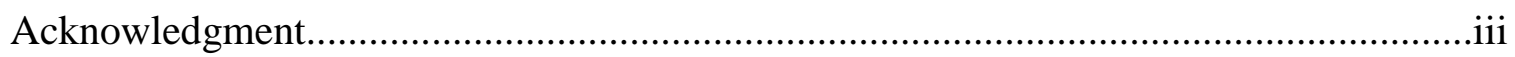

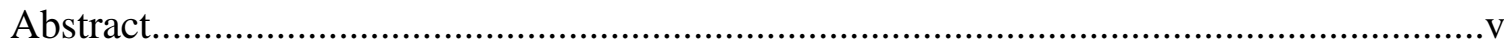

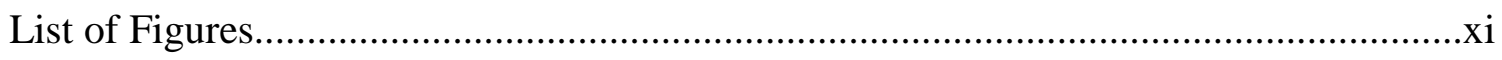

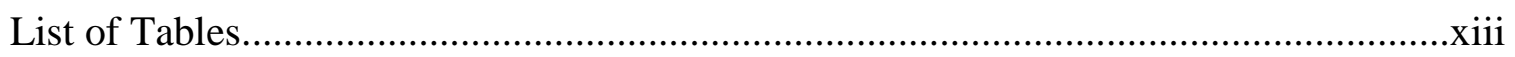

Chapter One: Introduction

Periodontal Diseases........................................................................................... 1

Epidemiology of Periodontal Diseases................................................................

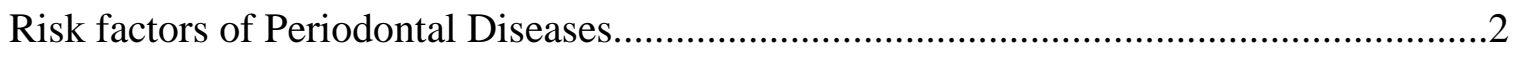

Association of Periodontal diseases with Systemic Diseases........................................3

Pathophysiology of Periodontal Diseases...................................................................4

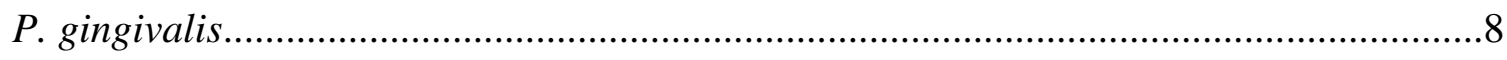

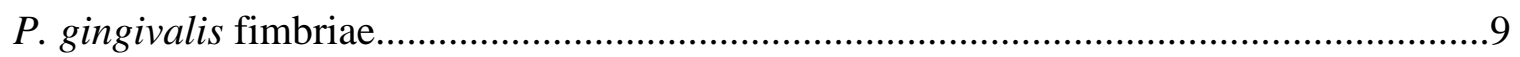

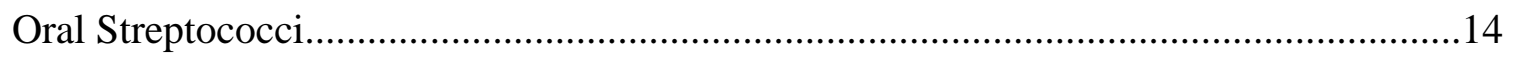


Streptococcal adhesins

Community formation between $P$. gingivalis with oral streptococci 16

Development of targeted therapeutics for the treatment of periodontal disease 19

Chapter Two: Methods and Materials

2.1. Bacterial strains and growth conditions 21

2.2. Recombinant protein/peptide constructs .24

2.3. Expression and purification of truncated Mfa1 peptides .26

2.4. Dual species biofilm model

2.5. SiteMap prediction of a putative binding cleft in Mfa1 .29

2.6. Site-directed mutagenesis. .29

2.7. Random mutation. .30

2.8. Complementation of $P$. gingivalis SMF1 with mutated Mfa .31

2.9. Cell surface expression of mutated Mfa1 polypeptides 31

2.10. Mfa1 polymerization. .32

2.11. Virtual screening of small molecule inhibitors. .32 
2.12. Murine in vivo model of periodontitis.

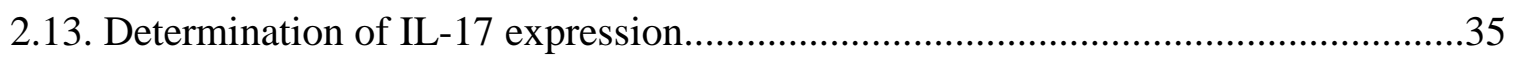

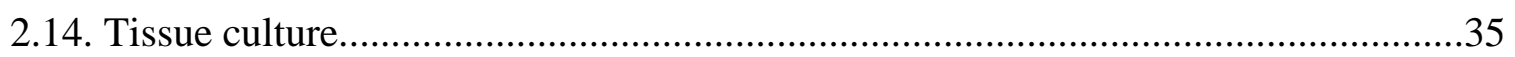

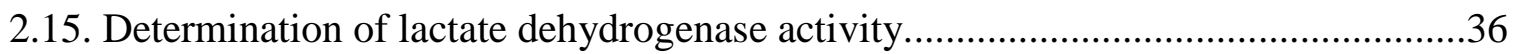

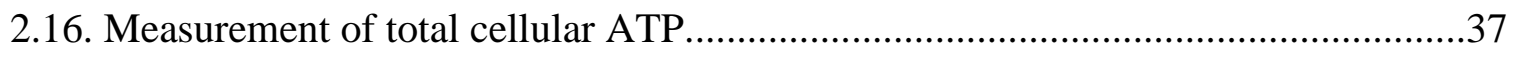

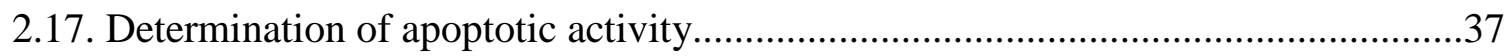

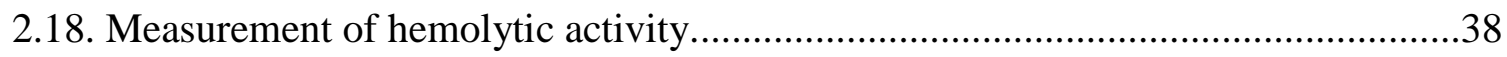

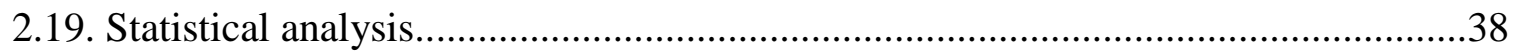

Chapter Three: Identification and characterization of functional motifs of Mfa1

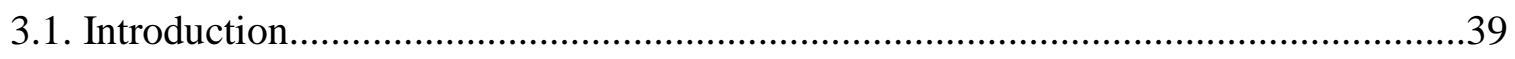

3.2. Results

3.2.1 Localization of Mfa1 functional domains...............................................41

3.2.2. In silico prediction of a putative Ag I/II binding cleft in Mfa1..................45

3.2.3. Complementation of $P$. gingivalis with site-specific Mfa1 mutants..........49

3.2.4. Polymerization of wild-type and mutant Mfa1 proteins............................51

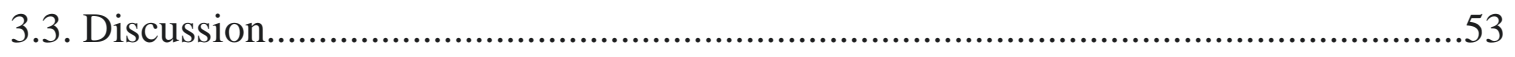


Chapter Four: Small molecule drug discovery

4.1. Introduction.

4.2. Results:

4.2.1. In vitro activity of the ZINC library candidates..........................................59

4.2.2. Small molecule inhibition of $P$. gingivalis virulence..................................63

4.2.3. Determination of cytotoxicity of the active compounds...............................69

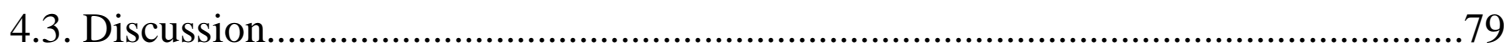

Chapter Five: Summary

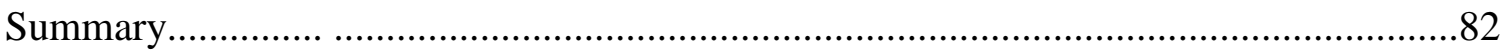

Chapter Six: Future Directions

6.1. Co-crystallization of Mfa1 with BAR peptide/peptidomimetics.................................89

6.2. Efficacy of the lead compounds in the presence of bridging organism...................89

6.3. Effectiveness of the lead compounds in combined treatment.....................................90

6.4. Structure-Activity Relationship (SAR) Study of the Lead compounds......................90

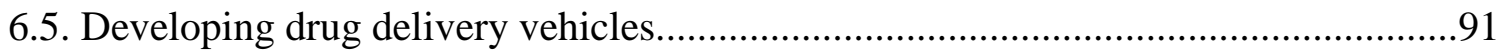

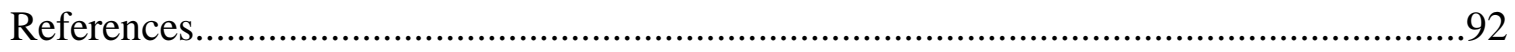

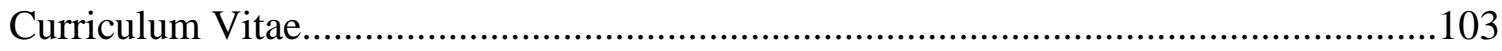




\title{
LIST OF FIGURES
}

\author{
Chapter One:
}

Figure 1.1. Simplified depiction of dental plaque biofilm.................................................

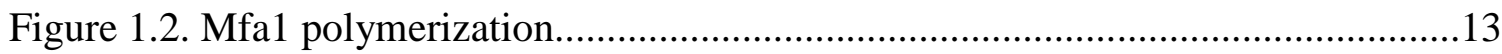

Figure 1.3. Multimodal interaction of $P$. gingivalis with $S$. gordonii................................18

Chapter Three:

Figure 3.1. Schematic representation of the series of Mfa1 peptide fragments.................42

Figure 3.2. Determination of the inhibitory activity of the peptides..................................44

Figure 3.3. Binding site prediction by Sitemap............................................................46

Figure 3.4. Inhibition of $P$. gingivalis adherence to $S$. gordonii by mutated Mfa1 peptides.

Figure 3.5. Complementation of $P$. gingivalis SMF1 with wild-type and site-specific

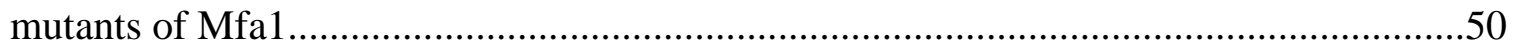

Figure 3.6. Denaturation of $P$. gingivalis minor fimbriae.............................................52

\section{Chapter Four:}

Figure 4.1. In vitro screening of the small molecules....................................................60

Figure 4.2. Dose dependent inhibition of $P$. gingivalis adherence...................................61

Figure 4.3. Chemical structures of the lead compounds.................................................62

Figure 4.4: Schematic timeline of the mice model of periodontitis....................................64

Figure 4.5. In vivo inhibition of $P$. gingivalis virulence................................................66 


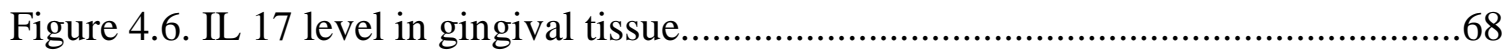

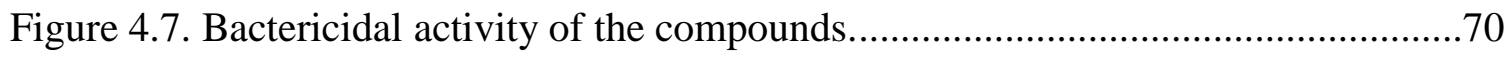

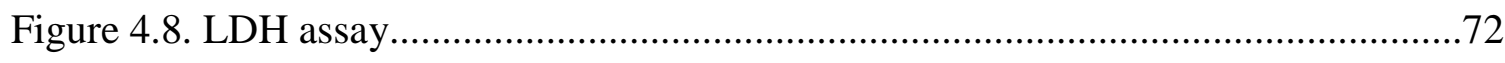

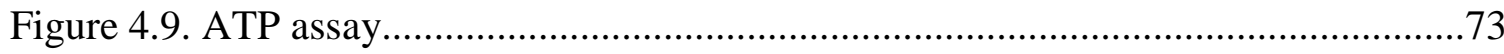

Figure 4.10. Cell death caused by the compounds.....................................................74

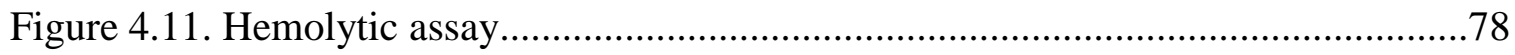

\section{Chapter Five:}

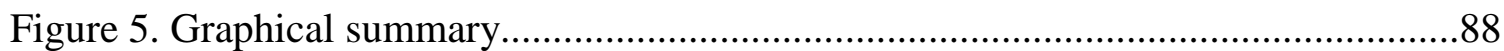




\section{LIST OF TABLES}

\section{Chapter Two:}

Table 2.1. Bacterial Strain used in this study

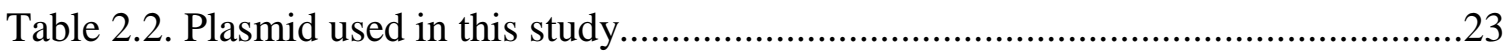

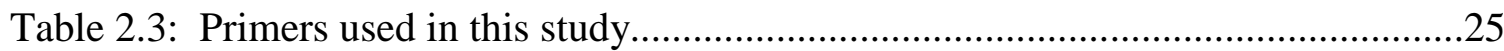

\section{Chapter Four:}

Table 4.1. Quantification of cells in each quadrant for each compound is shown in Figure

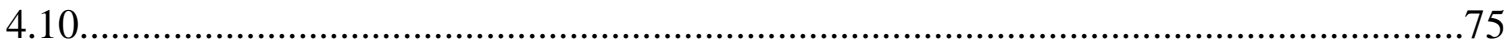

Table 4.2: Quantification of early and late apoptotic J774A.1 cells treated with

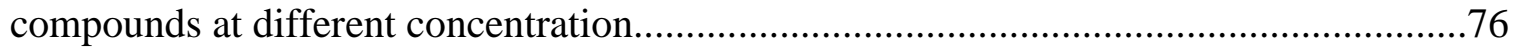

Table 4.3: Quantification of early and late apoptotic HL60 cells treated with compounds

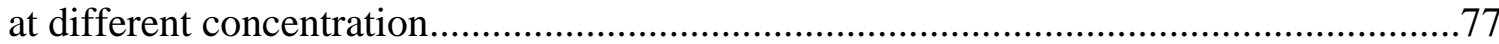




\section{CHAPTER ONE: INTRODUCTION}

Periodontal disease: The ancient Chinese and Egyptians described the periodontal disease as an inflammatory condition over 4000 years ago and Hippocrates (400-335 BC) defined the disease as "the gums were bleeding or rotten" [1, 2]. Since then, periodontal diseases have been considered to be a group of chronic inflammatory conditions of the gingiva (soft tissues surrounding the teeth) and tissues supporting the teeth (collagen fiber) caused by dental plaque or a microbial biofilm. This disease represents a significant oral health concern and is a substantial contributor to tooth loss [3] and if not treated properly could even lead to death [4]. The early stage of periodontal disease is gingivitis which is manifest by localized inflammation of gingival tissue, characterized by redness, swollen and tender gums or that readily bleed upon probing. If the infection persists, disease can advance to chronic irreversible inflammation that leads to the destruction of alveolar bone and ligament, resulting in attachment loss that increases the depth of the periodontal pockets, which is a hallmark symptom of advanced periodontal disease.

Epidemiology of Periodontal Disease: According to Tonetti et al., periodontal disease is the most prevalent disease in humankind [5]. The global burden of disease study from 1990 to 2010 ranked periodontal disease as the sixth most pervasive disease in the world that affects $11.4 \%$ or 743 million people worldwide [6,7] and 158 million people face consequences of tooth loss, especially older adults [6]. The World Health Organization (WHO) maintains an oral health database that collects data from different countries based 
on the Community Periodontal Index (CPI)[8]. The CPI score is an indication of the severity of periodontal disease in the community and ranges from 0 to 4 . As attachment loss and probing depth (PD) are considered to be the gold standard for the prevalence of the periodontal disease [9], a CPI score of 0 indicates no periodontal disease, a score of 1 indicates bleeding on probing; 2 indicates the presence of calculus and bleeding; 3 is associated with subgingival pocket depths $4-5 \mathrm{~mm}$ and 4 represents very deep subgingival pockets of $6 \mathrm{~mm}$ or greater. Based on these criteria, studies indicate that $35 \%$ to $70 \%$ of adolescents in developing nations have calculus deposits whereas only $4 \%$ to $34 \%$ exhibit calculus in developed countries. In the adult population, $36-63 \%$ exhibit calculus deposition in developing nations and $14-47 \%$ in developed nations [8]. In the US, $42 \%$ of the adult population at 30 years of age or older suffer from periodontitis and $7.8 \%$ of this adult group have severe periodontitis. Severe periodontitis is mostly prevalent in adults 65 years or older, and in Mexican American, non-Hispanic black populations, and in smokers [10].

Risk factors of periodontal disease: Some of the risk factors of periodontal disease are modifiable, and some are non modifiable. Smoking is the major modifiable risk factor of periodontal disease, and the smokers suffer three times greater risk of severe periodontitis than the non-smoker [11]. The initiation and progression of periodontitis in smokers is more rapid and show these individuals show inferior treatment outcomes compare to nonsmokers [11-13]. Diabetes mellitus is the most notable systemic disease considered as a risk factor for the onset of periodontal disease both in young people and adults. It contributes to periodontal disease by exerting an enhanced inflammatory response relative to non-diabetic patients [14-16]. Globally, socioeconomic conditions also play a 
vital role in periodontal disease due to the higher cost of treatments $[6,17]$. For example in the United States, severe periodontitis is most common in Mexican American and African American populations who live under the federal poverty line $[9,10,18]$. Other factors such as stress and increased insulin resistance also represent potential risk factors for periodontal disease $[19,20]$. This anger, job-related stress, or the stress associated with military service can predispose individuals to periodontal disease [21-23].

Age and heredity are some of the non modifiable risk factors. All of the systemic reviews have consistently shown the adults aged 60-69 years are more prone to periodontal disease than the 40-50 years age group [10, 24]. Although no single nucleotide polymorphisms related to genetic predisposition to periodontal disease have been identified, people with different genetic backgrounds and associated with various environmental factors can be more prone to this disease [23, 25].

Association of periodontal disease with systemic disease: Around 1891, W. D. Millar first advanced the notion of the relationship between oral and systemic infection [26]. In 1900, a British doctor, William Hunter, proposed the focal infection hypothesis and suggested that the extraction of the teeth alleviates the disease burden and improves the overall health in patients $[26,27]$. In the 1980 s, the association of periodontal disease and systemic disease became more apparent as a well-defined study observed that myocardial infraction was associated with poor oral health [28]. Since then, the number of studies have explored the association between oral health and other systemic diseases such as atherosclerotic cardiovascular disease [29], diabetes [16] 
, adverse pregnancy outcome [30], respiratory disease [31, 32], chronic kidney disease [33], rheumatoid arthritis [34], cognitive impairment [35], obesity [36], metabolic syndrome [37] and cancer [38]. The link between periodontal disease and other systemic diseases is bidirectional and exact mechanisms to explain these associations have yet to be defined. However, one possible mechanism may be the direct involvement of oral pathogens in systemic disease progression and oral pathogens have been detected in thrombi from patients with acute myocardial infarction [39]. In addition, an indirect mechanism may involve the secretion of inflammatory factors, such as $\mathrm{C}$ reactive protein which is elevated during chronic periodontitis into the bloodstream [40].

Pathophysiology of periodontal disease: Periodontal disease is defined as a polymicrobial community-mediated chronic inflammatory disease and chronic inflammation in the host leads to the destruction of alveolar bone and subsequent sulcus formation [41-43]. The microbes that reside in the oral cavity comprise hundreds of species of different bacteria, fungi, and viruses $[44,45]$. These organisms adhere to solid surfaces (e.g., the tooth surface or metal implants) and form a highly organized biofilm structure [46]. The simple depiction of organized microbial communities in oral biofilm represented by the Figure 1.1. The initial stage of biofilm formation is the adsorption of salivary macromolecules (mucin, proteins) on the enamel surface to generate the acquired pellicle. Gram-positive organisms such as Actinomyces and Streptococcus species represent primary colonizers, as these bacteria can readily adhere to this acquired pellicle through species-specific receptor-ligand interactions [47]. Once attached, these bacteria promote further increases in biofilm biomass through co-aggregation interactions and initiate the generation of an extracellular matrix, which also promotes the adhesion of 
other bacteria. As the biofilm biomass and thickness increases, the consumption and diffusion of oxygen and other nutrients promotes the generation of anaerobic environments that facilitates the enrichment of the later colonizing pathogenic Gramnegative flora, including red-complex bacteria Porphyromonas gingivalis, Tannerella forsythia, and Treponema denticola [48]. In many cases, the attachment of Gramnegative organisms to the Gram-positive colonizers is mediated by specific sets of adhesin-receptor interactions. Interspecies cell signaling, metabolic cross-feeding, synergistic cooperation and interspecies antagonism can each contribute to the establishment of this polymicrobial community [49-51]. Finally, calcification of this biofilm occurs through the deposition of calcium and phosphate ions from serum (in subgingival biofilm) or from the saliva (in supragingival biofilm) to form the mature dental plaque or calculus $[19,23]$. In a healthy individual, the host-microbe homeostasis is important for maintaining oral health. However, disrupting homeostasis and changing the overall microbial composition of the dental biofilm, especially by the Gram-negative bacterium $P$. gingivalis, can create a dysbiotic microbiota which can elicit uncontrolled inflammation leading to permanent tissue damage [52-54].

Both innate and adaptive immunity is involved in controlling the formation of dental plaque. Epithelial cells are the first-line of host defense and act as a physical barrier but in response to microbial metabolites can secrete cytokines and stimulate neurons to produce neuropeptides that increase blood flow in the local tissue [55]. Dendritic Langerhans cells uptake microbial antigens and present the antigen to the lymph node to promote the infiltration of neutrophils, granulocytes, and lymphocytes. Neutrophils phagocytose bacteria and contribute to maintaining homeostasis between oral microbes 
and the host. However, a dysbiotic microbiota leads to the hyperactivation of neutrophils that increases the production of enzymatic activity and reactive oxygen species leading to tissue damage. For example, the increased level of myeloperoxidase produced by hyperactive neutrophils impairs the balance of membrane metalloproteinases, thus eventually leading to bone resorption by the degradation of ligament fibers by metalloproteinases [56]. Most of the B cells that reach the site of infection represent sIgA antibody-producing plasma cells, which may also play a role in controlling the microbial growth [57]. However, plasma cells also produce various cytokines such as TNF $\alpha$, IL-6, IL-10, TGF $\beta$ and metalloproteinases, which can contribute to tissue destruction [58]. Additionally, $\mathrm{T}$ cell-mediated immune response occurs through stimulation of Th1, Th2, and Th17 subsets as well as various Treg populations [55]. 


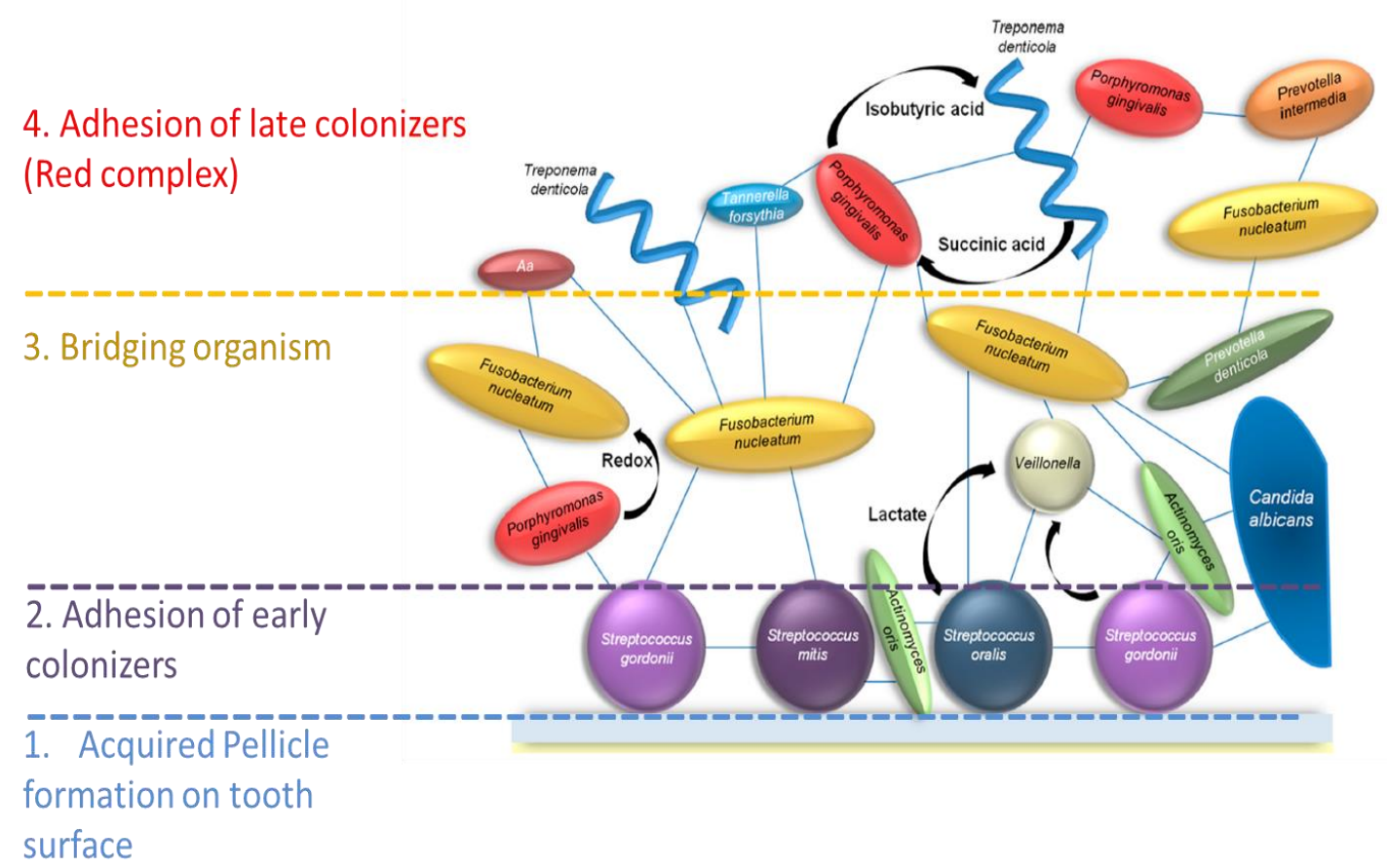

Figure 1.1. Simplified depiction of dental plaque biofilm: Dental biofilm is highly organized microbial structure started with acquired pellicle formation where early colonizer readily adhere and provide the substrata for late colonizer. Blue line indicate adhesin receptor interaction among microbes, also metabolic cross talk common event in dental biofilm. Image is modified from Wright et al. 2013 [59]. 
P. gingivalis: $P$. gingivalis is a Gram-negative rod-shaped, asaccharoytic, obligate anaerobic bacterium that produces a number of virulence factors. Most notable are the Arg- and Lys-specific gingipains that degrade host proteins, including complement system activation proteins. In addition, a serine phosphatase (SerB) can suppress IL-8 production, and lipid A1-4 phosphatase can function to modify lipid A to subvert host immune response. Nucleoside diphosphate kinase suppresses ATP induced cell apoptosis and $P$. gingivalis fimbriae mediate the colonization and interbacterial adhesion as well as contribute to immunosuppression [51, 60]. Although periodontal disease is caused by a polymicrobial infection, $P$. gingivalis is considered to be a vital contributor to disease onset and progression. $P$. gingivalis is detected in $85 \%$ of the disease cases [61], strongly correlates with subgingival pocket depth [62] and has been shown to induce alveolar bone loss in an animal model $[52,63]$.

The primary niche of $P$. gingivalis is the subgingival area of the teeth, where conditions are optimal for the successful colonization and growth of the obligate anaerobic bacteria [64]. However, to colonize this preferred niche, $P$. gingivalis must first overcome obstacles in the supragingival environment such as the mechanical shearing forces that arise from tongue movement or the flow of saliva and gingival crevicular fluid. Furthermore, specific salivary molecules can promote microbial clearance via expectoration or swallowing [65]. To survive in this hostile environment, $P$. gingivalis adheres to other bacterial species that exist in the supragingival microbiota [66-68]. Coadhesion of $P$. gingivalis with other bacteria is mediated by specific set of adhesinreceptor interactions and may be driven by physiologic compatibility of the adherent organisms. For instance, Fusobacterium nucleatum co-aggregates with $P$. gingivalis and 
supports the growth of $P$. gingivalis by reducing oxygen levels to that which can be tolerated by $P$. gingivalis [66]. F. nucleatum can also generate ammonia from salivary aspartate and glutamate, which raises the $\mathrm{pH}$ level, supporting the growth of acid intolerant $P$. gingivalis [69]. Similarly, $P$. gingivalis can adhere to the oral streptococci, specifically to streptococci of the oralis, sanguinis, and mitis groups but not to Streptococcus mutans [67, 70,71]. The physiological basis for this species-specific interaction might arise from the acidophilic nature of the mutans group in contrast to other streptococcal groups. Moreover, the introduction of $P$. gingivalis in human volunteers showed $P$. gingivalis localized exclusively in the supragingival biofilm where streptococcal species predominate [72]. Furthermore, S. gordonii secretes the folate synthesis precursor para-aminobenzoic acid (PABA), which is essential for histidine metabolism in $P$. gingivalis and thus may support the growth of this organism in supragingival biofilm [51]. Thus, $P$. gingivalis may initially colonize the oral cavity by interacting with streptococci in supragingival biofilm as a precursor to becoming established in its preferred niche in the subgingival biofilm.

P. gingivalis fimbriae: $P$. gingivalis express two distinct types of fimbriae in its surface that participate in nearly all host-pathogen interactions as well as bacterial co-adhesion with biofilm microbiota [73]. The fimbrial subunit of long fimbriae is FimA encoded by the fimA gene [74] which exists in six sub-families designated as genotypes I to VI [7375]. However, FimA genotype II is the most common in $P$. gingivalis, and both genotypes II and IV have been suggested to be more virulent than the other groups [7678]. Other accessory proteins that comprise the FimA fimbriae are encoded by the fimABCDE operon. FimB localizes in the outer membrane, and facilitates anchoring and 
the regulation of expression and length of FimA [79]. FimC, FimD, and FimE are accessory proteins that mainly contribute to tip formation and may be involved in the adhesive functions of the FimA fimbriae [80, 81]. FimA fimbriae play a crucial role in the pathogenesis of $P$. gingivalis as they mediate interaction with the $\alpha 5 \beta 1$-integrin family of proteins facilitate the endocytosis of this organism in phagocytic cells by actin cytoskeletal remodeling and once inside the host cells, $P$. gingivalis impairs phagocytic killing mechanisms [82]. FimA has also been suggested to be involved in the pathogenesis of rheumatoid arthritis since it mediates the initial invasion of osteoblasts [83, 84]. In addition, FimA mediates co-aggregation and microcolony formation with other bacterial communities in the oral biofilm. For example, FimA mediates adhesion to Actinomyces viscosus [85], Treponema denticola [86], Streptococcus gordonii [87], and Streptococcus oralis [88] via specific adhesin receptor interactions and also binds to dentilisin of $T$. denticola and glyceraldehyde-3-phosphate dehydrogenase (GAPDH) of $S$. gordonii and S. oralis [51].

The short or minor fimbriae of $P$. gingivalis are comprised of the structural protein Mfa1 and are antigenically distinct from the long fimbriae (FimA). However, a recent study indicates that FimA and Mfa1 are structurally related and contain a conserved fold [89]. Mfa1 is encoded by the $m f a l$ co-expressed with the other accessory proteins Mfa2, Mfa3, Mfa4, and Mfa5 (Figure 1.2a). Mfa2 functions to anchor the fimbriae and regulate fimbrial length, similar to the function of FimB. Mfa3, Mfa4, Mfa5 correspond to long fimbrial components FimC, FimD, and FimE, and may be involved in tip formation and essential for the adhesive function of minor fimbriae [82, 90]. Mfa1 also interacts with DC-SIGN (dendritic cell-specific ICAM-3 grabbing nonintegrin) of dendritic cells [91] 
and induces secretion of inflammatory cytokines such as IL-1 $\beta$, IL-8, IL-6, and TNF $\alpha$ [91, 92]. Minor fimbriae also stimulate the production of interleukin-1 $\alpha$ (IL-1 $\alpha)$, IL-1 $\beta$, IL-6, and tumor necrosis factor- $\alpha$ (TNF- $\alpha$ ) by macrophages and has been suggested to be a causative factor of alveolar bone resorption in animal models [78, 93]. A major function of the minor fimbriae involve the co-aggregation of $P$. gingivalis with specific streptococcal species. Park et al. showed that Mfa1 is required for community formation with $S$. gordonii, and interacts with the $S$ gordonii surface antigen Ag I/II [94]. Minor fimbriae also involved in $P$. gingivalis autoaggregation, monospecies microcolony formation, and mature biofilm formation [95].

Recent studies indicate that the biogenesis of Mfa1 and FimA fimbriae most likely occur through a donor strand based exchange mechanism (DSE) observed in type I and P fimbriae assembly in E. coli but no chaperone-usher pathway is involved in $P$. gingival fimbrial biogenesis [89, 96-101]. Mfa1 and FimA fimbriae are both synthesized as preproproteins (Figure 1.2b) containing an $\mathrm{N}$-terminal signal peptide that mediates translocation of the proteins across the inner membrane into periplasmic space. Upon translocation, the signal peptide is removed by signal peptidase and the proproteins become lipidated $[102,103]$. The proproteins are secreted across the outer membrane and are anchored on the membrane most likely by the lipid moiety. Each protein then undergoes further proteolytic cleavage by Rgp to produce the mature structural subunits of the respective fimbriae $[103,104]$. Cleavage by Rgp results in the formation of a long hydrophobic motif that subsequently interacts with a $\beta$-strand from the adjacent subunit of the growing fibril (Figure 1.2c) [89]. Mfa2 act as an anchor protein that anchor the Mfa1 fimbriae in the outer membrane and also act as an elongation and assembly 
terminator [105]. Finally, Mfa3, Mfa4 and Mfa5 accessory protein assembled in the distal part of the mature fimbriae $[106,107]$. 
A)

B)

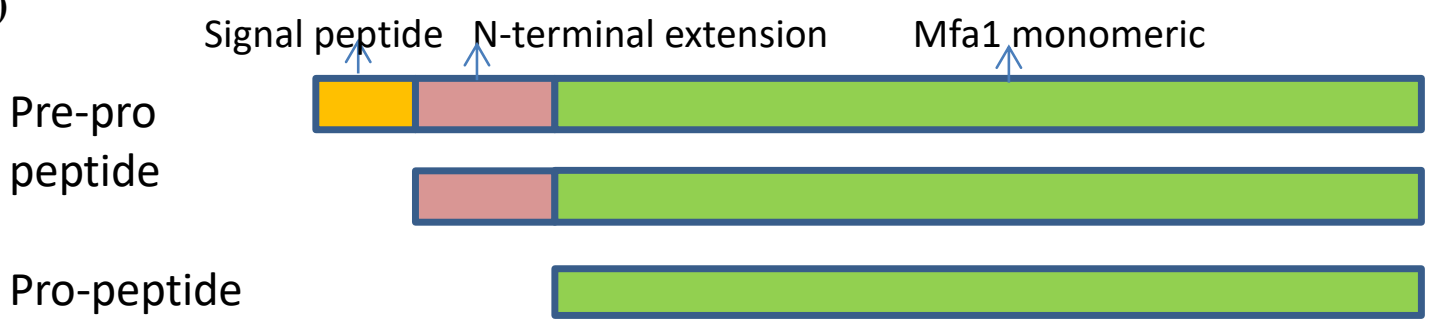

C)

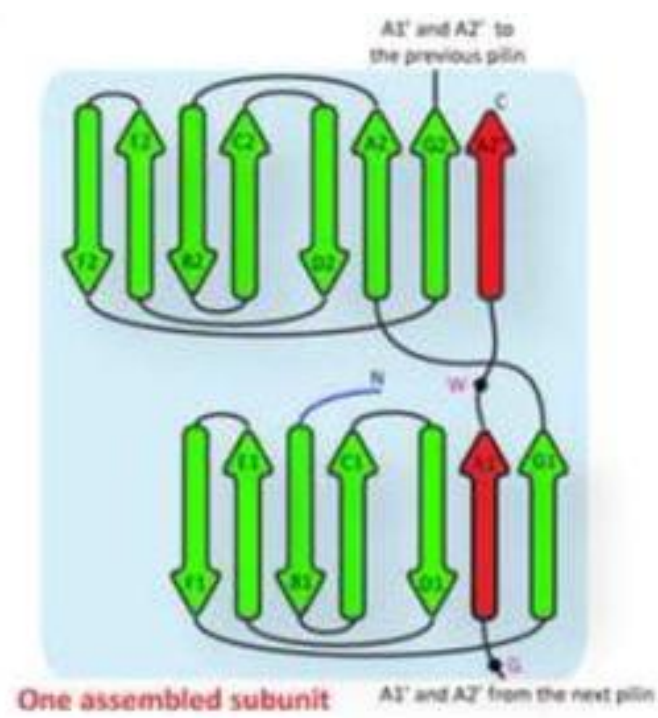

Figure 1.2. Mfa1 polymerization: A) The anchor protein Mfa2 along with tip protein Mfa3, Mfa4 and Mfa5 coexpressed with Mfa1. B) Mfa1 expressed as pre-pro peptide, the signal peptide remove by peptidase where the $\mathrm{N}$ terminal extension further removed by Rgp in the cell surface to produce mature Mfa1 monomer. C)The proposed donor strand exchange mechanism of type $\mathrm{V}$ fimbria assembly by $\mathrm{Xu}$ et al. [89]. 
Oral streptococci: The oral streptococci are Gram-positive, facultative bacteria that constitute the majority of the cultivatable bacterial community in dental plaque $[47,108$, 109] and are considered to be beneficial to oral health [110]. Oral streptococci promote the colonization and growth of other commensals such as Actinomyces spp and Veillonella spp and may antagonize the colonization by pathogenic organisms [111]. The presence of beneficial streptococci such as $S$. gordonii, S. sanguinis, and S. parasanguinis is associated with protection against cariogenic S. mutans pathogenesis [112]. Streptococcus mutans is notable for its ability to ferment pyruvic acid to lactic acid resulting in decreased $\mathrm{pH}$ levels (below 5.5) that promotes demineralization of enamel and dentin, contributing to cavity formation [113]. In contrast, the commensal streptococci produce ammonia by the arginine deaminase system (ads) [114]. Commensal streptococci also generate $\mathrm{H}_{2} \mathrm{O}_{2}$ which prevents colonization of $S$. mutans as well as downregulates bacteriocin expression by interfering with the $S$. mutans quorum-sensing system [115-118]. Other oral streptococci, such as S. cristatus downregulate FimA expression in $P$. gingivalis, which may interfere with $P$. gingivalis colonization of the subgingival biofilm $[118,119]$. However, recent studies indicate that the beneficial role of the oral streptococci may be questionable since they also contribute to the development of pathogenic dental biofilm. For instance, $S$ gordonii, along with the $F$. nucleatum, may reduce the oxygen concentration to levels which can be tolerated by $P$. gingivalis, resulting in $P$. gingivalis colonization [120]. A. actinomycetemcomitans, the predominant pathogen in localized aggressive periodontitis (LAP) can metabolize lactate produced by S. gordonii, an end product of the fermentation of low molecular weight carbohydrates, thus support the growth and enhance the virulence of $A$. 
actinomycetemcomitans [121, 122]. S. gordonii also enhances Candida albicans hyphal formation and promotes community formation in the oral cavity [123].

Streptococcal adhesins: Oral streptoccoci possess a plethora of adhesin molecules that facilitate the colonization of the tooth surface via interaction with the acquired pellicle, epithelial cell interactions and coaggregation with other organisms such as $F$. nucleatum, P. gingivalis and A. actinomycetemcomitans [110]. The most prominent adhesins of oral streptococci are the antigen I/II family of adhesins (e.g., SpaP, P1, PAc, SspA, SspB) that are expressed by many if not all species of oral streptococci [124]. The primary sequences of $\mathrm{Ag} \mathrm{I/II} \mathrm{proteins} \mathrm{highlight} \mathrm{distinct} \mathrm{features} \mathrm{of} \mathrm{their} \mathrm{structure,} \mathrm{including} \mathrm{a}$ signal peptide (residues 1-38), an Alanine rich N-terminal repeat domain (residues 164471), a divergent domain (residues 472-770), a Proline repeat domain (residues 771-887), a highly conserved C-terminal region (residues 888-1413) and a sorting sequence (LPXTG) and transmembrane domain (residues 1537-1556) [125]. These proteins mediate streptococcal binding to the salivary glycoprotein gp340 (DMBT1), speciesspecific community formation with $P$. gingivalis and coaggregation with Actinomyces and C. albicans $[70,125,126]$. S. gordonii expresses two paralogs of AgI/II (SspA and SspB) which are distinct from Ag I/II of S. mutans [87, 127]. Among other notable adhesins of streptococci is the serine rich repeat glycoprotein (srr) involved in binding to sialylated glycans of the soluble human salivary mucin $[112,128]$ and with platelet glycoproteins [129]. GAPDH, a glycolytic enzyme found on the streptococcal surface can bind to fibronectin, lysozyme, as well as other proteins related to cytoskeletal rearrangement [130]. CshA and $\mathrm{CshB}$, fibrillar proteins expressed by many oral 
streptococci also bind to fibronectin as well as to other organisms in the oral biofilm $[131,132]$.

Community formation between $\boldsymbol{P}$. gingivalis with oral streptococci: The adherence of $P$. gingivalis to $S$. gordonii is multimodal and is mediated by two sets of adhesin-receptor interactions (Figure: 1.3) [42]. P. gingivalis FimA binds to GAPDH on the streptococcal surface and Mfa1 interacts with specific streptococcal Ag I/II proteins. The binding region of GAPDH that interacts with FimA encompasses amino acids 166 to 183, a region predicted to be $\beta$-sheet and likely involves hydrophobic interactions with FimA [133]. However, this interaction alone is not sufficient to drive community formation. Park et al. showed that community formation is driven by the interaction of Mfal with Ag I/II [94] and Daep et al. showed that this interaction is essential for in vitro biofilm formation [134] and for the pathogenesis of $P$. gingivalis in a murine model of periodontitis [135]. Demuth et al. showed that SspB residues 1167 to 1192 are essential for the interaction of $S$. gordonii with $P$. gingivalis and within this region, Asn 1182 and Val1185 were identified as crucial amino acids [71]. Subsequently, Daep et al. demonstrated that a synthetic peptide derived from SspB residues 1167 to 1193 (designated BAR) functioned as a potent competitive inhibitor of $P$. gingivalis adherence to $S$ gordonii in vitro, exhibiting a $50 \%$ inhibitory concentration of $1.3 \mu \mathrm{M}$ [135]. Structural dissection of BAR peptide at the molecular level using combinatorial peptide libraries that replaced Asn1182, Thr1184, and Val1185 with each of the 19 common amino acids showed that positively charged residues at the 1182 position and hydrophobic residues at position 1185 improved BAR inhibitory actvity, suggesting that this adhesin-receptor interaction requires both electrostatic and hydrophobic interactions 
[134]. Further dissection of BAR identified a second motif in BAR that was important for $P$. gingivalis adherence. This motif (VQDLL) forms an amphipathic $\alpha$-helix and resembles the core element of the eukaryotic nucear receptor (NR) box protein-protein interaction domain $[135,136]$. Disruption of this motif severely impairs the binding of $P$. gingivalis to streptococci. Although $\mathrm{Ag} \mathrm{I} / \mathrm{II}$ has been well charecterized, the binding region of Mfa1 remains to be characterized. 


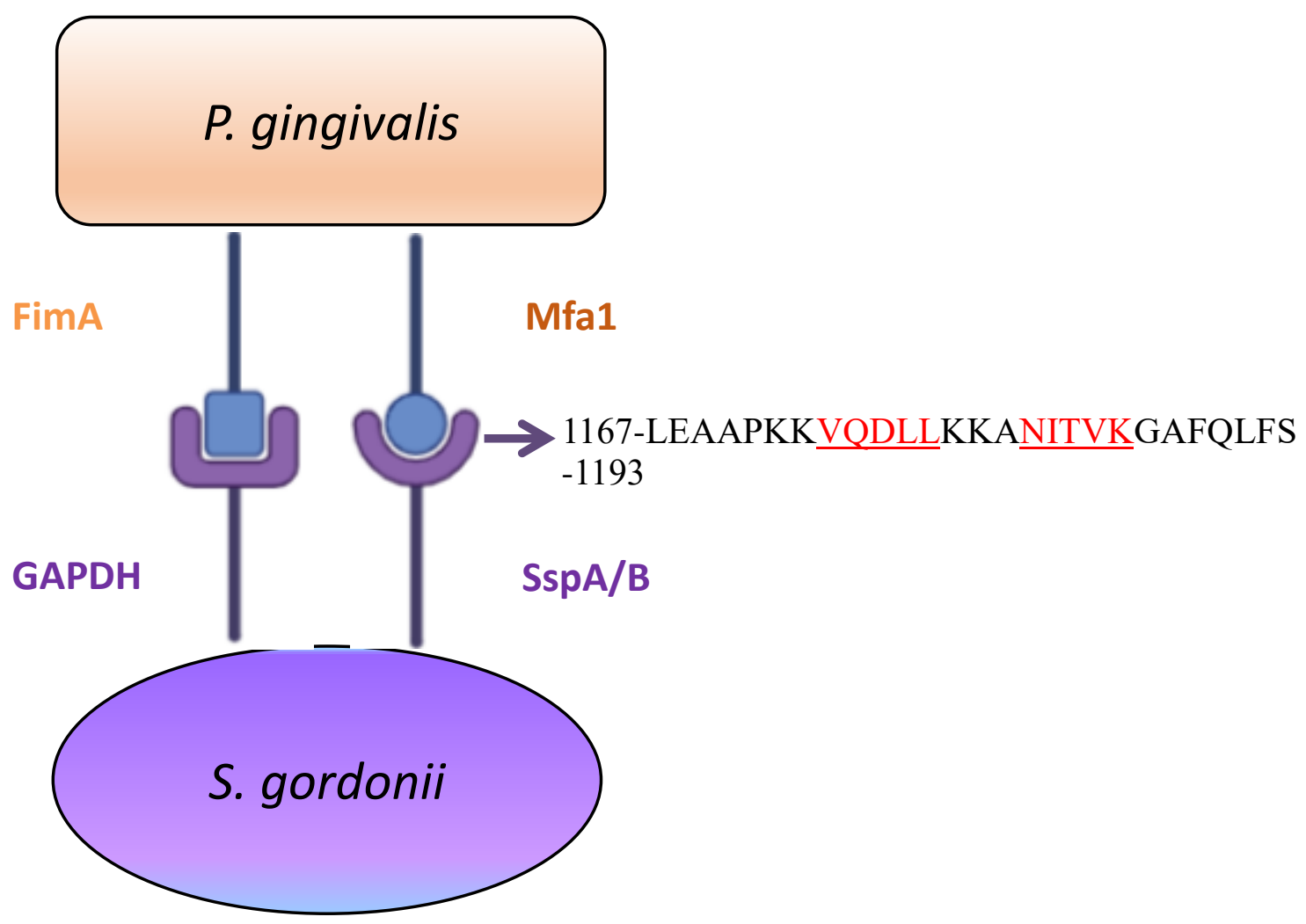

Figure 1.3. Multimodal interaction of $\boldsymbol{P}$. gingivalis with $S$. gordonii: Long fimbriae FimA of $P$. gingivalis interacts with GAPDH of $S$. gordonii, whereas short or minor fimbriae Mfa1 interacts with $\mathrm{SspA} / \mathrm{B}$ surface antigen. Binding region of SspA/B encompasses 1167-1193 amino acid residues comprised of VQDLL and NITVK motifs (red, underlined). 


\section{Development of targeted therapeutics for treatment of periodontal disease: Non-}

surgical treatment of periodontal disease consists of professional debridement of both supragingival and subgingival plaque and calculus with scaling and root planing. In conjunction with nonsurgical treatment, antibiotic therapy of several broad-spectrum antibiotics can significantly improve gum health $[137,138]$. However, this approach is inefficient when the subgingival pocket depth is $>6 \mathrm{~mm}$. For these cases, a surgical procedure such as open flap debridement is required to separate the gingival tissue from the underlying tissue in order to access the plaque and reduce subgingival pocket depth $[139,140]$. In general, these approaches have limitations. For instance, treatment with broad-spectrum antibiotics indiscriminately kills the oral microbiome, including commensal bacteria and concern is growing over the development of antibiotic resistance. The surgical procedures are invasive and expensive and disease often recurs. Thus, there is a need to develop novel therapeutic approaches for the targeted (e.g., species specific) elimination of pathogenic bacteria. To develop targeted therapy against P. gingivalis, Deap et. al. tested the efficacy of synthetic BAR peptide (SspB adherent region) in mouse model of periodontitis and demonstrated peptide-mediated inhibiton of P. gingivalis virulence [135]. Patil et. al synthesized small molecule peptidomimetics based on BAR that showed promising activity in the reduction of in vitro P. gingivalis biofilm formation with $S$. gordonii [141]. Subsequently, Tan et al. showed that these peptidomimetics prevent colonization of $P$. gingivalis and reduce virulence in the mouse model of infection [142]. However, additional structural information is required to better understand the Mfa1/SspB interaction in order to develop and design more potent inhibitors for species-specific novel therapy against $P$. gingivalis infections. 
The studies in this dissertation successfully identified and characterized the binding cleft of Mfal that interacts with $\mathrm{AgI} / \mathrm{II}$ and we showed that it is comprised in part of amino acids R240, W275 and alpha-helical residues 321-328 and 351-367. Furthermore, two small molecule inhibitors, N17 and V8, were identified that block the Mfa1/AgI/II protein-protein interaction. These compounds reduced adherence of $P$. gingivalis to streptococci in vitro and prevented $P$. gingivalis-mediated bone resorption in a murine model of periodontitis. Structural information obtained from characterizing the binding cleft of Mfa1 and the identification of lead compounds will facilitate a better understanding of this protein-protein interaction. In turn, this information will lead to further modification and optimization of the lead compounds to generate more potent $P$. gingivalis species-specific therapeutic agents to control periodontal diseases. 


\section{CHAPTER TWO: METHODS AND MATERIALS}

\subsection{Bacterial strains and growth conditions.}

The strains and plasmids used in this study are shown in Table 2.1 and Table 2.2. P. gingivalis ATCC 33277 was grown in TSBY medium comprised of trypticase soy broth (Difco) supplemented with $2 \%$ yeast extract, $1 \mu \mathrm{g} / \mathrm{ml}$ hemin and $5 \mu \mathrm{g} / \mathrm{ml}$ menadione. For growth on plates, this medium was further supplemented with $1.5 \%$ agar and $5 \%$ sheep blood. The Mfal-deficient and complemented strains were cultured in medium containing the appropriate antibiotics, that is, 1 and $5 \mu \mathrm{g} / \mathrm{ml}$ of tetracycline and erythromycin, respectively. All $P$. gingivalis cultures were incubated under anaerobic conditions $\left(10 \% \quad \mathrm{CO}_{2}, \quad 10 \% \quad \mathrm{H}_{2}\right.$ and $\left.80 \% \quad \mathrm{~N}_{2}\right)$. Brain heart infusion agar (Difco) supplemented with $5 \%$ yeast extract was used to grow S. gordonii DL-1. E. coli strains were maintained in LB medium supplemented with the appropriate antibiotic. Where necessary, the final concentration of ampicillin was $100 \mu \mathrm{g} / \mathrm{ml}$. All bacterial stocks were stored at $-80^{\circ} \mathrm{C}$ in the appropriate medium supplemented with $30 \%$ glycerol. 
Table 2.1. Bacterial Strain used in this study

\begin{tabular}{|l|l|l|l|}
\hline & Strain or Plasmid & Characteristic & $\begin{array}{l}\text { Source } \\
\text { reference }\end{array}$ \\
\hline $\begin{array}{l}\text { S. gordonii } \\
\text { DL1 }\end{array}$ & & & $\begin{array}{l}\text { Lab } \\
\text { stock[143] }\end{array}$ \\
\hline $\begin{array}{l}\text { P. } \\
\text { gingivalis }\end{array}$ & 33277 & STCC & {$[127]$} \\
\cline { 2 - 4 } & Smfa1 & $\begin{array}{l}\text { Derivative of 33277 with } \\
\text { insertional inactivation of } \\
\text { the mfa1 gene; Emr }\end{array}$ & [94] \\
\cline { 2 - 4 } & Csmfa1 & $\begin{array}{l}\text { SMF1 containing pTCOW-Mfa1, } \\
\text { complemented strain; Emr Tcr }\end{array}$ & This study \\
\cline { 2 - 4 } & Csmfa1 R240A & $\begin{array}{l}\text { Smfa1 containing pTCOW-Mfa1 } \\
\text { with the R240A mutation, } \\
\text { complemented strain; Emr Tcr }\end{array}$ & This study \\
\cline { 2 - 4 } & Csmfa1 A357P & $\begin{array}{l}\text { SMF1 containing pTCOW-Mfa1 } \\
\text { with mutation the A357P } \\
\text { mutation, complemented strain; } \\
\text { Emr Tcr }\end{array}$ & \\
\hline \multirow{2}{*}{ E coli } & XL1 blue cells & & Agilent \\
\cline { 2 - 4 } & BL21(DE3)pLysS & & \\
\hline
\end{tabular}


Table 2.2. Plasmid used in this study

\begin{tabular}{|c|c|c|c|}
\hline \multirow[t]{3}{*}{ Plasmid } & pGEX6p1 & \multicolumn{2}{|l|}{ GST tag expression vector } \\
\hline & pG-Mfa1 & $\begin{array}{l}\text { pGEX6p1 containing mfa1(21-563aa } \\
\text { residues) }\end{array}$ & $\begin{array}{l}\text { This } \\
\text { study }\end{array}$ \\
\hline & pG-N194 & $\begin{array}{l}\text { pGEX6p1 containing } \mathrm{n} \text { terminal } \\
\text { truncated mfa1(21-194aa residues) }\end{array}$ & $\begin{array}{l}\text { This } \\
\text { study }\end{array}$ \\
\hline & pG-N225 & $\begin{array}{l}\text { pGEX6p1 containing } \mathrm{n} \text { terminal } \\
\text { truncated mfa1(21-225aa residues })\end{array}$ & $\begin{array}{l}\text { This } \\
\text { study }\end{array}$ \\
\hline & pG-N279 & $\begin{array}{l}\text { pGEX6p1 containing } \mathrm{n} \text { terminal } \\
\text { truncated mfa1(21-279aa residues })\end{array}$ & $\begin{array}{l}\text { This } \\
\text { study }\end{array}$ \\
\hline & pG-N400 & $\begin{array}{l}\text { pGEX6p1 containing } \mathrm{n} \text { terminal } \\
\text { truncated mfa1(21-400aa residues) }\end{array}$ & $\begin{array}{l}\text { This } \\
\text { study }\end{array}$ \\
\hline & pG-C280 & $\begin{array}{l}\text { pGEX6p1 containing } \mathrm{n} \text { terminal } \\
\text { truncated mfa1(280-563aa residues })\end{array}$ & $\begin{array}{l}\text { This } \\
\text { study }\end{array}$ \\
\hline & pT-COW & $\begin{array}{l}\text { Shuttle vector plasmid; Amr Tcr in E. } \\
\text { coli; Tcr in P. gingivalis Mob+Rep+ }\end{array}$ & {$[144]$} \\
\hline & pTCOW-Mfa1 & $\begin{array}{l}\text { pT-COW containing a } 2.5-\mathrm{kb} \text { fragment } \\
\text { containing the upstream and coding } \\
\text { region of the mfal gene }\end{array}$ & {$[94]$} \\
\hline & $\begin{array}{l}\text { pTCOW-Mfa1 } \\
\text { R240A }\end{array}$ & $\begin{array}{l}\text { pT-MFA containing the R240A } \\
\text { mutation }\end{array}$ & $\begin{array}{l}\text { This } \\
\text { study }\end{array}$ \\
\hline & $\begin{array}{l}\text { pTCOW-Mfa1 } \\
\text { A357P }\end{array}$ & pT-MFA containing the A257P mutation & $\begin{array}{l}\text { This } \\
\text { study }\end{array}$ \\
\hline
\end{tabular}




\subsection{Recombinant protein/peptide constructs.}

Nucleotide primers used in this study are shown in Table 2.2. To generate the full-length Mfa1 construct lacking the signal sequence, the mfal sequence from $61 \mathrm{bp}$ to $1689 \mathrm{bp}$ was amplified using the forward and reverse primers listed in Tablec2.3. from $P$. gingivalis ATCC33277 genomic DNA using platinum PCR supermix (Invitrogen) according to the manufacturer's instructions. Briefly, initial denaturation was carried out at $94^{\circ} \mathrm{C}$ for $3 \mathrm{~min}$. This was followed by 30 cycles comprised of denaturation at $94^{\circ} \mathrm{C}$ for $30 \mathrm{~s}$, primer annealing at $55^{\circ} \mathrm{C}$ for $30 \mathrm{~s}$ and strand extension at $72^{\circ} \mathrm{C}$ for $90 \mathrm{~s}$. The amplified products were subsequently digested with SalI and XhoI, ligated into the pGEX6p-1 expression vector and transformed into chemically component $E$. coli BL21. For the construction of the Mfa1 N-terminal and C-terminal peptide fragments N194, N225, N279, N400 and C280, mfal gene fragments encoding residues 21-194, 21-225, 21-279, 21-400 and a C-terminal fragment encoding residues 280-563 of Mfa1 were amplified using the primers shown in Table2. 2 from $P$. gingivalis ATCC33277 genomic DNA. A similar approach to that described above was followed to clone these fragments in pGEX6p1 expression vector and introduce the constructs into E. coli BL21. 
Table 2.3: Primers used in this study. Restriction enzyme sites are shown in italics.

\begin{tabular}{|c|c|}
\hline $\begin{array}{l}\text { Protein/peptide } \\
\text { name }\end{array}$ & Primer sequence \\
\hline \multirow[t]{2}{*}{ Mfa1 } & $\begin{array}{l}\text { FP: 5' ATTA GTCGAC } \\
\text { AGTAAAGAGGGCAATGGCCCCGATCCG 3, }\end{array}$ \\
\hline & RP: 5' ATGG $C T C G A G$ TAA GAGATCAACCTCATAG 3' \\
\hline \multirow[t]{3}{*}{ N194 } & FP: 5' ATTA GTCGAC \\
\hline & AGTAAAGAGGGCAATGGCCCCGATCCG 3' \\
\hline & $\begin{array}{l}\text { RP: 5' GAAT CTCGAG TAA ACCATTCTTTTTGGCAATC } \\
\text { 3, }\end{array}$ \\
\hline \multirow[t]{2}{*}{$\mathrm{N} 225$} & $\begin{array}{l}\text { FP: 5' ATTA GTCGAC } \\
\text { AGTAAAGAGGGCAATGGCCCCGATCCG 3, }\end{array}$ \\
\hline & $\begin{array}{l}\text { RP: 5' TAAT } C T C \text { GAG TAA } \\
\text { CCCTGCGATAGCATTGGCCTCGGATA 3, }\end{array}$ \\
\hline \multirow[t]{3}{*}{ N279 } & $\begin{array}{l}\text { FP: 5' ATTA GTCGAC } \\
\text { AGTAAAGAGGGCAATGGCCCCGATCCG 3, }\end{array}$ \\
\hline & RP: 5' ACCT CTCGAG TAA \\
\hline & TTGAGCAACAACCCATCTGA 3' \\
\hline \multirow[t]{2}{*}{$\mathrm{N} 400$} & $\begin{array}{l}\text { FP: 5' ATTA } G T C G A C \\
\text { AGTAAAGAGGGCAATGGCCCCGATCCG 3, }\end{array}$ \\
\hline & $\begin{array}{l}\text { RP: 5' } \\
\text { ATTACTCGAGTTATTCTTTCTTGGGAGTAAACTTCGC } \\
\text { ACGAACC 3, }\end{array}$ \\
\hline \multirow[t]{2}{*}{$\mathrm{C} 280$} & FP: 5' AAAA $G T C G A C$ GGAGAACGTCGCCAATACCT 3' \\
\hline & RP: 5' ATGG CTCGAG TAA GAGATCAACCTCATAG 3' \\
\hline \multirow[t]{2}{*}{ N279 R240A } & $\begin{array}{l}\text { FP: 5' - CGT TCT GTA GCA GCT GCG ATG GTT TCA - } \\
\text { 3' }\end{array}$ \\
\hline & $\begin{array}{l}\text { RP: 5'- CGT TGA AAC CAT CGC AGC TGC TAC AGA } \\
\text { ACG CTC -3' }\end{array}$ \\
\hline \multirow[t]{2}{*}{ N279 W275A } & $\begin{array}{l}\text { FP: 5'- ATT ACG GAT ATC AGA GCG GTT GCT CAA } \\
\text { GGA -3' }\end{array}$ \\
\hline & $\begin{array}{l}\text { RP: 5'- TCC TTG AGC AAC CGC TCT GAT ATC CGT } \\
\text { AAT -3' }\end{array}$ \\
\hline \multirow[t]{2}{*}{ N400 D321A } & $\begin{array}{l}\text { FP: 5' GCT ACC GAG TAT GCT TAT GCC GGT CTG } \\
\text { TGG 3, }\end{array}$ \\
\hline & $\begin{array}{l}\text { RP: 5' CAG ACC GGC ATA AGC ATA CTC GGT AGC } \\
\text { ATT TGT 3, }\end{array}$ \\
\hline \multirow[t]{2}{*}{ N400 A357P } & FP: 5’ ACT GGC GAA TTG CCA AAT GCT CTT TCA 3' \\
\hline & $\begin{array}{l}\text { RP: 5' TGA AAG AGC ATT TGG CAA TTC GCC AGT } \\
\text { CAC 3, }\end{array}$ \\
\hline
\end{tabular}




\subsection{Expression and purification of truncated Mfa1 peptides.}

To express the full-length and truncated Mfa1 proteins, an overnight culture containing the desired construct was diluted in pre-warmed LB medium supplemented with $100 \mu \mathrm{g} / \mathrm{ml}$ ampicillin to an $\mathrm{OD}_{600 \mathrm{~nm}}$ of 0.1 and incubated at $37^{\circ} \mathrm{C}$ in a rotating shaker at speed of $220 \mathrm{rpm}$. When the $\mathrm{OD}_{600 \mathrm{~nm}}$ reached 0.5 , protein expression was induced by adding IPTG to a final concentration of $1 \mathrm{mM}$. After further incubation for $4 \mathrm{hr}$ at $37^{\circ} \mathrm{C}$, cells were harvested by centrifugation at $3,000 \times \mathrm{g}$ for $10 \mathrm{~min}$ and the cell pellets were frozen. One gram of frozen cell pellet was suspended in $5 \mathrm{ml}$ of CellLytic B (SigmaAldrich) containing lysozyme $(0.2 \mathrm{mg} / \mathrm{ml})$ and Benzonase $(50 \mathrm{U} / \mathrm{ml})$. A protease inhibitor cocktail (Thermo Fisher Scientific) was added as per manufacturer recommendations and incubated at $25^{\circ} \mathrm{C}$ for $30 \mathrm{~min}$ with gentle shaking. To complete the disruption of the cells, brief sonication was carried out using a Vibra-Cell ultrasonic Liquid Processor VCX 130 (Sonics). Cells were pulsed at $20 \mathrm{kHz}$ for 2 min using a $10 \mathrm{~s}$ short burst followed by a 30 s cooling interval. During sonication, all steps were carried out in ice. Cell debris was removed by centrifugation at $13,000 \times \mathrm{g}$ for $20 \mathrm{~min}$ and the supernatant was transferred to a fresh tube.

Purification of GST-tagged fusion proteins was carried out using the Pierce GST Spin Purification Kit (ThermoFisher). Briefly, spin columns were equilibrated with the equilibration/wash buffer supplied with the kit at $4^{\circ} \mathrm{C}$, and then $15 \mathrm{ml}$ of cell lysate supernatant was added to each column and incubated overnight at $4^{\circ} \mathrm{C}$. Columns were washed three times with $15 \mathrm{ml}$ of wash buffer by centrifugation at $700 \mathrm{x} g$ for $2 \mathrm{~min}$. In column cleavage with Precision Protease (ThermoFisher) was carried out by overnight incubation at $4^{\circ} \mathrm{C}$ to generate the truncated Mfa1 proteins. The Mfa1 polypeptides were 
eluted by centrifugation at $700 \mathrm{x} g$ for $2 \mathrm{~min}$. The eluted peptides were subsequently chromatographed in disposable PD-10 Desalting Columns (GE Healthcare) to remove salts. Purity of the eluted proteins was assessed using SDS-PAGE electrophoresis and quantification of proteins was carried out using the BCA assay (Pierce).

\subsection{Dual species biofilm model.}

Interspecies adherence and biofilm formation between $P$. gingivalis and $S$. gordonii were carried out essentially as previously described [141]. S. gordonii cells were harvested from a $10 \mathrm{ml}$ of overnight culture by centrifugation at $3,000 \mathrm{x} g$ for $5 \mathrm{~min}$, washed with $10 \mathrm{ml}$ of pre-reduced PBS $\left(10 \mathrm{mM} \mathrm{Na}_{2} \mathrm{HPO}_{4}, 18 \mathrm{mM} \mathrm{KH}_{2} \mathrm{PO}_{4}, 1.37 \mathrm{M} \mathrm{NaCl}\right.$ and $2.7 \mathrm{mM}$ $\mathrm{KCl}, \mathrm{pH}$ 7.2) and suspended in $1 \mathrm{ml}$ of PBS. Suspended $S$. gordonii cells were labeled with $20 \mu 1$ Hexidium Iodide ( $1.6 \mathrm{mg} / \mathrm{ml}$; Molecular Probes, Eugene, OR) in the dark at $25^{\circ} \mathrm{C}$ with gentle shaking on a rocker platform for $15-30 \mathrm{~min}$. Unbound dye was removed by washing with PBS and labeled cells were then suspended in $1 \mathrm{ml}$ of prereduced PBS. Cells were diluted to O.D.600nm of 0.8 and $1 \mathrm{ml}$ of the labeled cells was added to each well of a 12-well microtiter plate (Greiner Bio-one) containing a circular glass coverslip. Plates were incubated for $24 \mathrm{hr}$ on a rotary shaker under anaerobic conditions. The following day, $P$. gingivalis cells were harvested from $10 \mathrm{ml}$ of overnight culture, suspended in $1 \mathrm{ml}$ pre-reduced PBS containing $10 \mu \mathrm{l}$ of carboxyfluorescein $\left(1.6 \mathrm{mg} / \mathrm{ml}\right.$; Molecular Probes) and incubated for $30 \mathrm{~min}$ at $25^{\circ} \mathrm{C}$ on a rocking platform. Unbound dye was removed by centrifugation at 3,000 $\mathrm{g}$ for $2 \mathrm{~min}$. After removing unbound $S . \quad$ gordonii from the plates by aspiration, $1 \mathrm{ml}$ of labeled $P$. gingivalis suspension (O.D.600 nm of 0.4) was added to each well and incubated for $24 \mathrm{hr}$ 
on a rotary shaker under anaerobic conditions. To determine the functional activity of the truncated Mfal polypeptides, $S$. gordonii cells were incubated with $1 \mathrm{uM}$ of peptide (in PBS) at $25^{\circ} \mathrm{C}$ for $30 \mathrm{~min}$ prior to adding the labeled $P$. gingivalis.

To visualize $P$. gingivalis/S. gordonii adherence and biofilm formation, unbound $P$. gingivalis cells were removed by aspiration and coverslips were washed once with PBS. Biofilms were fixed by incubating the coverslips with $1 \mathrm{ml}$ of $4 \%$ paraformaldehyde for 5 min followed by two washes with PBS. The coverslips were then removed, placed face down on a glass microscope slide containing a drop of anti-fade reagent (Life Technology) and sealed with nail polish. Visualization of biofilms was carried out by laser scanning confocal microscopy on a Leica SP8 confocal microscope (Leica Microsystems Inc.) using a $488 \mathrm{~nm}$ laser to detect labeled $P$. gingivalis and a $552 \mathrm{~nm}$ laser to detect $S$. gordonii. Z-plane scans of $25 \mu \mathrm{m}$ in depth were collected at three randomly chosen frames on each coverslip using a $z$-step thickness of $0.7 \mu \mathrm{m}$. Background noise was minimized using software provided with the Leica SP8 and threedimensional constructions of the Z-plane scans and quantification of total green and red fluorescence was conducted using Volocity 6.3 Image analysis software (Perkin Elmer, Akron, Ohio). Data were expressed as the ratio of total green ( $P$. gingivalis) to red $(S$. gordonii) fluorescence. Each experiment was carried out in triplicate and three independent experiments were conducted for each peptide. A pairwise, nonparametric analysis of variance was used to determine the statistical difference of $P$. gingivalis association with $S$. gordonii between the experimental and control samples. A $p$ value of <.05 was considered significant. 


\subsection{SiteMap prediction of a putative binding cleft in Mfa1.}

The Mfa1 protein structure (Protein Data Bank entry 5NF3) [100] was examined using SiteMap v4.5.011 (Schrodinger Release 2017-4). Standard parameters were used with a maximum of 10 binding sites reported. The top six sites with a sitescore greater than 0.8 were examined further. Residues within 5 angstroms of the potential sites were identified and the highest scoring site (sitescore 1.04) was used for validation by mutagenesis. The five peptidomimetic compounds (pcp-iii-201, pcp-iii-206, pcp-iii-212, pcp-iii-293 and pcp-iv-20) [141] were built and minimized using Macromodel (Schrodinger Release 2017-4) and docked using Glide (Schrodinger Release 2017-4) in SP mode centered on the highest scoring site from SiteMap.

\subsection{Site-directed mutagenesis.}

Site-specific mutation reactions were carried out using the Quick-change II XL SiteDirected Mutagenesis Kit (Agilent Tech) according to the manufacturer's protocol. Mutagenic primers were designed such that the desired mutation was flanked by $10-$ $15 \mathrm{bp}$ of $m f a l$ sequence and are listed in Table2.3. The reaction mixture contained $5 \mu 1$ of reaction buffer, $10 \mathrm{ng}$ of plasmid pTCOW-Mfa1 template DNA [94] (125 ng of each

primer, $1 \mu \mathrm{l}$ dNTP mix, $1 \mu \mathrm{l}$ of $P f u$ Ultra HF DNA polymerase $(2.5 \mathrm{U} / \mu \mathrm{l})$ and water to a final volume of $50 \mu$ l. Cycling parameters were as follows: initial denaturation was carried out at $95^{\circ} \mathrm{C}$ for $30 \mathrm{~s}$, followed by 16 cycles of denaturation at $95^{\circ} \mathrm{C}$ for $30 \mathrm{~s}$, annealing at $55^{\circ} \mathrm{C}$ for $1 \mathrm{~min}$ and extension at $68^{\circ} \mathrm{C}$ for $14 \mathrm{~min}$. After amplification, products were immediately transferred to ice. A reaction containing pWhitescript $4.5-\mathrm{kb}$ and primers supplied by the manufacturer was carried out simultaneously and served as 
positive reaction control. To eliminate parental plasmid following amplification, PCR products were digested with $D p n \mathrm{I}$ for $1 \mathrm{hr}$ at $37^{\circ} \mathrm{C}$. Subsequently $1 \mu \mathrm{l}$ of the digested product was transformed into chemically competent E. coli XL10 blue cells (Agilent Tech) by heat shock at $42^{\circ} \mathrm{C}$ for $45 \mathrm{~s}$. The transformation reaction was transferred into $500 \mathrm{ul}$ of pre-warmed SOC medium (2\% tryptone, $0.5 \%$ yeast extract, $10 \mathrm{mM} \mathrm{NaCl}$, $2.5 \mathrm{mM} \mathrm{KCl}, 10 \mathrm{mM} \mathrm{MgCl} 2,10 \mathrm{mM} \mathrm{MgSO}{ }_{4}$ and $20 \mathrm{mM}$ glucose) and incubated at $37^{\circ} \mathrm{C}$ for $1 \mathrm{hr}$ with shaking at $225 \mathrm{rpm}$. Positive transformation was selected by plating on LB agar plates supplemented with $100 \mu \mathrm{g} / \mathrm{ml}$ of ampicillin. Five positive colonies were picked for plasmid extraction and successful mutation was confirmed by DNA sequencing.

\subsection{Random mutation.}

Random mutagenesis was performed using GeneMorph II Random Mutagenesis kit (Agilent Tech.) to generate additional mutations V238A, I252F and $\Delta \mathrm{K} 253$. Briefly, reactions contained $2 \mu \mathrm{g}$ of plasmid pG-N279, $5 \mu \mathrm{l}$ of 10X Mutazyme II reaction buffer, $1 \mu 1$ of $10 \mathrm{nM}$ dNTP, $0.5 \mu 1$ of primer mix (250 ng each), $1 \mu 1$ Mutazyme II DNA Polymerase $(2.5 \mathrm{U} / \mu \mathrm{l})$ and $41.5 \mu \mathrm{l}$ of deionized water. The PCR profile was as follows: denaturation at $95^{\circ} \mathrm{C}$ for $2 \mathrm{~min}, 20$ cycles comprised of denaturation at $95^{\circ} \mathrm{C}$ for $30 \mathrm{~s}$, annealing at $60^{\circ} \mathrm{C}$ for $30 \mathrm{~s}$ and extension at $72^{\circ} \mathrm{C}$ for $1.5 \mathrm{~min}$ with final extension at $72^{\circ} \mathrm{C}$ for 10 min. Following the amplification, PCR products were excised from an agarose gel after electrophoresis, cloned into pGEX6p1 and transformed into chemically competent E. coli BL21. Colonies were randomly chosen and plasmids were purified. Successful mutation was confirmed by DNA sequencing. 


\subsection{Complementation of $P$. gingivalis SMF1 with mutated Mfa.}

Complementation of the Mfa1-deficient $P$. gingivalis strain SMF1 was carried out using a modification of the protocol previously described [94]. P. gingivalis SMF1 was grown on a blood agar plate under anaerobic conditions for 2-3 days and donor E. coli S17-1 was grown aerobically on a LB agar plate. pTCOW-mfa1 containing the desired mutation was electroporated into $E$. coli strain S17-1 and subsequently conjugated with $P$. gingivalis SMF1 using the agar plate method. Briefly, cells from both donor and recipient were scraped from the agar plates and spread on a $4 \mathrm{~cm}^{2}$ area on a blood agar plate containing no antibiotics. After incubation for $24 \mathrm{hr}$, mixed cells from blood agar plates were collected and incubated in TSBY supplemented with hemin $(1 \mu 1 / \mathrm{ml})$ and menadione $(5 \mu \mathrm{l} / \mathrm{ml})$ for $1 \mathrm{hr}$ at $37^{\circ} \mathrm{C}$ under anaerobic conditions. Subsequently, $0.1 \mathrm{ml}$ of the cell suspension was plated on blood agar containing $20 \mu \mathrm{g}$ of erythromycin per $\mathrm{ml}$ and $200 \mu \mathrm{g}$ of gentamicin per $\mathrm{ml}$ and was incubated anaerobically at $37^{\circ} \mathrm{C}$ for 10 days. Transconjugants were subsequently grown in the presence of antibiotics and the purified plasmid was confirmed to possess the desired mutation by DNA sequencing.

\subsection{Cell surface expression of mutated Mfa1 polypeptides.}

Cell surface expression of Mfa1 by the transconjugants was determined using an enzymelinked immunosorbent assay (ELISA) after adsorption of $P$. gingivalis strains onto Maxisorp plates (Nunc). Briefly, P. gingivalis cells were centrifuged at 3,000 $\mathrm{g}$ for $5 \mathrm{~min}$ and cell pellets were washed there times with PBS. Subsequently, $10^{7}$ cells were incubated in each well for $2 \mathrm{hr}$ at $4^{\circ} \mathrm{C}$ followed by washing with PBS to remove unbound bacteria. Bound cells were incubated with rabbit rMfa monoclonal antibodies (1:5,000 
dilution) (Covance, Denver, PA) for $1 \mathrm{hr}$ at $37^{\circ} \mathrm{C}$. After washing with PBS, wells were reacted with horseradish peroxidase-conjugated goat anti-rabbit antibody $(1: 3,000$ [ImmuneReagents Inc.]) for $1 \mathrm{hr}$ at $25^{\circ} \mathrm{C}$. Antigen-antibody binding was determined by adding $200 \mu \mathrm{l}$ of $1 \times$ TMB ELISA substrate solution [3, 3', 5, 5'-tetramethylbenzidine] (Invitrogen) and the reaction was incubated for $15 \mathrm{~min}$ at $25^{\circ} \mathrm{C}$. Reactions were stopped using $50 \mu \mathrm{l}$ of stop solution $\left(0.16 \mathrm{M} \mathrm{H}_{2} \mathrm{SO}_{4}\right)$ and the endpoint was measured at $450 \mathrm{~nm}$ in a Victor Multilabel counter (Perkin Elmer).

\subsection{Mfa1 polymerization.}

Whole cell lysates were prepared using a modification of the procedure previously described by Hasegawa et al. [145]. Briefly, $P$. gingivalis strains were grown until early stationary phase in TSBY media supplemented with hemin $(5 \mu \mathrm{g} / \mathrm{ml})$ and menadione $(1 \mu \mathrm{g} / \mathrm{ml})$. Following centrifugation at $6,000 \mathrm{~g}$ for $5 \mathrm{~min}$, cell pellets were collected and suspended in 1× NuPAGE LDS sample buffer (Thermo Fisher) at the final OD of 2. The cell suspensions were then denatured by incubation either at $60^{\circ} \mathrm{C}$ or $100^{\circ} \mathrm{C}$ for $10 \mathrm{~min}$. Following the heat treatment, the whole cell lysate was centrifuged at $20,000 \mathrm{~g}$ for 10 min to remove cellular debris, electrophoresed in $12 \%$ Bis-Tris Plus gel (Thermo Fisher) and Mfa1 was visualized by ELISA as described above.

2.11. Virtual screening of small molecule inhibitors. The structures of the NITVK and VQDLL motifs of SspB were taken directly from the Streptococcus gordonii SspB Cterminal domain crystal structure (protein databank entry 2WZA) [146]. The structure was processed using the Protein Preparation Wizard in Maestro (Schrödinger Release 2018-1: Schrödinger, LLC, New York, NY, 2020). The similarity searches for 
the NITVK and VQDLL motifs were performed with Surflex-sim vers. 2.601 [147] using two approaches. The first approach was to use all atoms of the peptide structures for the NITVK and VQDLL motifs as the hypothetical ligand. The second approach was to use the side chains of residues for the NITVK motif, and the side chains of residues VLL for the VQDLL motif. The screened libraries were created from the ZINC [148] drug-like library (ZINC 2014 version) containing 24,877,119 compounds and the ZINC 15 [149] drug-like library (ZINC 2016 version) containing 17,244,856 compounds. The results were ranked and the top 500 compounds of each screen were retained. Selection of compounds was based on compound score, diversity, by eliminating compounds that were structurally similar to a higher scoring compound, and finally compounds that were commercially readily available for purchase. Seventeen compounds and sixteen compounds were purchased for the NITVK and VQDLL motifs, respectively.

2.12. Murine in vivo model of periodontitis. The protocol used in this study (protocol 16486) was approved by the Institutional Animal Care and Use Committee at the University of Louisville under Federal guidelines for the use and care of laboratory animals. Ten week old BALB/c/ByJ specific pathogen free mice were obtained from Jackson Laboratory (Bar Harbor, ME) and housed in the University of Louisville Research Resource Center animal facility. During the entire course of the study, mice were fed with Lab Diet 5001 (Purina Mills, LLC, Gray Summit, MO).

Oral infection of the mice was carried out essentially as described by Deap et al. [135]. Prior to infection, mice were subjected to a combined antibiotic treatment for 10 days by providing animals with water ad libitum containing $800 \mu \mathrm{g} / \mathrm{ml}$ sulfamethaxozole (MP Biomedical, Solon, OH) and $400 \mu \mathrm{g} / \mathrm{ml}$ trimethoprim (Sigma, St. Louis, MO). Four days 
after conclusion of the antibiotic treatment, mice were infected by oral gavage with $10^{9} \mathrm{cfu} / \mathrm{ml}$ of $S$. gordonii suspended in $2 \%$ carboxymethylcellulose (CMC; MP Biomedical, Solon, $\mathrm{OH}$ ) in sterile PBS using a $2.25 \mathrm{~mm}$ feeding needle (Popper and Son Inc., New Hyde Park, NY). Infections were conducted every other day for a period of 10 days. Subsequently, mice were infected with $10^{9} \mathrm{cfu} / \mathrm{ml} P$. gingivalis suspended in $2 \%$ $\mathrm{CMC}$ in PBS alone or in 2\% CMC in PBS containing the small molecule inhibitors every other day for 10 days. After the last infection with $P$. gingivalis, the mice were rested for 47 days and then euthanized by carbon dioxide asphyxiation.

To obtain the mouse skulls, the heads were removed and autoclaved for $15 \mathrm{~min}$ to remove flesh and musculature. The defleshed skulls were then immersed in $3 \%$ hydrogen peroxide overnight at room temperature to remove any remaining flesh. The skulls were submerged in deionized water to remove residual hydrogen peroxide, soaked in $1 \%$ bleach solution for $30 \mathrm{sec}$, sonicated at $14 \mathrm{~V}$ for $1 \mathrm{~min}$, and washed again with deionized water. Samples were brushed using toothpaste, sonicated again in $1 \%$ bleach for an additional $30 \mathrm{sec}$ at $14 \mathrm{~V}$ and washed with water. The cleaned skulls were stained by immersion in $1 \%$ methylene blue for $15 \mathrm{sec}$ followed by washing with water until the excess dye was removed.

To measure alveolar bone loss, a dissecting microscope fitted with a video imaging marker measurement system (model VIA-170K; Fryer) was used. Bone loss was determined by measuring the distance between the alveolar bone crest $(\mathrm{ABC})$ and cemento-enamel junction (CEJ) at eight sites on the buccal sides of both left and right maxillary molars. Bone loss was measured in $\mathrm{mm}$ for each group of mice and bone loss data was normalized by subtracting the average bone loss that was observed in sham 
infected mice. Data was analyzed using one way ANOVA (Graph Pad Prism, La Jolla, CA) and a pair wise parametric analysis of variance using a Bonferroni multiplecomparison post-test was used to determine the statistical difference among the individual mouse groups. A $p$ value of $\leq 0.05$ was considered statistically significant.

2.13. Determination of IL-17 expression. To assess the level of IL-17 expression, gingival tissue from the maxillary molar region was dissected from each mouse and fixed in $4 \%$ paraformaldehyde overnight. Tissue samples were dehydrated by passing through a series of ascending concentrations of ethanol and then cleared in xylene followed by paraffin embedding. Tissue sections $(5-6 \mu \mathrm{m}$ in thickness) were prepared and mounted on glass slides. Sections were deparaffinized by immersing in xylol twice for 15 min each, and rehydrated by passing through absolute, $95 \%$ and $70 \%$ ethanol. Samples were washed with distilled water to remove excess ethanol and epitope antigenicity was recovered by microwave heating in water for $15 \mathrm{~min}$. To prevent non-specific binding, tissues were treated with $5 \%$ bovine serum albumin for $1 \mathrm{hr}$ followed by reaction with IL17A monoclonal antibody conjugated with AlexaFluor 488 (eBioscience, San Diego, CA) at $4^{\circ} \mathrm{C}$ for $24 \mathrm{hr}$. Binding of IL-17 monoclonal antibodies was observed using confocal microscopy. Three images were taken from each tissue section and IL-17 immunofluorescence quantification was performed using Volocity software.

2.14. Tissue culture. Human telomerase immortalized gingival keratinocytes (TIGKs) [150] were cultured at $37^{\circ} \mathrm{C}$ in basal medium Dermalife K complete kit with Supplements (LifeLine, Frederick, MD) and incubated for 5 days in an atmosphere of $5 \% \mathrm{CO}_{2}$ to attained $>95 \%$ confluence. The mouse macrophage cell line J774A.1 was grown in Dulbecco modified Eagle medium (DMEM) (Thermo Fisher Scientific, Waltham, MA) 
supplemented with $4.5 \mathrm{~g} / \mathrm{ml}$ glucose, $10 \%$ fetal bovine serum (FBS), and $100 \mathrm{U} / \mathrm{ml}$ penicillin-streptomycin (Sigma-Aldrich, St. Louis, MO). HL60 (ATCC® CCL240 ${ }^{\mathrm{TM}}$ ) cells were obtained from the American Type Culture Collection and cultured in Iscove's Modified Dulbecco's Medium (Sigma-Aldrich, St. Louis, MO) supplemented with 20\% fetal bovine serum (FBS) (Sigma-Aldrich, St. Louis, MO). Both J774A.1 and HL60 cells were incubated at $37^{\circ} \mathrm{C}$ in an atmosphere of $5 \% \mathrm{CO}_{2}$ for 4 days to reach $>95 \%$ confluence.

2.15. Determination of lactate dehydrogenase activity. CytoTox 96 nonradioactive cytotoxicity assay (Promega Inc. Madison, WI) was used to determine extracellular lactate dehydrogenase activity (LDH) in TIGK, J774A.1 and HL60 cell cultures treated with the test compounds. Briefly, cells were inoculated in a 96 well microtiter plate at an initial density of 4000 cells per well and grown at $37^{\circ} \mathrm{C}$ in an atmosphere of $5 \% \mathrm{CO}_{2}$ for $24 \mathrm{hr}$. The spent medium was removed and replaced with fresh medium containing the desired concentration of the compound. After $18 \mathrm{hr}$ incubation, the cell supernatant was collected by centrifugation at $250 \times g$ for 4 min and $50 \mu l$ of cell free supernatant was transferred into wells of a fresh 96 well microtiter plate. Subsequently, $50 \mu 1$ of LDH substrate was added in each well and incubated at room temperature for $30 \mathrm{~min}$. Reactions were stopped by adding $50 \mu \mathrm{l}$ of stop solution according to the manufacturer's protocol and the end point was measured by determining optical density at $490 \mathrm{~nm}$. Cells treated with culture medium containing $0.1 \%$ DMSO or with medium alone served as negative controls and cells incubated with $15 \mu \mathrm{l}$ lysis buffer (supplied by manufacturer) for $1 \mathrm{hr}$ served as a positive control for lysis. All samples were tested in triplicate. 
2.16. Measurement of total cellular ATP. To determine the metabolic activity of cells, the total cellular ATP level was measured in cell culture samples using CellTiterGlo reagent (Promega Inc. Madison, WI). Cells were grown as described above in the presence of the desired concentration of compounds. The spent medium was decanted and cells were washed three times with PBS and subsequently incubated with $100 \mu$ of CellTiterGlo substrate. To facilitate the reaction, plates were incubated at room temperature for 2 min with shaking and for an additional 10 min without shaking. Total light production was measured using a Victor 3 multilabel plate reader (PerkinElmer).

2.17. Determination of apoptotic activity. The apoptotic activity of the compounds was determined using the phycoerythrin (PE) annexin V/dead cell apoptosis kit with SYTOX green for flow cytometry (Invitrogen, Carlsbad, CA). Cells were grown in 12 well flat bottom microtiter plates at an initial density $2 \times 10^{5}$ cells in $1.5 \mathrm{ml}$ medium per well for $24 \mathrm{hr}$. Following the incubation period, spent medium was replaced with fresh medium containing the desired concentration of the test compound and incubated for another 18 hr. After trypsinization, cells were harvested by centrifuging at $250 \times g$ for 4 min and the cell pellet was suspended in $100 \mu$ of binding buffer supplemented with $1 \mu 1$ Sytox and 5 $\mu \mathrm{l}$ annexin $\mathrm{V}$ followed by incubation at $37^{\circ} \mathrm{C}$ for $15 \mathrm{~min}$. Samples were then diluted by adding $400 \mu \mathrm{l}$ binding buffer and flow cytometry was performed using a FACScalibur flow cytometer (Becton Dickinson, Franklin Lakes, NJ), measuring the fluorescence emissions at $530 \mathrm{~nm}$ and $575 \mathrm{~nm}$. Cells treated with medium alone or with medium containing $0.1 \%$ DMSO served as negative controls, while cells treated with $2 \mathrm{mM}$ hydrogen peroxide at $37^{\circ} \mathrm{C}$ for $4 \mathrm{hr}$ served as a positive control for apoptosis. 
2.18. Measurement of hemolytic activity. The hemolytic activity of compounds was determined using both sheep and human red blood cells. Briefly, $100 \mu \mathrm{l}$ of $1 \%$ sheep or human erythrocytes (BioreclamationIVT, MD) was suspended in $1 \mathrm{ml}$ of sterile PBS containing 5\% FBS and the appropriate concentration of compound was added. The cell suspension was incubated at $37^{\circ} \mathrm{C}$ for $3 \mathrm{hr}$, centrifuged at $3,500 \times g$ for $5 \mathrm{~min}$, and a 200 $\mu \mathrm{l}$ aliquot of the cell free supernatant was transferred into each well of a 96-well microtiter plate. Hemolytic activity was measured by quantifying hemoglobin release in the supernatant using a Victor 3 multilabel plate reader (PerkinElmer, Waltham, MA) at a wavelength of $538 \mathrm{~nm}$. All samples were analyzed in triplicate. Erythrocytes suspended in PBS with 5\% FBS served as a negative control, and erythrocytes that were lysed by suspension in distilled water $\left(\mathrm{dH}_{2} \mathrm{O}\right)$ served as a positive control.

2.19. Statistical analysis: For each of the cytotoxicity assays described above, data was analyzed using a pair wise non parametric $t$ test using GraphPad Prism version 8.0. A p value $<0.05$ is considered as statistically significant. 


\section{CHAPTER THREE: IDENTIFICATION AND CHARACTERIZATION OF FUNCTIONAL MOTIFS OF MFA1}

3.1. Introduction: Periodontal disease is the sixth most prevalent disease in the world and approximately $50 \%$ of adults in the USA suffer from some form of periodontitis [6, 9]. The human oral cavity is home to $\sim 700$ species of bacteria and maintaining host/microbe homeostasis is key to maintaining periodontal health. Porphyromonas gingivalis is strongly associated with chronic adult periodontitis and is an important pathogen that is capable of modulating the host immune response and disrupting normal host/microbe homeostasis $[151,152]$. This can lead to the development of a dysbiotic microbial community which can induce uncontrolled inflammation leading to the destruction of tooth supporting tissues, and ultimately tooth loss [41-43]. Periodontitis is also associated with increased risk of other systemic diseases such as rheumatoid arthritis, cardiovascular disease, some cancers, and chronic respiratory disease $[27,153$, 154].

The primary niche for $P$. gingivalis is the subgingival pocket but the organism also adheres efficiently to supragingival bacteria such as various commensal streptococci $[70,87,127]$. Indeed, adherence to streptococci can modulate the pathogenic potential of P. gingivalis $[51,135,155]$ and may also be important for the initial colonization of the oral cavity by the organism. Thus, adherence of $P$. gingivalis to streptococci represents a viable target for therapeutic intervention. $P$. gingivalis adherence to streptococci is 
driven by a protein-protein interaction between the minor fimbrial antigen, Mfa1, and the streptococcal antigen I/II protein $[71,87,94,156]$. Deap et al. identified several discrete structural motifs in $\mathrm{SspB}$ that are essential for adherence and suggested that this functional region resembles the eukaryotic nuclear receptor (NR) box protein-protein interaction domain [136]. In addition, a synthetic peptide (BAR) that encompasses this region potently inhibited $P$. gingivalis/streptococcal adherence in vitro and significantly reduces $P$. gingivalis virulence in vivo [135]. Subsequently, Patil et al. designed and synthesized small molecule BAR peptidomimetics that potently inhibit $P$. gingivalis adherence [141, 157]. Thus, the binding region in antigen I/II has been well characterized but little is known about the binding domains or motifs of Mfal that contribute to this protein-protein interaction.

In this chapter, $\mathrm{N}$ - and $\mathrm{C}$-terminal truncated Mfa1 polypeptides were shown to inhibit $P$. gingivalis/streptococcal adherence and suggested that Mfa1 functional motifs are present between residues $225-400$ of the protein. Using the three-dimensional structure of Mfa1 [100], a putative binding cleft was identified using the prediction tool SiteMap. Sitespecific mutation of amino acids in the predicted cleft, for example, R240A, W275A, D321A and A357P inhibited the interaction of Mfa1 with streptococci. Finally, complementation of an Mfa1-deficient $P$. gingivalis strain with wild-type $m f a l$ restored adherence to streptococci, whereas complementation with the site-specific mfal mutants resulted in significantly reduced levels of adherence. Together, these results identify specific residues and motifs that are important for the Mfa1/SspB protein-protein interaction. 


\subsection{Results.}

\subsubsection{Localization of Mfa1 functional domains}

To identify regions of Mfa1 that contribute to the interaction with antigen I/II, a series of $\mathrm{N}$ - and C-terminal truncated Mfa1/GST fusion proteins were constructed and expressed. The truncated Mfa1 polypeptides were purified by affinity purification and the GST tag removed by in column cleavage and were designated as N194, N225, N279, N400 and C280 as shown in Figure 3.1. The functional activity of these peptides was determined by assessing their ability to inhibit $P$. gingivalis/S. gordonii adherence and biofilm formation using the dual species biofilm model described previously by Patil et al.[141]. Representative images of biofilms formed in the presence of each peptide are shown in Figure 3.2a and inhibition results are summarized in Figure 3.2b. Peptides N194 and N225 were relatively poor inhibitors of $P$. gingivalis adherence ( $20 \%$ inhibition) compared to the full-length Mfal protein (80\% inhibition). In contrast, peptide N279 exhibited $70 \%$ inhibition and adherence inhibition by peptide N400 was similar to that of the full-length Mfal protein. Peptide C280 exhibited reduced activity ( 40\% inhibition) compared to peptides $\mathrm{N} 279$ and N400 but was significantly more active than peptides N194 and N225. Together, these results suggest that essential functional residues that contribute to $P$. gingivalis adherence to streptococci reside in the region of Mfa1 comprising amino acids $225-400$. 


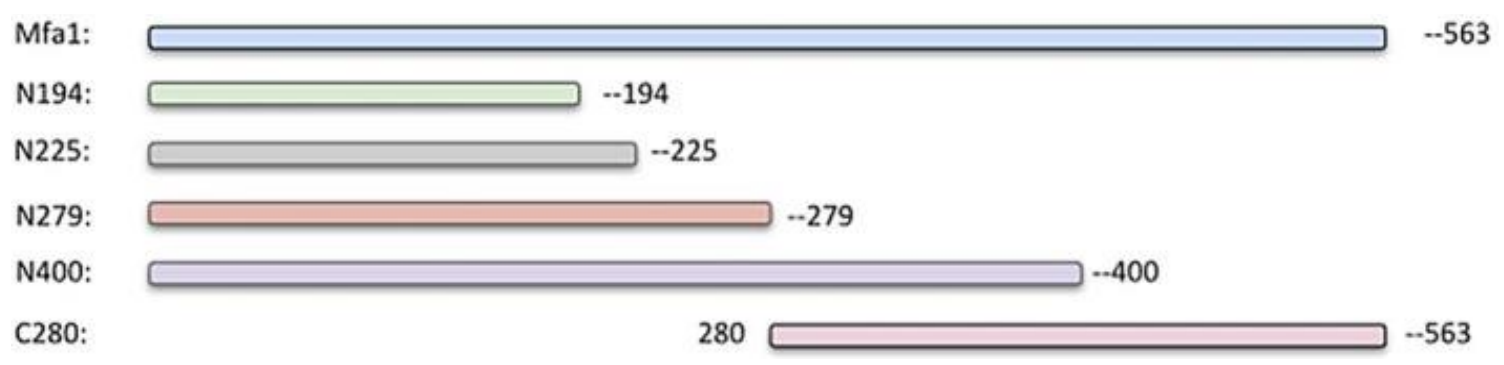

Figure 3.1. Schematic representation of the series of Mfa1 peptide fragments: The full-length Mfa1 lacking the signal peptide (21-563aa residues), and N-terminal peptide fragments N194, N225, N279 and N400 encoding residues 21-194, 21-225, 21-279 and $21-400$, respectively, are shown. The C-terminal peptide fragment, C280, is comprised of Mfa1 residues 280-563. 
A.
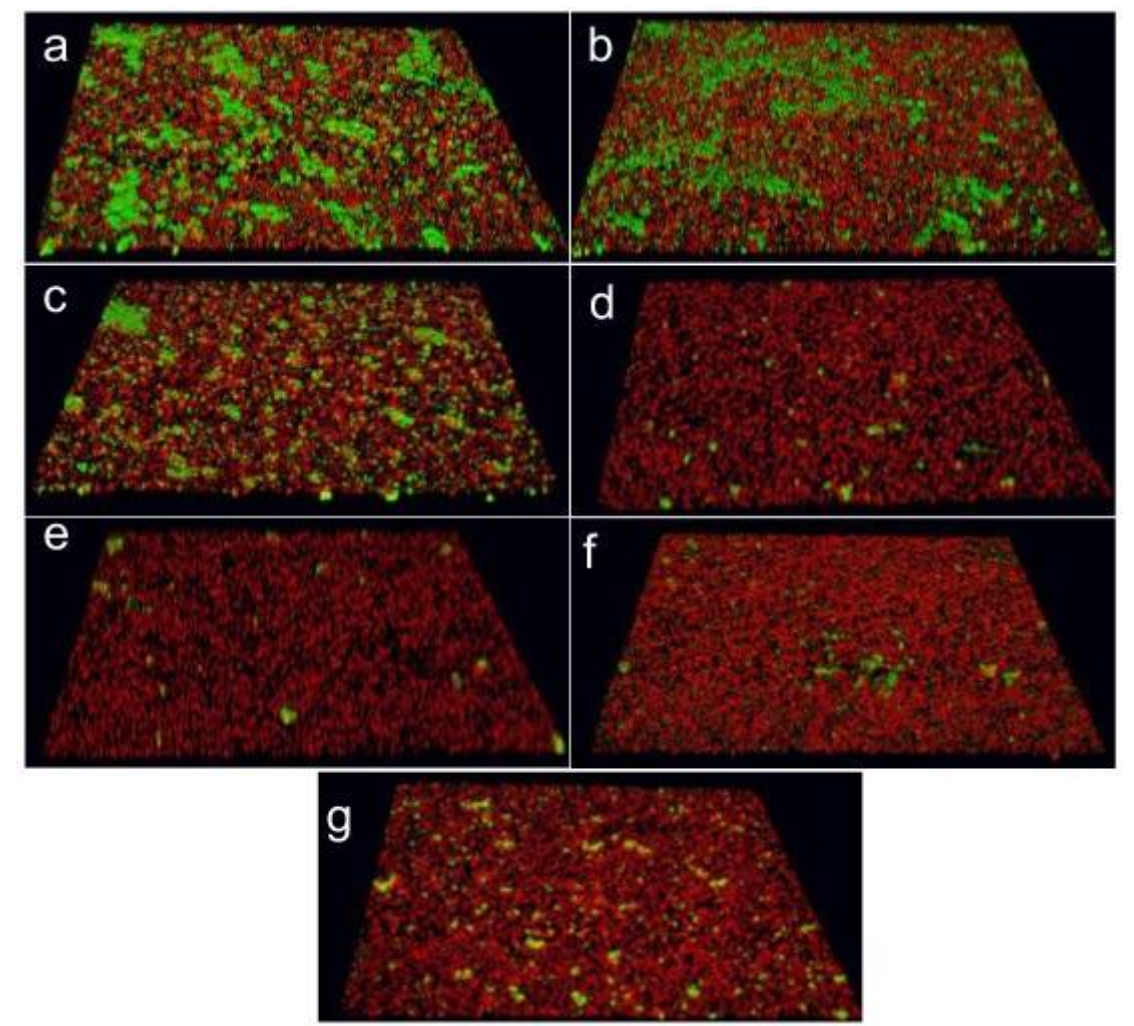

B.

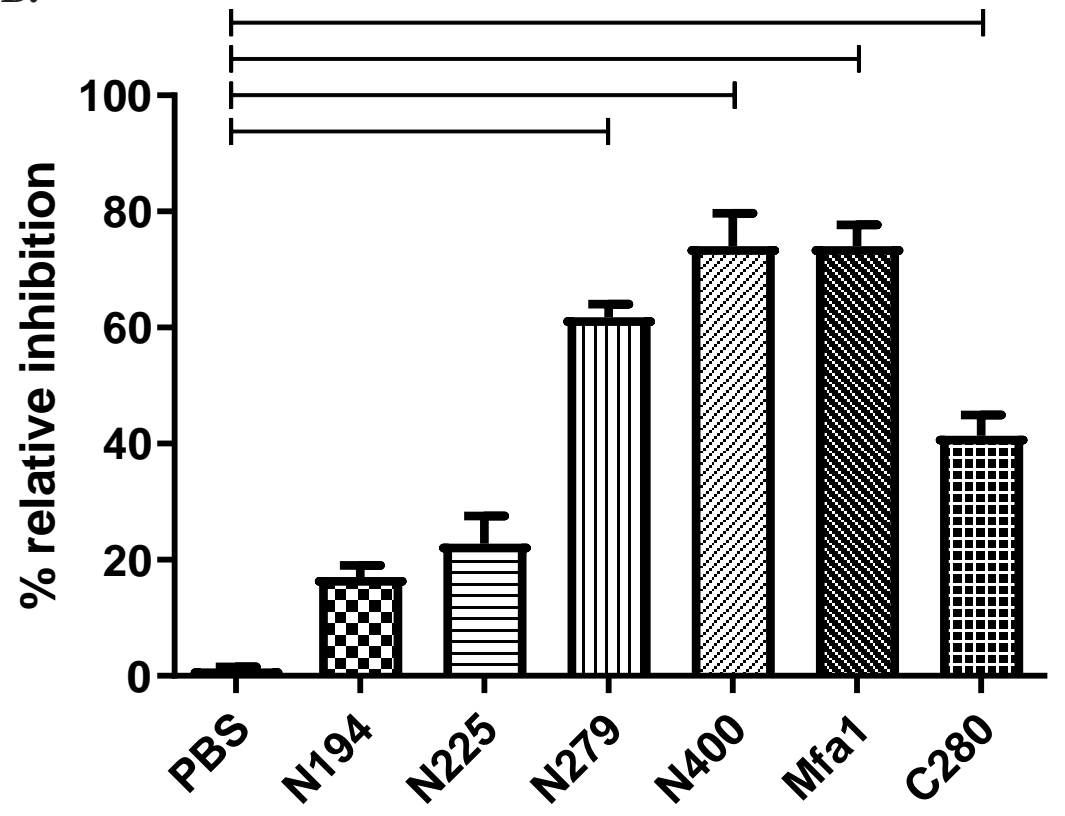


Figure 3.2. Determination of the inhibitory activity of the peptides: A) Peptide mediated inhibition of $P$. gingivalis adherence in a dual species biofilm model comprising S. gordonii (red) and P. gingivalis (green). Panels (a) PBS treated, (b), (c), (d), (e), (f) and (g) were treated with peptides N194, N225, N279, N400, full-length Mfa1 and C280, respectively. (B) Quantification of relative adherence of $P$. gingivalis and $S$. gordonii was determined by VOLOCITY software. Each experiment was carried out in triplicate and three independent experiments were conducted for each peptide. Comparisons of biofilms formed in PBS (control) with peptide-treated biofilms were carried out using one way ANOVA followed by Dunnett's multiple comparison test. $* p<.05$. 


\subsubsection{In silico prediction of a putative Ag I/II binding cleft in Mfa1}

To further highlight the functional region(s) of Mfa1, we took advantage of the recently published three-dimensional structure of Mfa1 [100] to predict putative binding clefts using SiteMap. In addition, a series of in silico docking experiments were conducted using five peptidomimetic compounds that mimic the BAR peptide and were previously shown by Patil et al. $[141,157]$ to be potent competitive inhibitors of $P$. gingivalis/S. gordonii adherence. As shown in Figure 3.3a, all five of the mimetic compounds could be docked in the putative binding cleft that exhibited the highest sitescore by SiteMap. Amino acids of the Mfa1 protein that comprise the putative binding cleft are highlighted in red and underlined in Figure 3.3b.

To validate the predicted binding cleft, a series of Mfa1 site-specific mutant peptides that targeted residues and putative motifs predicted in Figure 3.3b to comprise the binding cleft were constructed and expressed. Since the results of the truncated Mfa1 peptides in Figure 3.2.b indicated that the region comprising residues 226-279 was important for $P$. gingivalis adherence, site-specific mutations R240A and W275A were introduced into peptide N279 since both of these residues are predicted by SiteMap to be part of the binding cleft. Additional mutations, D321A and A357P, were also constructed in peptide N400 to disrupt two predicted amphipathic helices in the putative binding cleft (residues 321-329 and 351-364). Finally, several additional residues in peptide N279 that were not predicted to comprise the binding cleft were tested (e.g., V238A, I252F and $\Delta \mathrm{K} 253$ ). As shown in Figure 3.4., peptides N279 and N400 inhibited $P$. gingivalis adherence to streptococci by $66 \%$ and $79 \%$, respectively, consistent with the results shown in Figure 3.2b. Polypeptide N279 containing the R240A or N275A mutations were significantly 
less potent inhibitors relative to the parent N279 peptide, exhibiting only $32 \%$ and $38 \%$ inhibition of $P$. gingivalis adherence, respectively.

(a)

\section{Figure 3.3.(a) Three-dimensional}

structure of the Mfa1 with a

composite of five peptidomimetic

adherence inhibitory compounds

docked in a putative binding cleft.

The residues that comprise the

predicted binding cleft shown in "a"

are shown in red underlined text in

the Mfa1 sequence (b) or highlighted

in red in the Mfa1 structure (c). The

positions of residues R240 and W275

(see text) are shown in green and

cyan, respectively.

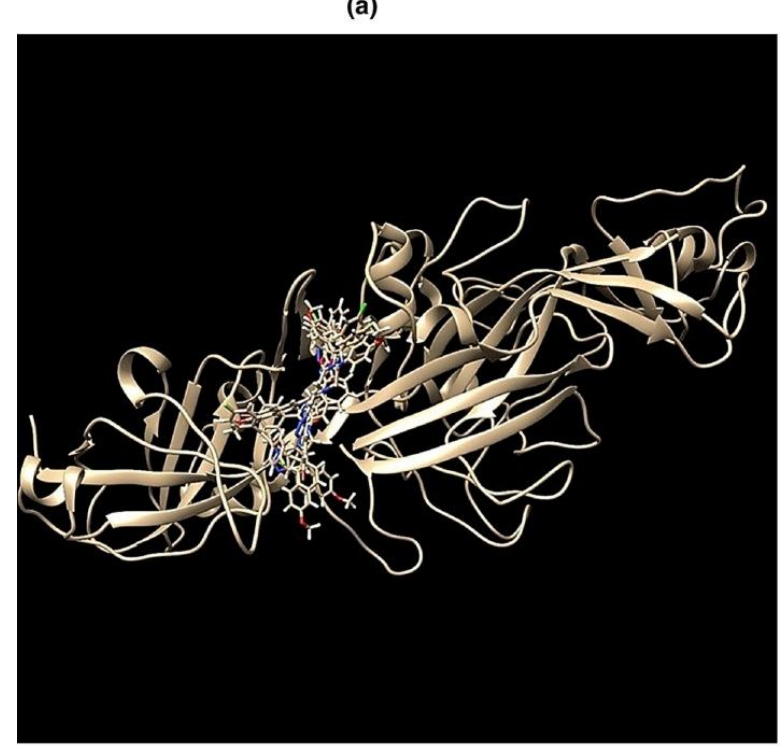

(b)

MKLNKMFLVGALLLSLGFASCSKEGNGPDPDNAAKSYMSMT LSMPMGSARA GDGQDQANPDYHYVGEWAGKDKIEKVSIYMVPQGGPGLVESAEDLDFGTY YENPTIDPATHNAILKPKKKGIKVNSAVGKTVKVYVVLNDIAGKAKALLAN VNAADFDAKFKEI IELSTQAQALGTVADGPNPATAAGKIAKKNGTTDET I MMTCLQPSDALTIEAAVSEANAIAG IKNQAKVTVERSVARAMVSTKAQSY EIKATTQIGEIAAGSVLAT ITDIRWVVAQGERRQYLSKKRGTVPENTWVT PGSGFVPTSSTFHTNATEYYDYAGLWEDHNTNEAVISGTQVPT LADY YLL DVTGELANALSGKFLLPNTHKS GANAAS SDYKRGNTA YVLVRAKET PKKE AFIDRGKTYS DNTAVPEYVAGEDFFVGENGQFYVSMKSVT DPKVGGVAGM KAHKYVKGKVLYYAWLNPSTTS PDSWWNSPVVRNNIYHIHIKS IKKLGFN WNPLVPDPDPSNPENPNNPDPNPDE PGT PVPTDPENPLPDQDT FMSVEVT VLPWKVHSYEVDL

(c)

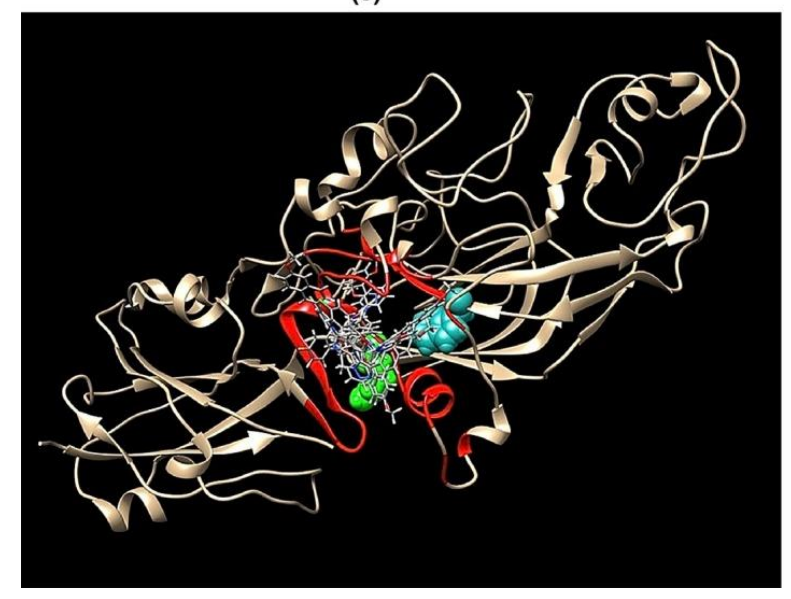


In addition, peptide N279 containing both mutations, R240A and W275A exhibited significantly lower inhibitory activity than either of the peptide fragments containing a single mutation. In contrast, peptide N279 containing the mutations V238A, I252F or $\Delta \mathrm{K} 253$ showed no significant reductions in inhibitory activity. Furthermore, mutations D321A and A357P, intended to disrupt the two putative helices, also reduced inhibitory activity relative to the parent $\mathrm{N} 400$ peptide (79\% to $59 \%$ and $79 \%$ to $38 \%$, respectively). Together, these results provide preliminary validation of the binding cleft predicted by SiteMap and identify specific Mfa1 residues that contribute to adherence of $P$. gingivalis to streptococci. 


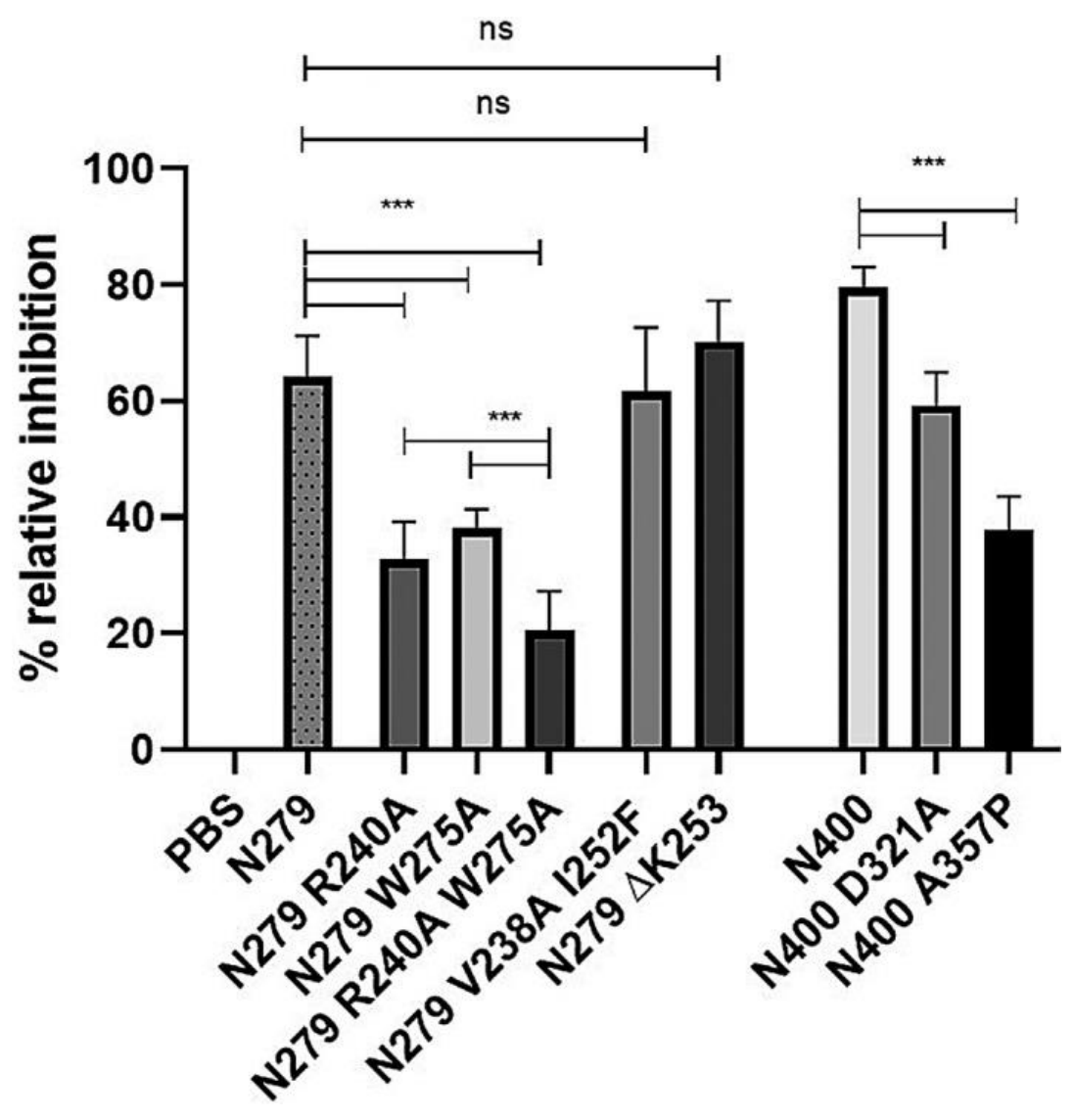

Figure 3.4. Inhibition of $P$. gingivalis adherence to $S$. gordonii by mutated Mfa1 peptides. Each experiment was carried out in triplicate and three independent experiments were conducted for each peptide. Biofilms treated with parent and mutated peptides were compared and analyzed using an unpaired $T$ test. ***p $<.05$, ns, not statistically significant. 


\subsubsection{Complementation of Mfa1-deficient $P$. gingivalis with site-specific Mfa1 mutants}

To further confirm the functional roles for R240 and A357, full-length Mfa1 polypeptides containing the R240A and A357P mutations were constructed and introduced into the Mfa1-deficient strain $P$. gingivalis SMF1. As shown in Figure 3.5a, cell surface expression of Mfa1 was significantly reduced in $P$. gingivalis SMF1 compared to the wild-type strain, $P$. gingivalis 33277 . Complementation of $P$. gingivalis SMF1 with wildtype $m f a l$ or with the site-specific mutants restored cell surface expression of Mfal to wild-type levels (Figure 3.5a). Consistent with its level of cell surface expression, adherence of $P$. gingivalis SMF1 to streptococci was significantly reduced relative to the parent strain 33277 but was restored to wild-type levels by complementation with fulllength $m f a l$, as shown in Figure 3.5b. In contrast, although complementation with Mfa1 containing either the R240A or A357P mutations restored cell surface expression, both of these complemented strains showed significantly reduced levels of adherence to streptococci. Indeed, adherence by the complemented strain expressing Mfa1-A357P was indistinguishable from $P$. gingivalis SMF1 (Figure 3.5b). 

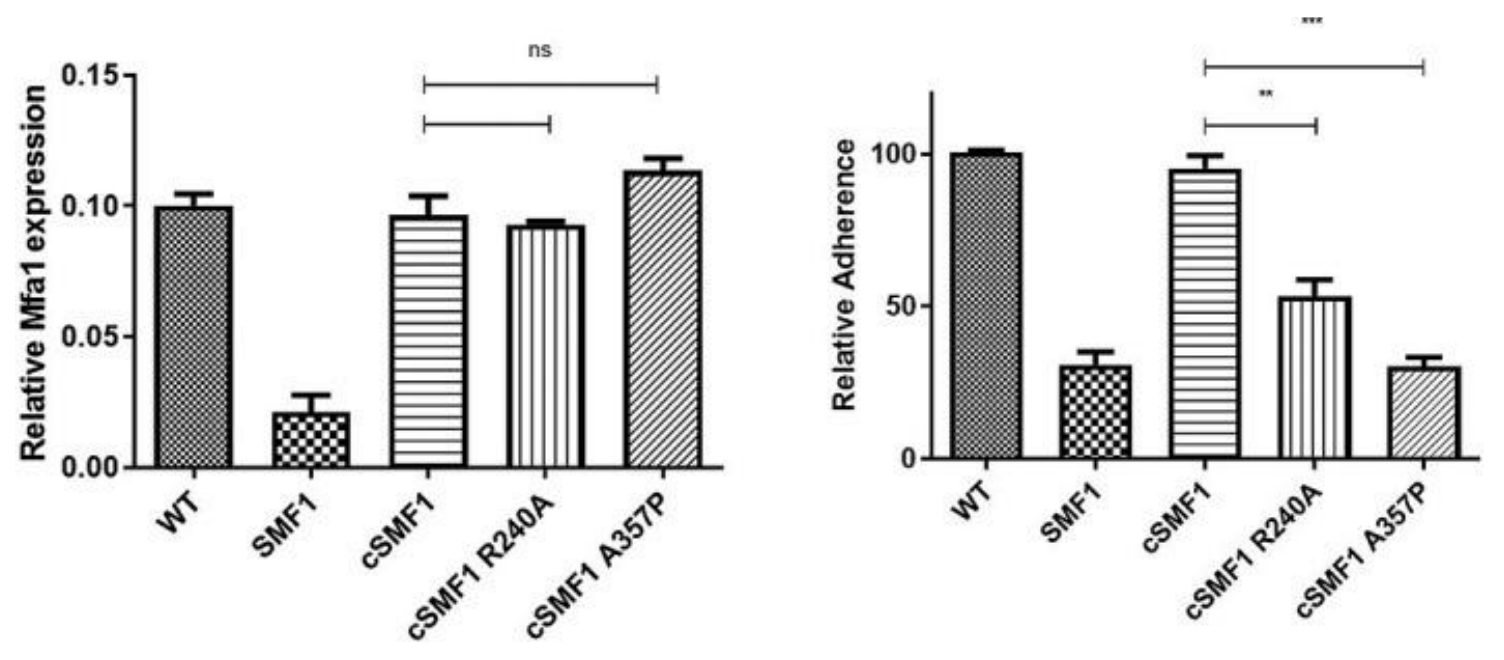

Figure 3.5. Complementation of $P$. gingivalis SMF1 with wild-type and site-specific mutants of Mfa1. (a) Cell surface expression of Mfa1 was determined by ELISA using polyclonal anti-Mfal antibodies. Cell surface expression was normalized to the level of Mfa1 expression in wild-type $P$. gingivalis 33277. (b) Adherence of $P$. gingivalis to streptococci was determined using a two species biofilm model as described in Materials and Methods. Each experiment was carried out in triplicate for each group. Adherence data were normalized to the level of adherence of the wild-type $P$. gingivalis 33277 and data were analyzed using an unpaired $T$ test. $* * * p<.001, *^{*} p<.01$, ns, not statistically significant. 


\subsubsection{Polymerization of wild-type and mutant Mfa1 proteins}

In vivo, $P$. gingivalis Mfal is post-translationally modified by glycosylation [92] and likely polymerizes to form the intact minor fimbrial structure by a donor strand based assembly mechanism involving both $\mathrm{N}$ - and C-terminal domains in Mfa1 [100, 101]. In addition, intact minor fimbriae resist complete denaturation by SDS unless samples are incubated at $100^{\circ} \mathrm{C}[94,158]$. To determine whether the mutations described above affect Mfa1 polymerization, $P$. gingivalis cells were suspended in 1x LDS buffer and incubated at either $100^{\circ} \mathrm{C}$ or $60^{\circ} \mathrm{C}$. As shown in Figure 3.6 a, incubation at $100^{\circ} \mathrm{C}$ resulted in a single protein band of $67 \mathrm{kDa}$ in all samples except the Mfa1-deficient SMF1 strain, consistent with the completely denatured Mfa1 polypeptide. In contrast, incubation at $60^{\circ} \mathrm{C}$ produced a high molecular weight smear in all samples except strain SMF1 (Figure 3.6b), indicating that incomplete denaturation of the minor fimbriae had occurred. Mfa1 proteins containing either R240A or A357P mutations behaved similarly to the wild-type protein in the 33277 and complemented cSMF1 strains, suggesting that these mutations do not affect Mfa1 processing or polymerization and that the strains expressing the mutated Mfa1 polypeptides are still capable of producing intact minor fimbriae. 
(a)

(b)

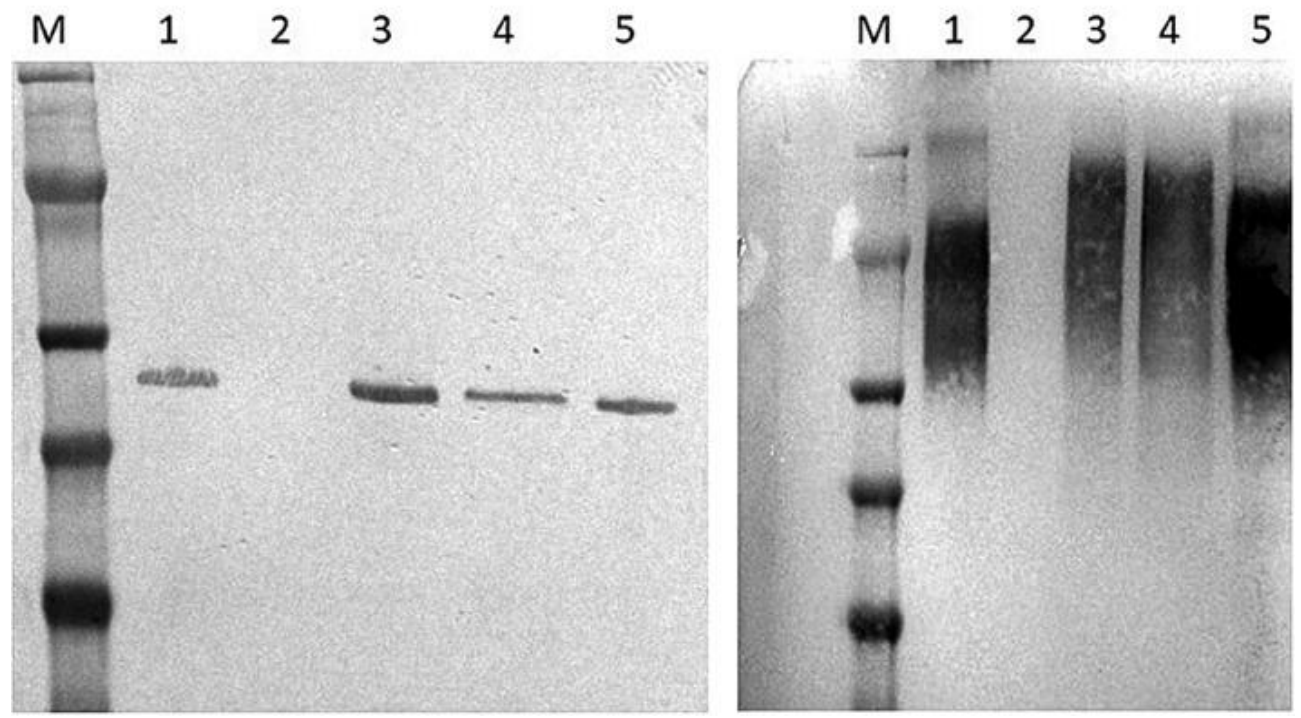

Figure 3.6. Denaturation of $\boldsymbol{P}$. gingivalis minor fimbriae. $P$. gingivalis cells were suspended in $1 \times \operatorname{LDS}$ buffer and incubated either at (a) $100^{\circ} \mathrm{C}$ or (b) $60^{\circ} \mathrm{C}$ for $10 \mathrm{~min}$. Extracts were electrophoresed in a $12 \%$ Bis-Tris gel and after transfer, Mfa1 was visualized using polyclonal anti-Mfal antibodies. Lanes 1, P. gingivalis ATCC 33277; 2, $P$. gingivalis $\mathrm{SMF} 1 ; 3, P$. gingivalis cSMF1; 4, $P$. gingivalis cMF1-R240A; and 5, $P$. gingivalis cSMF1-A357P; M, size markers. 
3.3. Discussion: Heterotypic community formation of $P$. gingivalis with oral streptococci is driven by a protein-protein interaction between the minor fimbrial antigen (Mfa1) of $P$. gingivalis and streptococcal surface antigen I/II, for example, SspB of S. gordonii [71, 87, 94]. This interaction has been shown to modulate the virulence potential of $P$. gingivalis $[43,51]$ and may also be important for initial colonization of the oral cavity by $P$. gingivalis. Therefore, disruption of heterotypic community formation by targeting the Mfa1/antigen I/II interaction may represent a potential therapeutic approach to control $P$. gingivalis colonization and virulence $[135,142,159][135,142,159]$. The region of antigen I/II involved in the interaction with Mfa1 has been extensively characterized $[134,135,160]$ and these studies led to the development of both peptide and small molecule peptidomimetics that potently inhibit $P$. gingivalis/streptococcal adherence in vitro and significantly reduced $P$. gingivalis virulence in vivo $[135,141$, 142, 161]. However, the interacting interface of Mfal that drives this protein-protein interaction has not been well characterized.

Based on peptide mapping, our results indicate that important functional residues and/or motifs of Mfa1 reside between residues 225 and 400 of the protein and truncated peptides comprising this region inhibited $P$. gingivalis adherence to streptococci as effectively as the full-length Mfa1 protein. In addition, analysis of the three-dimensional structure of Mfa1 using SiteMap identified a putative ligand binding cleft in which five small molecule mimetics of the BAR peptide could be readily docked. Interestingly, many of the residues within five angstroms of the peptidomimetic ligands are present in the 225400 residue region of Mfa1. BAR peptide can also associate with this site but docking studies using the more structurally complex peptide will require further refinement. The 
functional properties of several of these residues were confirmed by site-specific mutagenesis and peptides containing the R240A, W275A or A357P mutations were significantly less effective inhibitors of $P$. gingivalis adherence that the parent peptide or full-length Mfa1. Amino acids R240 and W275 form hydrogen bonds with residues that stabilize the binding cleft and those residues are directly accessible in the binding site pocket. The A357P mutation likely disrupts a short amphipathic $\alpha$-helix in the binding site pocket and we can speculate that this region may interact with the amphipathic VQDLL motif of BAR peptide which is essential for its interaction with Mfa1.

Consistent with this, complementation of an Mfa1-deficient strain of $P$. gingivalis with full-length copies of Mfa1 containing the R240A, W275A or A357P mutations did not restore $P$. gingivalis adherence whereas complementation with native Mfa1 restored the wild-type phenotype. Even though the Mfa1/Ag I/II interaction is essential for $P$. gingivalis adherence and stable biofilm formation, it should be noted that inactivation of $m f a 1$ did not completely eliminate adherence to streptococci in vitro. One explanation for this is that the major fimbrial subunit protein, $P$. gingivalis FimA, can also interact with streptococcal cell surface GAPDH [88] ; however, this interaction by itself is insufficient to promote stable $P$. gingivalis-streptococcal biofilms [127]. Together, these results validated the ligand binding cleft identified by SiteMap, identified specific amino acids that contribute to $P$. gingivalis adherence and suggest that the central region of Mfa1 is essential for the interaction of the minor fimbriae with the BAR motif of streptococcal antigen I/II. 
Biogenesis of the minor fimbriae in $P$. gingivalis requires proteolytic and posttranslational processing of Mfa1 and subsequent polymerization to form the fimbrial structure, most likely via a donor strand based exchange mechanism. Polymerization of Mfa1 may involve $\beta$-strands at both the $\mathrm{N}$ - and C-terminal regions of Mfa1 $[100,101]$. In contrast, our results indicate that the central region of Mfa1, between residues 225 and 400, is required for $P$. gingivalis adherence to streptococci and consistent with this, the highest scoring ligand binding cleft identified by SiteMap is mostly comprised of residues in this central domain. Furthermore, the polymerization of mutated Mfa1 peptides that are defective in streptococcal adherence was similar to the wild-type Mfal protein, suggesting that independent domains of Mfa1 are required for fimbrial biogenesis and $P$. gingivalis-streptococcal adherence. Consistent with this, it was recently shown that peptides CT1 and CT2 which are both derived from the C-terminal region of Mfa1 encompassing residues 546-563 inhibit Mfa1 polymerization [162]. Peptide CT2 also inhibited $P$. gingivalis-streptococcal biofilm formation and functioned by interfering with minor fimbrial biogenesis. In contrast, the BAR peptide and the BAR peptidomimetics function as competitive inhibitors of streptococcal adherence and have no effect on minor fimbrial biogenesis. The mature minor fimbriae of $P$. gingivalis also contain three additional tip proteins, Mfa3, Mfa4 and Mfa5. These proteins appear to play a role in the assembly of the tip complex itself and its incorporation into the fimbrial shaft and are required for optimal surface expression of the minor fimbriae [106, 107, 145]. While Mfa1 has been shown to interact with Mfa3 [101], there is little information to suggest that the tip proteins contribute directly to $P$. gingivalis adherence to streptococci. Indeed, purified recombinant Mfa1 in the absence of the tip proteins potently inhibits $P$. 
gingivalis adherence, suggesting that Mfa3, Mfa4 and Mfa5 do not play a major role in the interaction with streptococcal antigen I/II.

Although several specific amino acids and/or structural motifs of Mfa1 were shown to be important for its interaction with $\mathrm{Ag} \mathrm{I} / \mathrm{II}$, the functional properties of other residues predicted to comprise the ligand binding cleft have yet to be determined. For example, K70 and Mfa1 amino acids 180-194 were identified as putative cleft residues; however, the truncated peptide N225 was only a poor inhibitor of $P$. gingivalis adherence. This suggests that these residues may not interact directly with Ag I/II (or the BAR peptide), or alternatively, that they may also require the contribution of downstream residues. Since Mfa1 has been recently crystallized [100], it may be possible to co-crystallize the protein with the BAR peptide or with recently developed peptidomimetics of BAR [161] to generate a more complete picture of the Mfa1-Ag I/II interacting interface. Ultimately, a thorough understanding of the mechanism of the Mfa1/Ag I/II interaction will facilitate structure-based drug design and the development of potential therapeutics that may limit $P$. gingivalis colonization of the oral cavity. 


\section{CHAPTER FOUR: SMALL MOLECULE DRUG DISCOVERY}

4.1. Introduction : Treatment of periodontal disease typically involves the mechanical removal of dental plaque by scaling and root planning, antibiotic therapy, and if necessary, gingival surgery to reduce the depth of the subgingival pocket [163]. Although periodontal disease is considered to be a polymicrobial infection, Porphyromonas gingivalis has been suggested to function as a keystone pathogen that can alter host innate immune functions leading to dysbiosis and chronic inflammation $[41,52,152]$. The primary niche of $P$. gingivalis is the subgingival pocket $[54,164]$ but initial colonization of the oral cavity by $P$. gingivalis occurs in the supragingival biofilm where the organism can adhere to primary colonizing organisms such as oral streptococci [59] [72]. Adhesion of $P$. gingivalis to streptococci is primarily driven by a proteinprotein interaction between the minor fimbrial antigen of $P$. gingivalis (Mfa1) and specific members of the streptococcal surface antigen I/II family of proteins (e.g., SspB of $S$. gordonii) $[94,127,135]$. As one of the initial interactions contributing to $P$. gingivalis colonization, this protein-protein interaction represents an ideal candidate for therapeutic intervention.

The interaction of Mfal with SspB has been well characterized. Deap et al. identified two discrete motifs of SspB comprised of the amino acids NITVK and VQDLL and showed that these motifs are essential for the interaction with Mfa1 [134]. Daep et al. also showed that these motifs in SspB closely resembled the functional motifs of the 
eukaryotic nuclear receptor (NR) box protein-protein interaction domain [134, 136]. Furthermore, a synthetic peptide containing both NITVK and VQDLL (designated BAR) potently inhibited $P$. gingivalis adhesion to $S$. gordonii and significantly reduced $P$. gingivalis virulence in a murine model of periodontitis $[135,136]$. Subsequently, Patil et al. synthesized a series of highly active small molecule peptidomimetics of BAR using a click chemistry approach and demonstrated that these compounds exhibited no toxicity towards a variety of human cells and cell lines [141, 142].

The advent of computer assisted molecular modeling technologies and structure-based virtual screening methods provides an additional platform for rational drug design to identify targeted small molecule inhibitors of biologic interactions. For example, Stone et al. utilized a high throughput virtual screening approach of the ZINC database of commercially available chemical compounds to identify small molecule inhibitors of $P$. gingivalis $m$-diaminopimelate dehydrogenase, an essential enzyme involved in protein and cell wall synthesis [165]. In this chapter, I performed virtual screening of the ZINC drug-like chemical libraries to identify small molecule homologs similar to the NITVK and VQDLL motifs of SspB. The three most potent compounds that were identified inhibited $P$. gingivalis adherence to streptococci and reduced $P$. gingivalis virulence in vivo. Two of these active compounds showed no cytotoxic activity towards a variety of human and murine cell lines and represent potential lead compounds for the development of novel therapies to limit $P$. gingivalis colonization of the oral cavity. 


\subsection{Results:}

\subsubsection{In vitro functional assessment of the identified ZINC library candidates. After}

virtual screening, a total of 33 commercially available molecules with structural similarity to either the NITVK or VQDLL motifs were identified and obtained for functional testing. Using the two species biofilm model described by Patil et. al. [141], the in vitro effectiveness of the compounds was determined by their ability to inhibit $P$. gingivalis adherence to $S$. gordonii and subsequent biofilm formation at an initial concentration of $40 \mu \mathrm{M}$. As shown in Figure 4.1A, of the 17 compounds selected based on similarity with the NITVK motif, two inhibited adherence and biofilm formation at $\geq 40 \%$, N7 ( 40\%) and N17 ( 60\%). In addition, of the 16 selected compounds based on similarity with the VQDLL motif, only compound V8 inhibited biofilm formation by $\geq 40 \%$ (Figure 4.1B). Subsequently, dose dependent inhibition studies were carried out for compounds N7, N17 and V8 using concentrations of 5, 10, 15, 25 and $40 \mu \mathrm{M}$. As shown in Figure 4.2, each of these compounds inhibited $P$. gingivalis adherence and biofilm formation in a dose dependent manner. The structure of the N7, N17 and V8 presented in Figure 4.3a, b and c respectively and Figure 4.3.d and 4.3.e indicate the structural similarities between N17 and NIVTK, and V8 and VQDLL motifs. Thus, compounds that are similar to both of the functional domains of the streptococcal SspB protein inhibited $P$. gingivalis/S. gordonii adherence in vitro. 
A

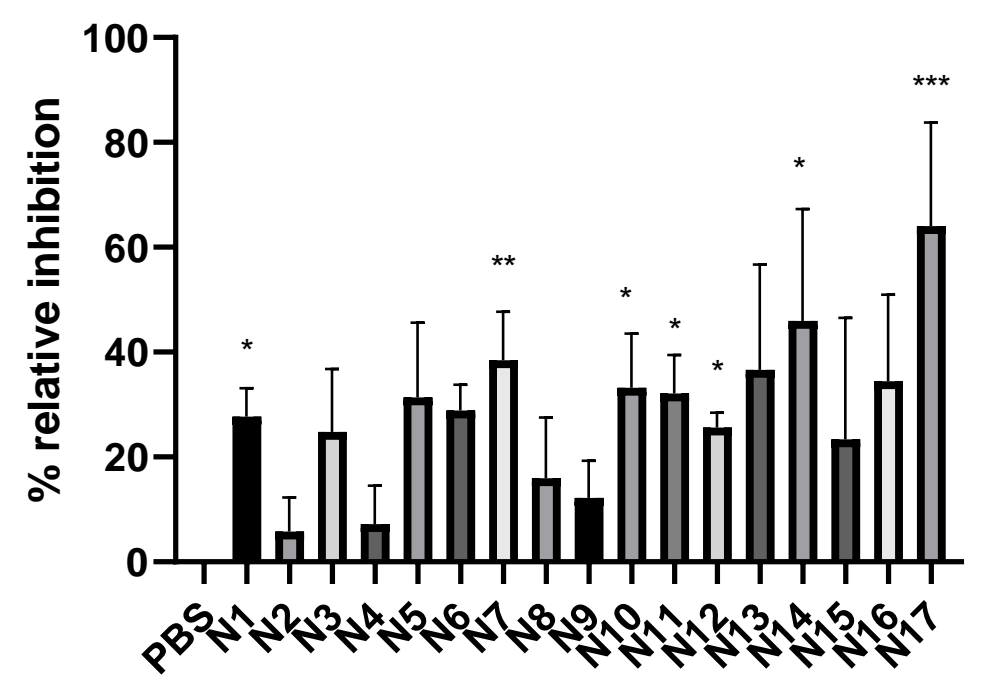

B

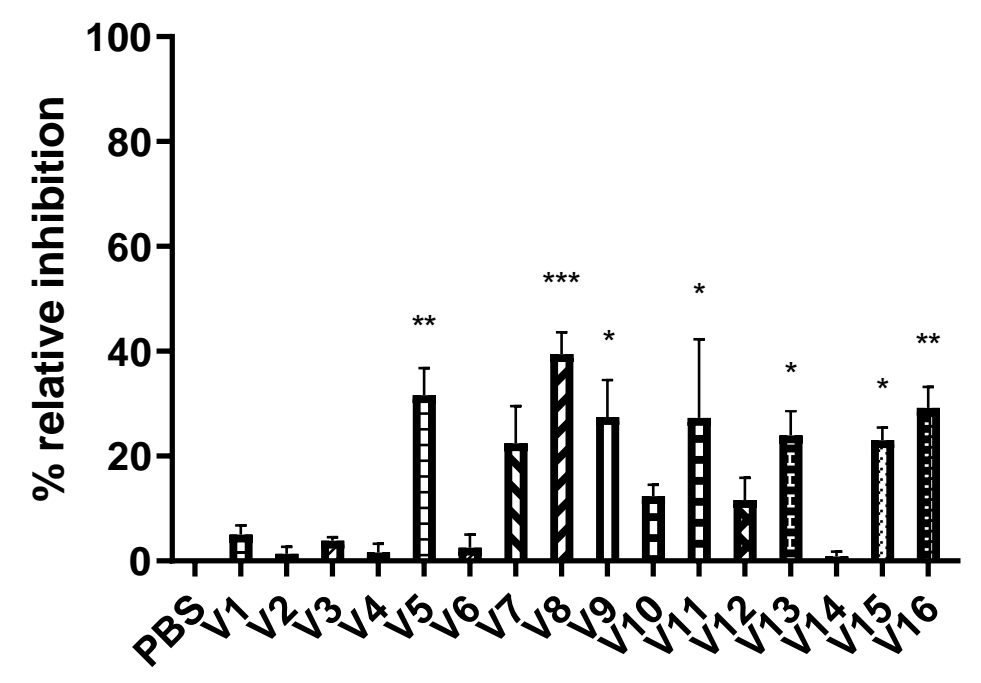

Figure 4.1. In vitro screening of the small molecules. Compounds N1 - N17 (A) and V1 - V16 (B) were screened for inhibition of $P$. gingivalis adherence to $S$. gordonii at a concentration of $40 \mu \mathrm{M}$. Relative inhibition was normalized to the PBS control. Each experiment was carried out in triplicate and three independent experiments were conducted for each compounds. Data was analyzed by one way ANOVA followed by Dunnett's multiple comparison test using PBS as control. Significance was defined as $* \mathrm{p}<0.05, * * \mathrm{p}<0.01, * * * \mathrm{p}<0.001$. 


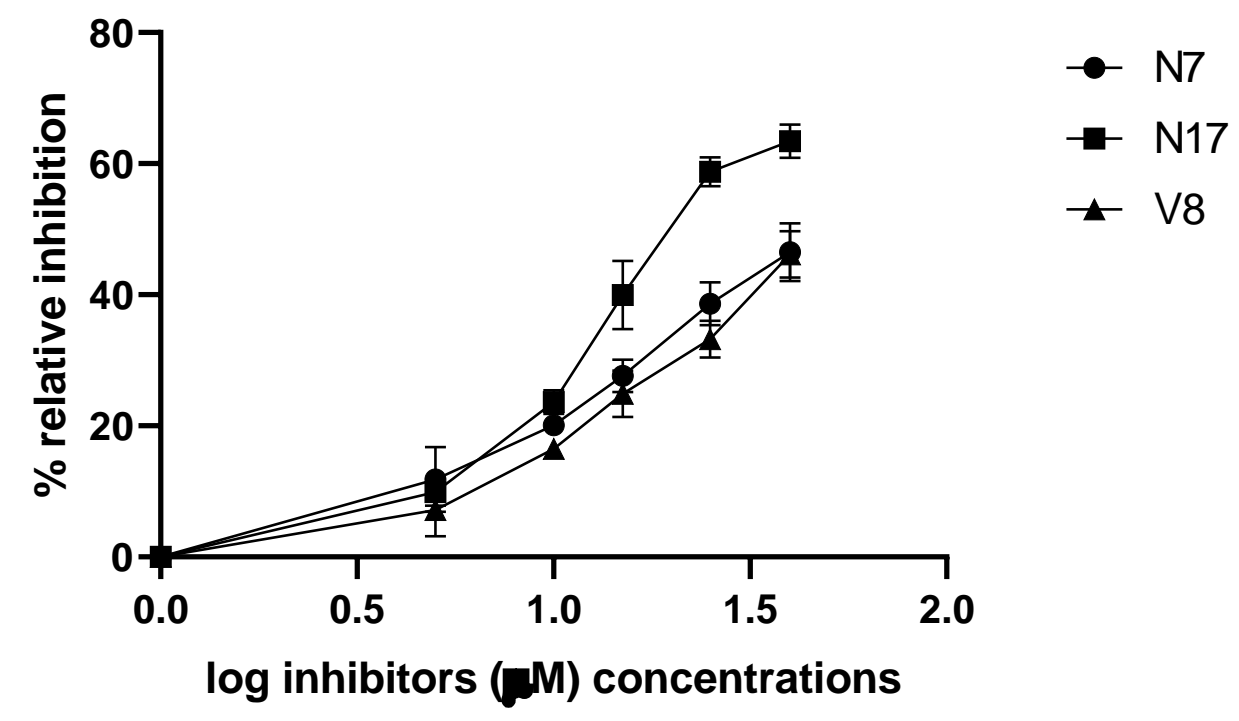

Figure 4.2. Dose dependent inhibition of $\boldsymbol{P}$. gingivalis adherence. Compounds N7, N17 and V8 were each tested at concentrations of 5, 10, 15, 25 and $40 \mu \mathrm{M}$ and inhibition was normalized to the PBS control. 
A.

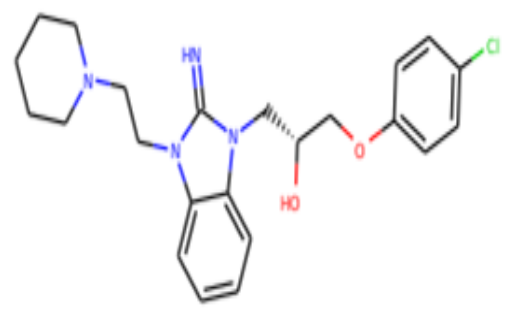

N7:

ZINC000004797470

D.

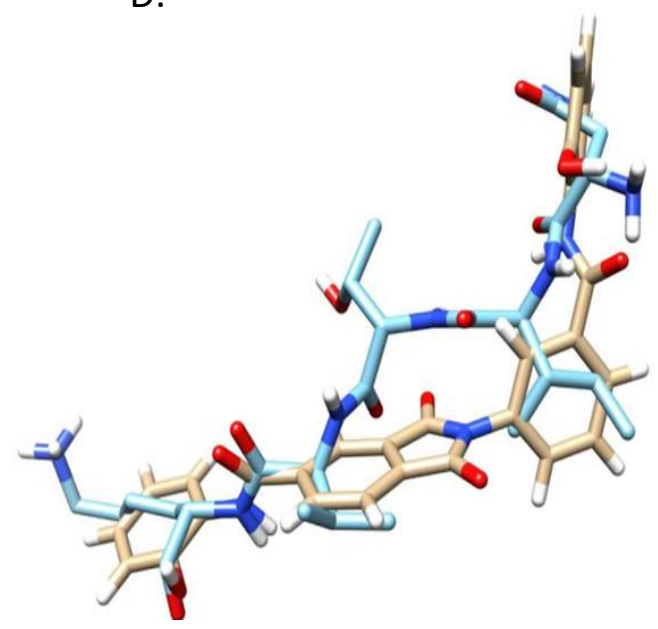

B.

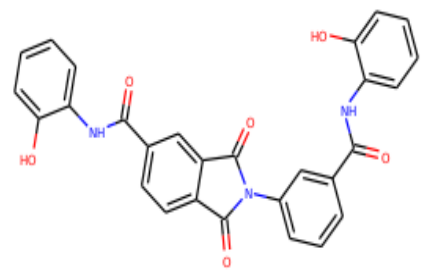

N17: ZINC03142014

C.

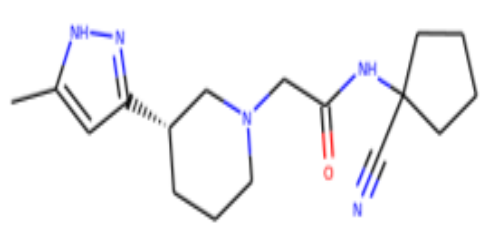

V8: ZINC84110921

C.

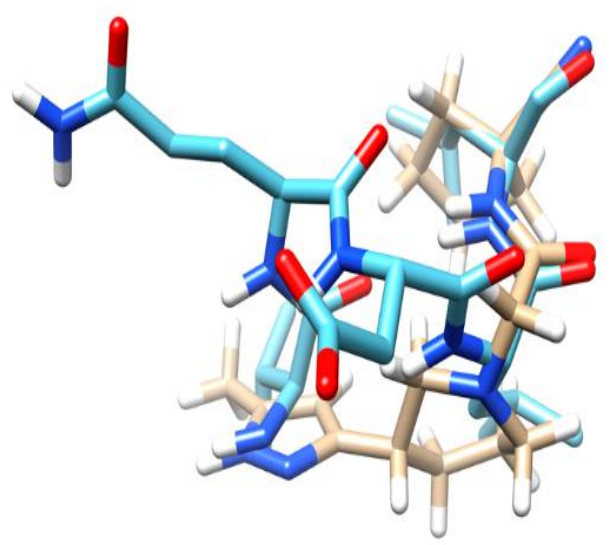

Figure 4.3. Chemical structures of the lead compounds: A) N7: 1-(4chlorophenoxy)-3-\{2-imino-3-[2-(piperidin-1-yl)ethyl]-2,3-dihydro-1H-1,3-benzodiazol1-yl $\}$ propan-2-ol hydrochloride, $\quad$ B) N17: N-(2-hydroxyphenyl)-2-\{3-[(2hydroxyphenyl)carbamoyl]phenyl \}-1,3-dioxo-2,3-dihydro-1H-isoindole-5-carboxamide, C) V8: N-(1-cyanocyclopentyl)-2-[3-(5-methyl-1H-pyrazol-3-yl)piperidin-1-yl] acetamide, D) overlay of compound N17 on the NITVK motif, E) overlay of compound V8 on the VXXLL motif. In the overlay images, compounds N17 and V8 are indicated with the tan backbones and the AgI/II motifs are shown with the blue backbones. 
4.2.2. Small molecule inhibition of $\boldsymbol{P}$. gingivalis virulence. In vivo activity of compounds N7, N17 and V8 was determined using a murine model of periodontitis as described by Deap et al. [135] (Figure 4.4). Briefly, Antibiotic pretreated mice were challenged with $10^{9} \mathrm{cfu} / \mathrm{ml}$ of $S$. gordonii suspends in $2 \%$ carboxyl methyl cellulose (CMC) using feeding needle for 10 days in every other days. Then mice were infected with $P$. gingivalis in same way of $S$. gordonii in presence or absence of the compounds at concentration of $40 \mu \mathrm{M}$. After 47 days of post infection, mice were euthanized and mice maxillary was recovered. Since a hallmark of periodontal disease in humans is the resorption of alveolar bone anchoring the teeth, $P$. gingivalis virulence was assessed by alveolar bone loss, determined by measuring the distance from the alveolar bone crest $(\mathrm{ABC})$ to the cemento enamel junction (CEJ). Figure 4.5A shows representative images of the maxillary jaws of treated and untreated animals. Infected but untreated mice exhibited an uneven $\mathrm{ABC}$ and more extensive exposure of tooth roots (arrows in Figure 4.5A) than control animals or mice treated with N1, N17 or V8. The quantification of bone loss for each group of mice is shown in Figure 4.5B. Consistent with our previous results [135], mice infected with both $S$. gordonii and $P$. gingivalis showed significantly greater alveolar bone loss than sham-infected mice or animals infected with $S$. gordonii or $P$. gingivalis alone. In contrast, infection of mice with $S$. gordonii and $P$. gingivalis in the presence of N7, N17 or V8 resulted in a significant reduction in alveolar bone loss $(\mathrm{p}<0.001)$ 


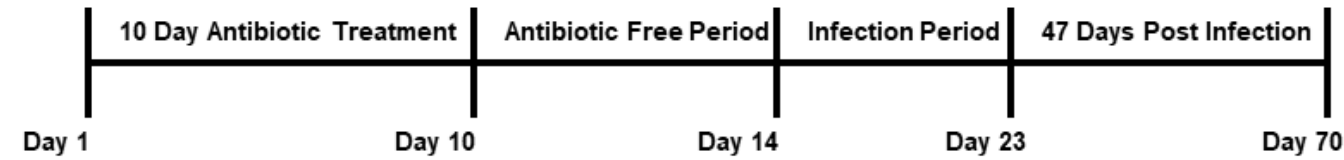

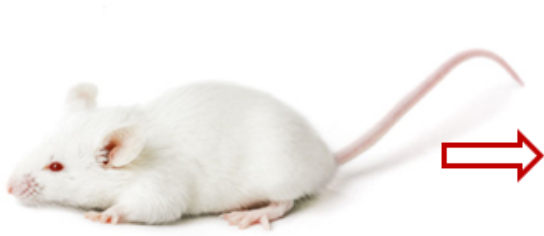

Antibiotic pretreated
Challenged with S. $g$ for five times using feeding needle for 10 days in every other days. Then Infected with $P . g$ in absence or presence of the compounds
Euthanized and alveolar bone loss was measured by dissecting microscope fitted with a video imaging marker.

Figure 4.4: Schematic timeline of the mice model of periodontitis. Mice were treated with sulfamethoxazole and trimethoprim in water for 10 days ad libitum. Antibiotic pretreated mice were challenged with $10^{9} \mathrm{cfu} / \mathrm{ml}$ of $S$. gordonii suspends in $2 \%$ carboxyl methyl cellulose (CMC) using feeding needle for 10 days in every other days. Then mice were infected with $\mathrm{P}$. gingivalis in same way of $\mathrm{S}$. gordonii in presence or absence of the compounds. After 47 days of post infection, mice were euthanized and alveolar bone loss was measured. 
A.

P. $g$-S. $g$

P. $g-S . g+\mathrm{N} 17$

P. $g-S . g+\mathrm{N} 7$
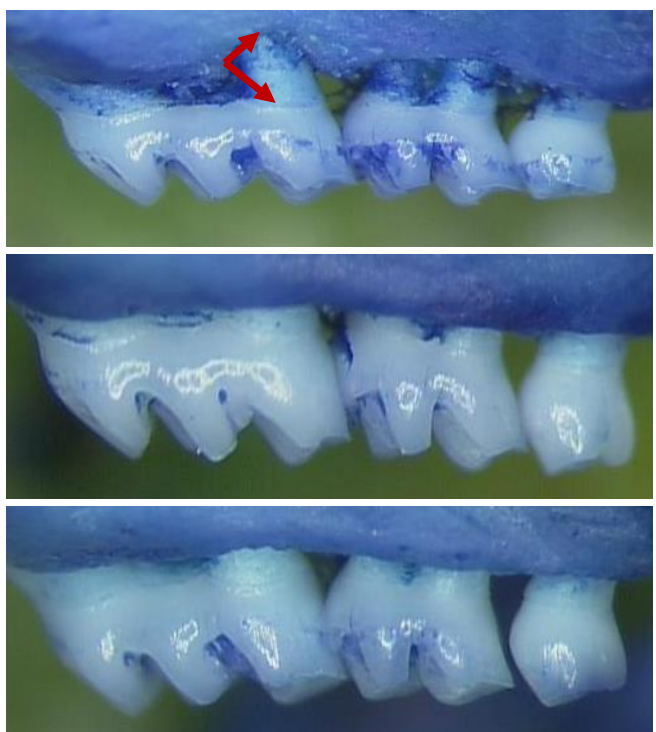

P. $g-S . g+V 8$

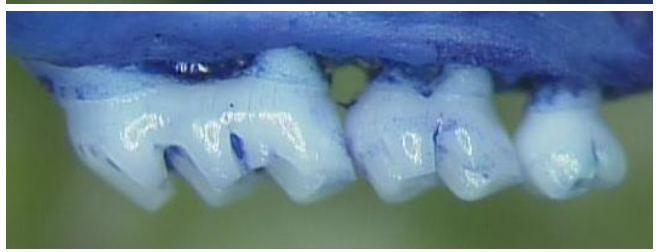

B.

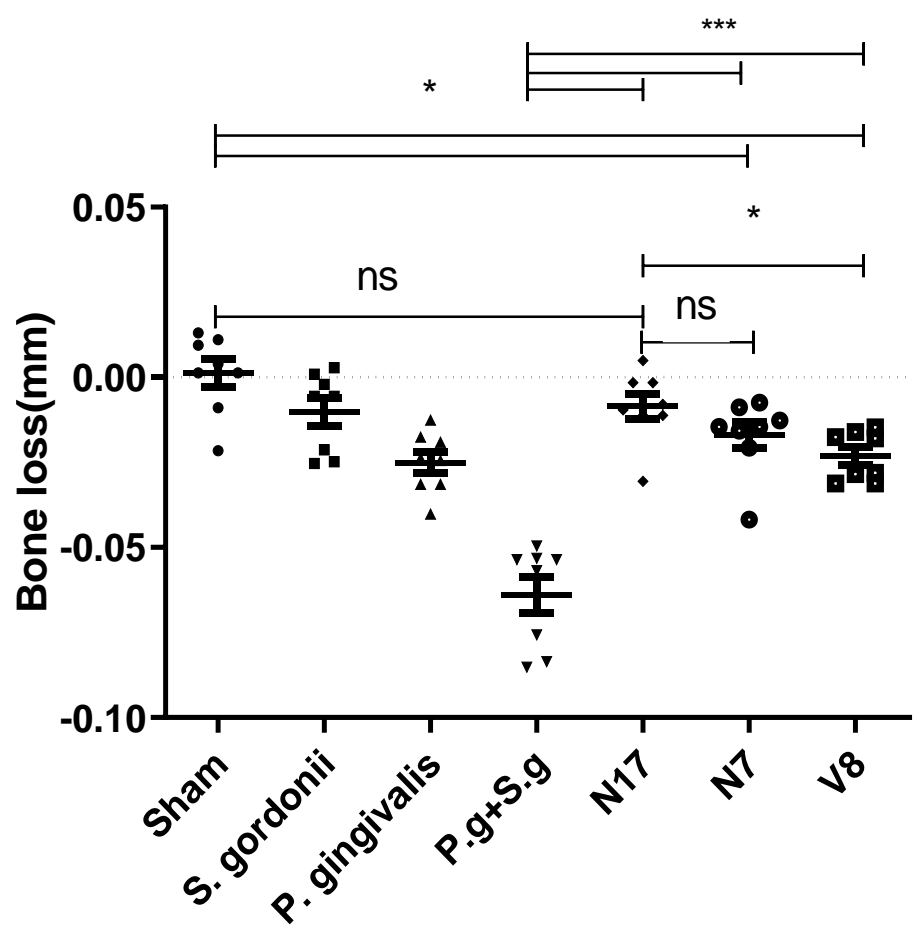


Figure 4.5. In vivo inhibition of $\boldsymbol{P}$. gingivalis virulence. A) Representative images of maxillary molars of mice infected with $P$. gingivalis and $S$. gordonii and treated with compounds N7, N17 or V8 at a concentration of $40 \mu \mathrm{M}$. B) Quantification of alveolar bone loss. Bone loss was determined by measuring the distance from the alveolar bone crest to the cemento-enamel junction and values were normalized against sham infected mice. Each group had eight mice. Statistically significant differences were determined using one way ANOVA. ${ }^{*} \mathrm{p}<0.05 ; * * * \mathrm{p}<0.001 ; \mathrm{ns}$, not significant. 
Furthermore, since IL-17-mediated recruitment of neutrophils is an important contributor to the inflammatory process leading to alveolar bone resorption [166, 167], we also determined whether treatment with N7, N17 or V8 influenced the level of IL-17 expression in gingival tissue relative to untreated animals. As shown in Figure 4.6, IL-17 expression was significantly increased in mice infected with both $S$. gordonii and $P$. gingivalis relative to animals infected only with S. gordonii. Treatment of dual infected mice with each of the compounds significantly reduced IL-17 expression in the maxillary gingiva to levels similar to that in mice infected with $S$. gordonii alone. Together, these data indicate that treatment with each of the three lead compounds resulted in reduced gingival inflammation and reduced alveolar bone loss in mice infected with both $S$. gordonii and P. gingivalis. 

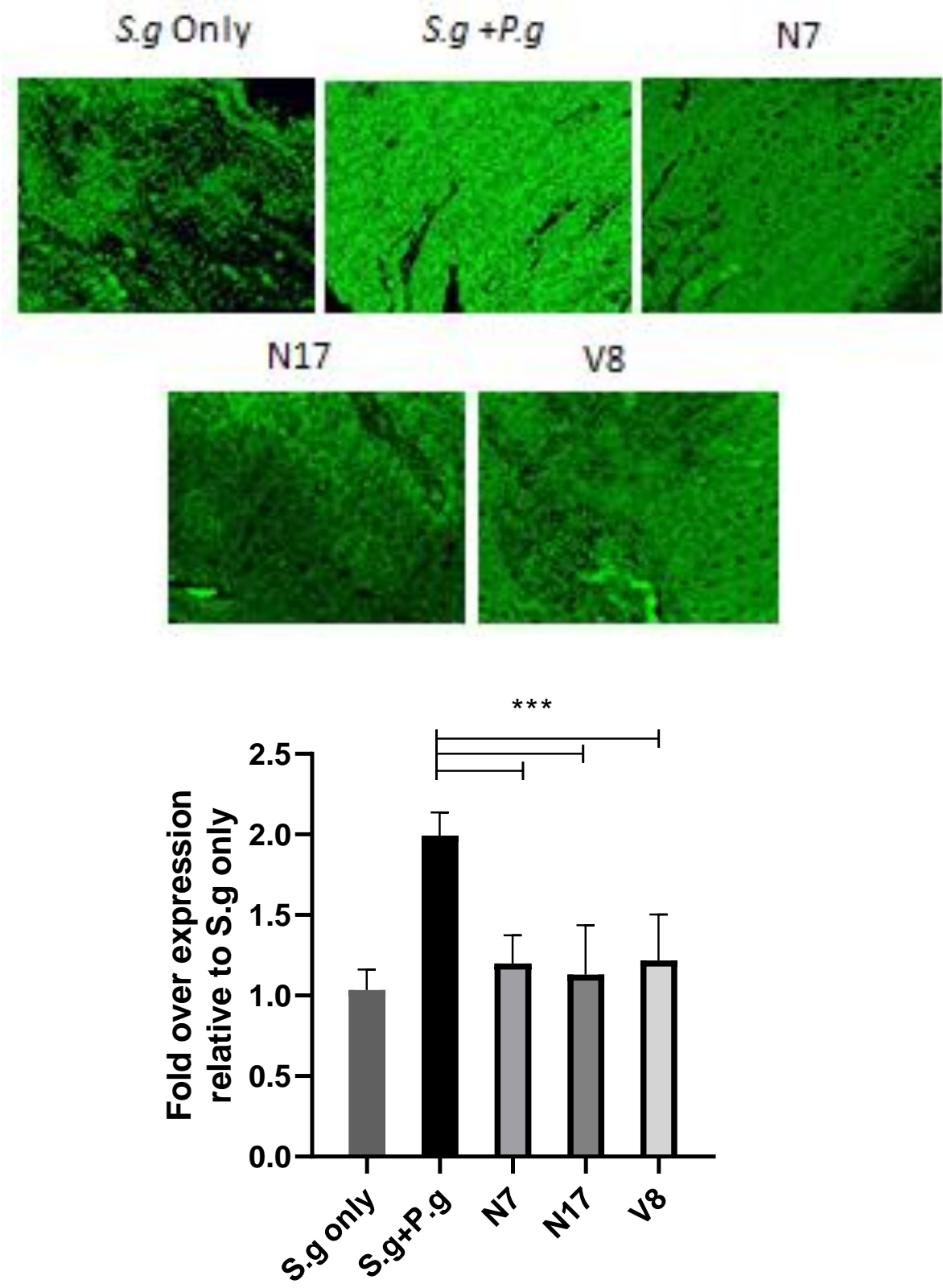

Figure 4.6. IL-17 levels in gingival tissue. A) IL-17 expression was determined by immunofluorescence staining of maxillary gingival tissue obtained from mice infected with $S$. gordonii alone, S. gordonii and $P$. gingivalis or from dual infected animals treated with compound N7, N17 or V8. B) Quantification of IL-17 expression in control and treated mice. Experiment in each group carried out in triplicate. One way ANOVA was performed to determine statistical significance. ${ }^{* * *}, \mathrm{p}<0.05$. 
4.2.3. Determination of cytotoxicity of the active compounds. To confirm that N7, N17 and V8 function by inhibiting $P$. gingivalis adherence to $S$. gordonii rather than acting as an antibiotic, microbicidal activity of the compounds was determined by growing the organisms in medium containing $40 \mu \mathrm{M}$ of each compound for $24 \mathrm{hr}$. As shown in Figure 4.7, none of the compounds affected the growth of $S$. gordonii or $P$. gingivalis either in early stage or late stage of growth. 
A. S. gordonii

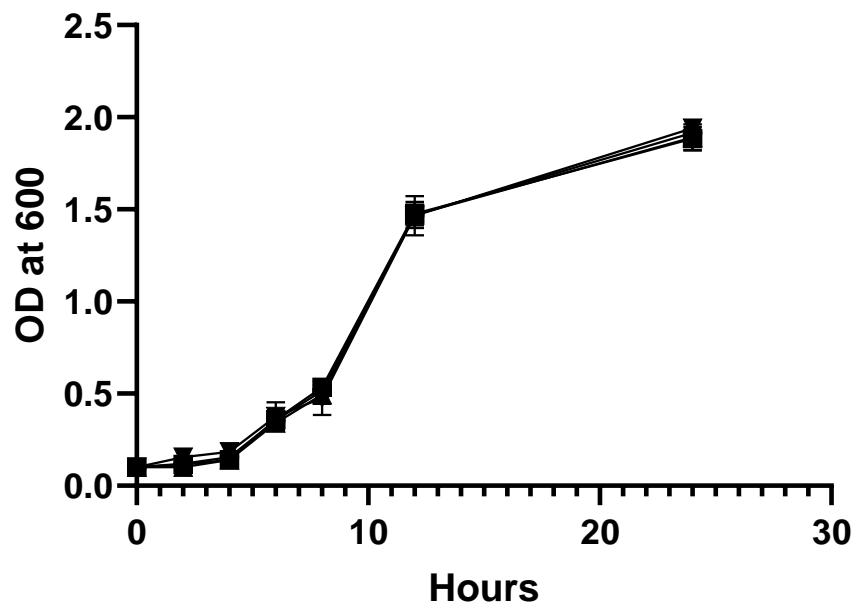

$\rightarrow$ Medium Only

- Medium+DMSO

$\rightarrow \mathrm{N} 17$

$\rightarrow \quad$ V8

B.

\section{P. gingivalis}

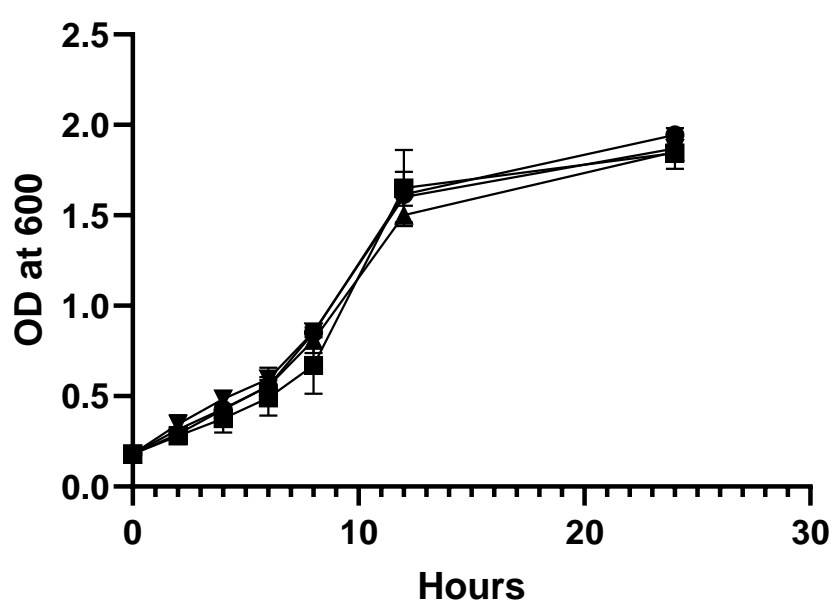

-- Medium Only

- Medium+DMSO

$\rightarrow \mathrm{N} 17$

$\rightarrow \quad$ V8

Figure 4.7. Bacteriocidal activity of the compounds. S. gordonii (A) and P. gingivalis (B) were grown for $24 \mathrm{hr}$ in medium containing $40 \mu \mathrm{M}$ of each compound and growth was quantified by measuring $\mathrm{OD}_{600 \mathrm{~nm}}$ for each culture. Each experiment carried out in triplicate. 
Next, to assess compound cytotoxicity towards eukaryotic cells, a series of toxicity tests were carried out using telomerase immortalized human gingival keratinocytes (TIGK) and the murine J774.A1 and human HL-60 cell lines. These tests included measuring lactate dehydrogenase (LDH) release and overall cell viability (cellular ATP levels) of cells after treatment with each compound. In addition, the apoptotic and hemolytic activity of each compound was determined. As shown in Figure 4.8, LDH release by cells treated with compounds N17 and V8 did not significantly differ from the negative controls for any of the cell lines. In contrast, exposure of cells to N7 resulted in a significant increase in LDH release at the higher concentrations that were tested (20 - 40 $\mu \mathrm{M})$ suggesting that this compound may disrupt the integrity of the cell membrane. Compounds N17 and V8 also exhibited minimal effects on cell viability, measured by total ATP levels, whereas N7 significantly reduced cellular ATP levels (Figure 4.9). Consistent with the results above, N17 and V8 did not induce apoptosis over the control reaction whereas treatment with compound N7 significantly reduced the live cell count and increased the number of late apoptotic cells (Figure 4.10) and Table 4.1, 4.2 and 4.3. Finally, as shown in Figure 4.11, none of the compounds exhibited hemolytic activity towards either sheep or human red blood cells. Together, these data indicate that N17 and V8 exhibit little cytotoxic activity towards the eukaryotic cell lines tested. In contrast, compound N7 exhibited significant cytotoxicity and may not be biocompatible. 
A

J774A. 1

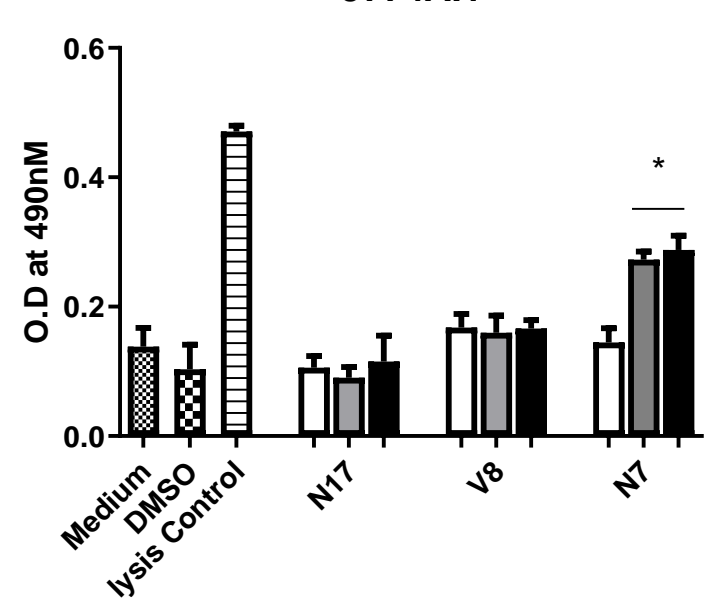

B

\section{TIGK}

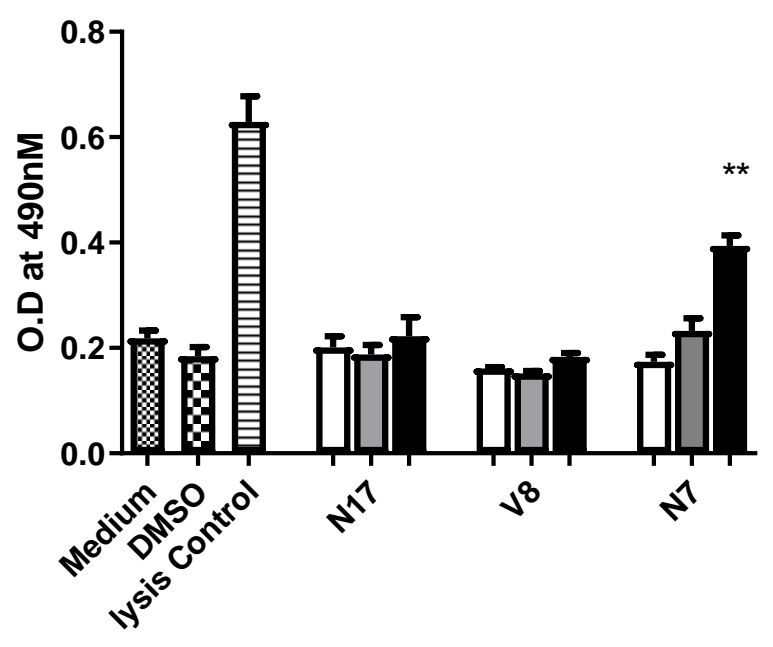

C

\section{HL60}

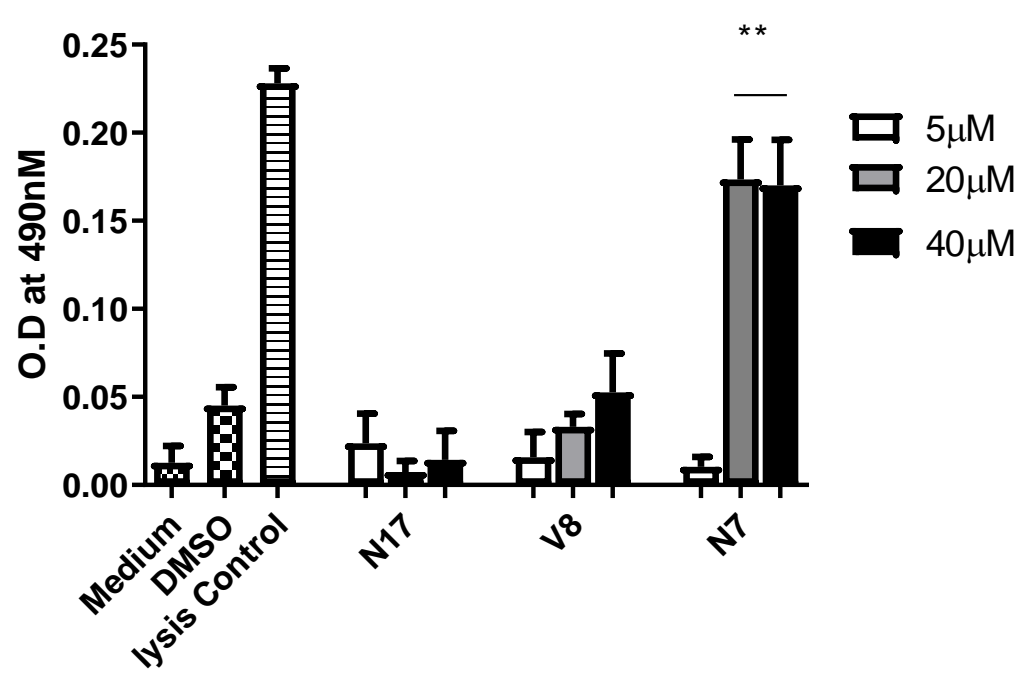

Figure 4.8. LDH assay: Cytolytic activity of compounds N7, N17 and V8 against TIGK (A), J774A.1 (B), and HL60 (C) cells. LDH activity in cell free medium supernatants was determined after incubation of cells with the compounds for $18 \mathrm{hr}$ at a concentration 5,20 or $40 \mu \mathrm{M} .{ }^{*} \mathrm{p}<0.05, * * \mathrm{p}<0.01$. 
A

J774A.1

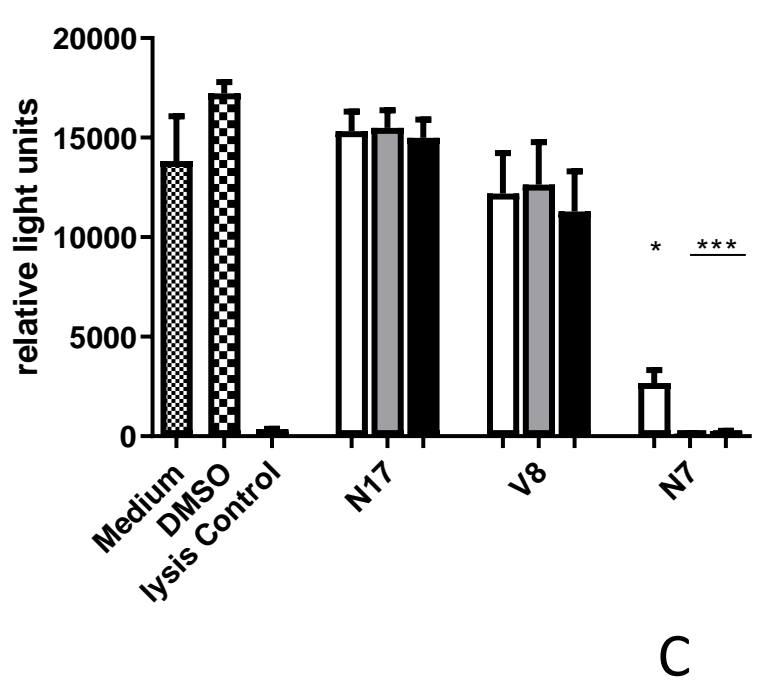

B

TIGK

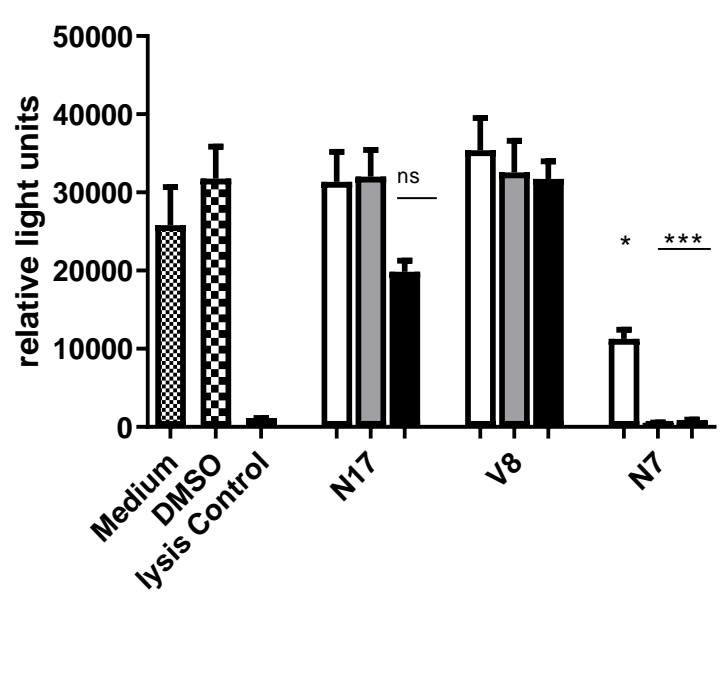

HL60

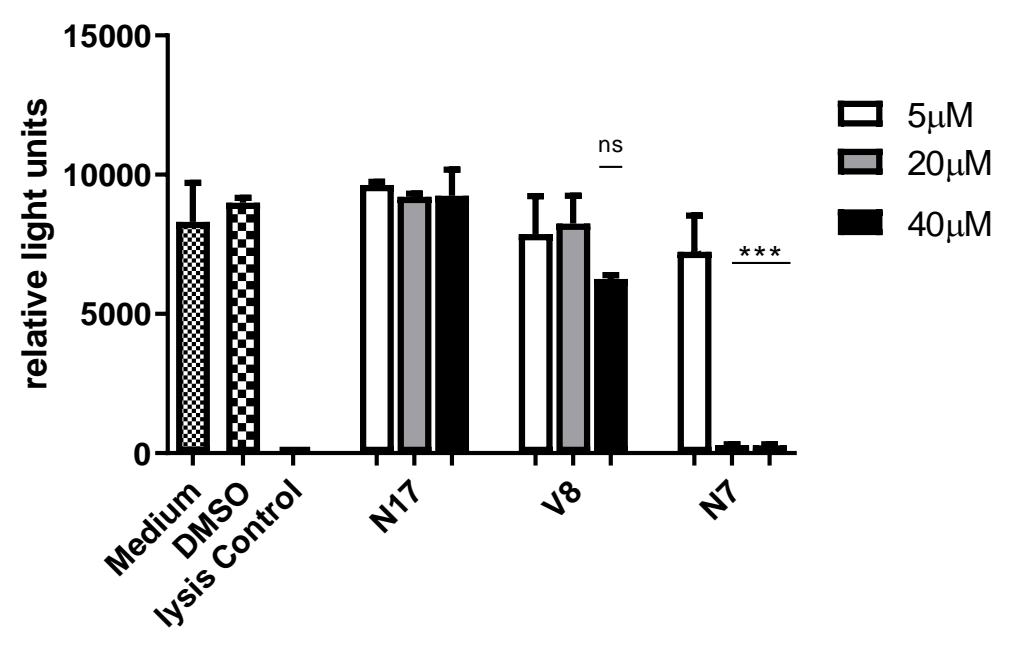

Figure 4.9. ATP assay: Effect of compounds N7, N17 and V8 on TIGK (A), J774A.1 (B), and HL60 (C) cell viability. Cellular ATP levels were determined after treating cells with the compounds for $18 \mathrm{hr}$ at a concentration 5, 20, or $40 \mu \mathrm{M}$. Significant differences were determined by comparing experimental samples to the medium only and medium/DMSO controls. ${ }^{*} \mathrm{p}<0.05, * * * \mathrm{p}<0.001, \mathrm{~ns}-$ not significant. 


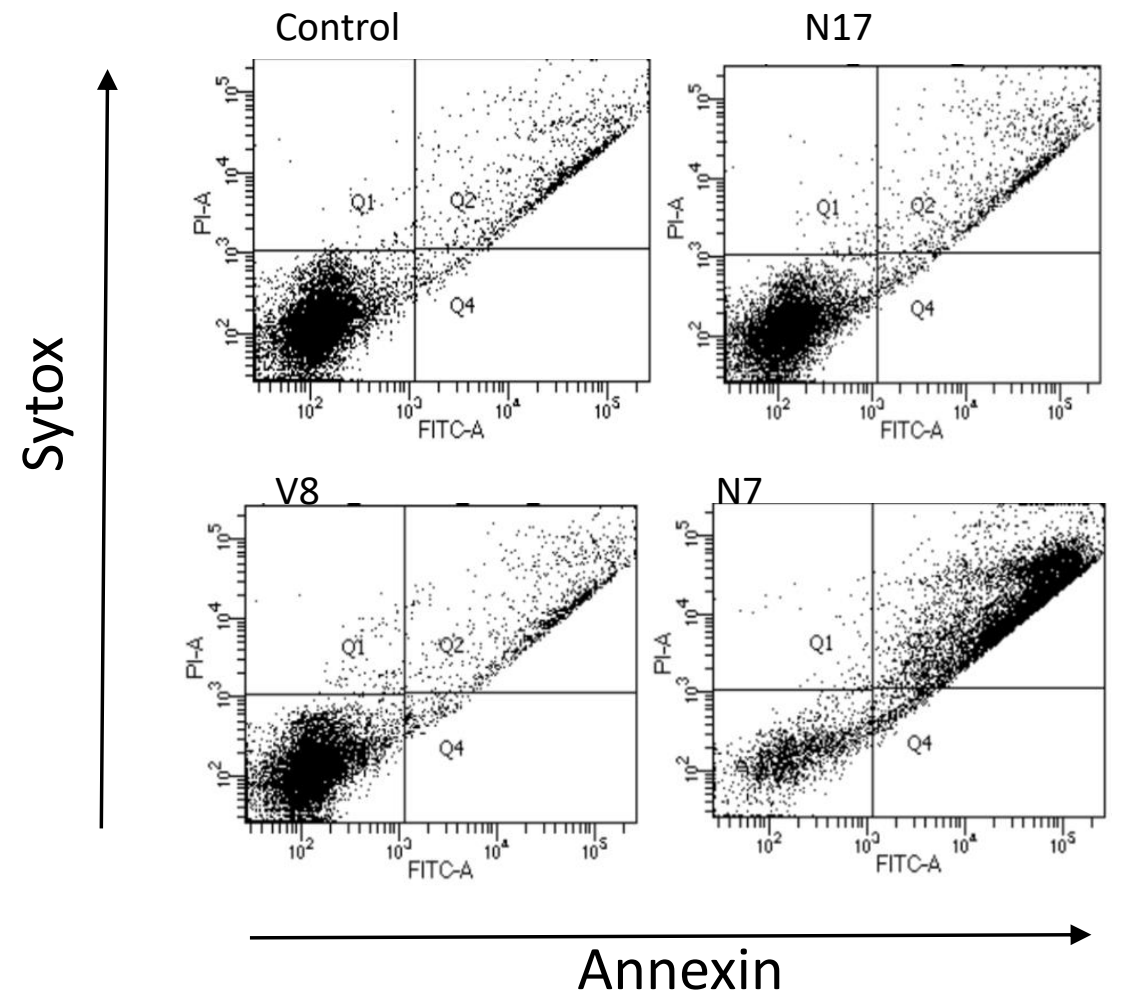

Figure 4.10. Cell death caused by the compounds. Induction of apoptosis by compounds N7, N17 and V8. HL60 cells were treated for $18 \mathrm{hr}$ with each compound (5, 20 or $40 \mu \mathrm{M}$ ) and apoptosis was quantified by flow cytometry. A representative image of flow cytometry using treated HL60 cells. The lower left quadrant represents live cells, the lower right quadrant represents cells exhibiting early apoptosis and the upper right quadrant represents late apoptotic cells. 
Table 4.1 Quantification of cells in each quadrant for each compound is shown in Figure 4.10. Average of triplicate of each experiment was measured when the TIGK cells were treated with the compounds. * indicates a significant increase $(\mathrm{p}<0.001)$ in late apoptotic cells over medium and medium/DMSO controls.

Late apoptosis/

\begin{tabular}{|c|c|c|c|c|}
\hline$\underline{\text { Treat }}$ & & $(\mu \mathrm{M})$ & Early apoptosis (\%) & necrosis $(\%)$ \\
\hline \multicolumn{2}{|c|}{ Medium } & & 2.6 & 2.7 \\
\hline \multicolumn{2}{|c|}{ Medium/DMSO } & & 1.4 & 3.9 \\
\hline \multicolumn{2}{|c|}{ Medium $/ \mathrm{H}_{2} \mathrm{O}_{2}$} & & 4.9 & $21.9 *$ \\
\hline \multirow[t]{3}{*}{ N17 } & 5 & & 2.9 & 4.2 \\
\hline & 20 & & 2.4 & 3.6 \\
\hline & 40 & & 1.5 & 5.1 \\
\hline \multirow[t]{3}{*}{ V8 } & 5 & & 3.1 & 4.2 \\
\hline & 20 & & 2.1 & 3.5 \\
\hline & 40 & & 2.4 & 3.4 \\
\hline \multirow[t]{3}{*}{ N7 } & 5 & & 2.4 & 8.3 \\
\hline & 20 & & 1.0 & $14.9 *$ \\
\hline & 40 & & 5.9 & $40.7 *$ \\
\hline
\end{tabular}


Table 4.2: Quantification of early and late apoptotic J774A.1 cells treated with compounds at different concentration. Average of triplicate of each experiment was measured. * indicates a significant increase $(\mathrm{p}<0.001)$ in late apoptotic cells over medium and medium/DMSO controls.

\begin{tabular}{lcccc} 
Treatment & Conc $(\mu \mathrm{M})$ & Live cells $(\%)$ & Early apoptosis $(\%)$ & $\begin{array}{c}\text { Late apoptosis/ } \\
\text { necrosis }(\%)\end{array}$ \\
\hline Medium & & & & 5.3 \\
Medium/DMSO & & 89.6 & 0.1 & 5.6 \\
Medium $/ \mathrm{H}_{2} \mathrm{O}_{2}$ & & 49.6 & 1.3 & $34.7^{*}$ \\
$\mathrm{~N} 17$ & 5 & 87.8 & 1.0 & 6.1 \\
& 20 & 85.3 & 1.0 & 6.9 \\
& 40 & 87.3 & 1.2 & 6.6 \\
& & & & 8.3 \\
V8 & 5 & 85.1 & 1.1 & 8.0 \\
& 20 & 83.4 & 0.9 & 9.1 \\
& 40 & 84.3 & 12.5 & 5.5 \\
& & & & $46.6^{*}$ \\
& 5 & 83.9 & 2.5 & $38.0^{*}$
\end{tabular}


Table 4.3: Quantification of early and late apoptotic HL60 cells treated with compounds at different concentration. Average of triplicate of each experiment was measured. * indicates a significant increase $(\mathrm{p}<0.001)$ in late apoptotic cells over medium and medium/DMSO controls.

\begin{tabular}{|c|c|c|c|c|}
\hline Treatment & Conc $(\mu \mathrm{M})$ & Live cells (\%) & Early apoptosis $(\%)$ & $\begin{array}{l}\text { te apoptosis/ } \\
\text { necrosis }(\%)\end{array}$ \\
\hline Medium & & 88.9 & 1.1 & 6.9 \\
\hline Medium/DMSO & & 90.0 & 1.2 & 6.6 \\
\hline Medium/ $\mathrm{H}_{2} \mathrm{O}_{2}$ & & 52.7 & $12.3^{*}$ & $31.4^{*}$ \\
\hline \multirow[t]{3}{*}{ N17 } & 5 & 91.3 & 2.7 & 4.7 \\
\hline & 20 & 90.3 & 2.2 & 6.0 \\
\hline & 40 & 91.6 & 2.3 & 6.3 \\
\hline \multirow[t]{3}{*}{ V8 } & 5 & 91.8 & 2.9 & 5.6 \\
\hline & 20 & 91.3 & 3.7 & 5.0 \\
\hline & 40 & 88.4 & 2.4 & 6.7 \\
\hline \multirow[t]{3}{*}{ N7 } & 5 & 87.4 & 3.6 & 7.8 \\
\hline & 20 & 27.3 & $20.9^{*}$ & $43.9 *$ \\
\hline & 40 & 18.9 & 7.7 & $70.8^{*}$ \\
\hline
\end{tabular}




\section{A}
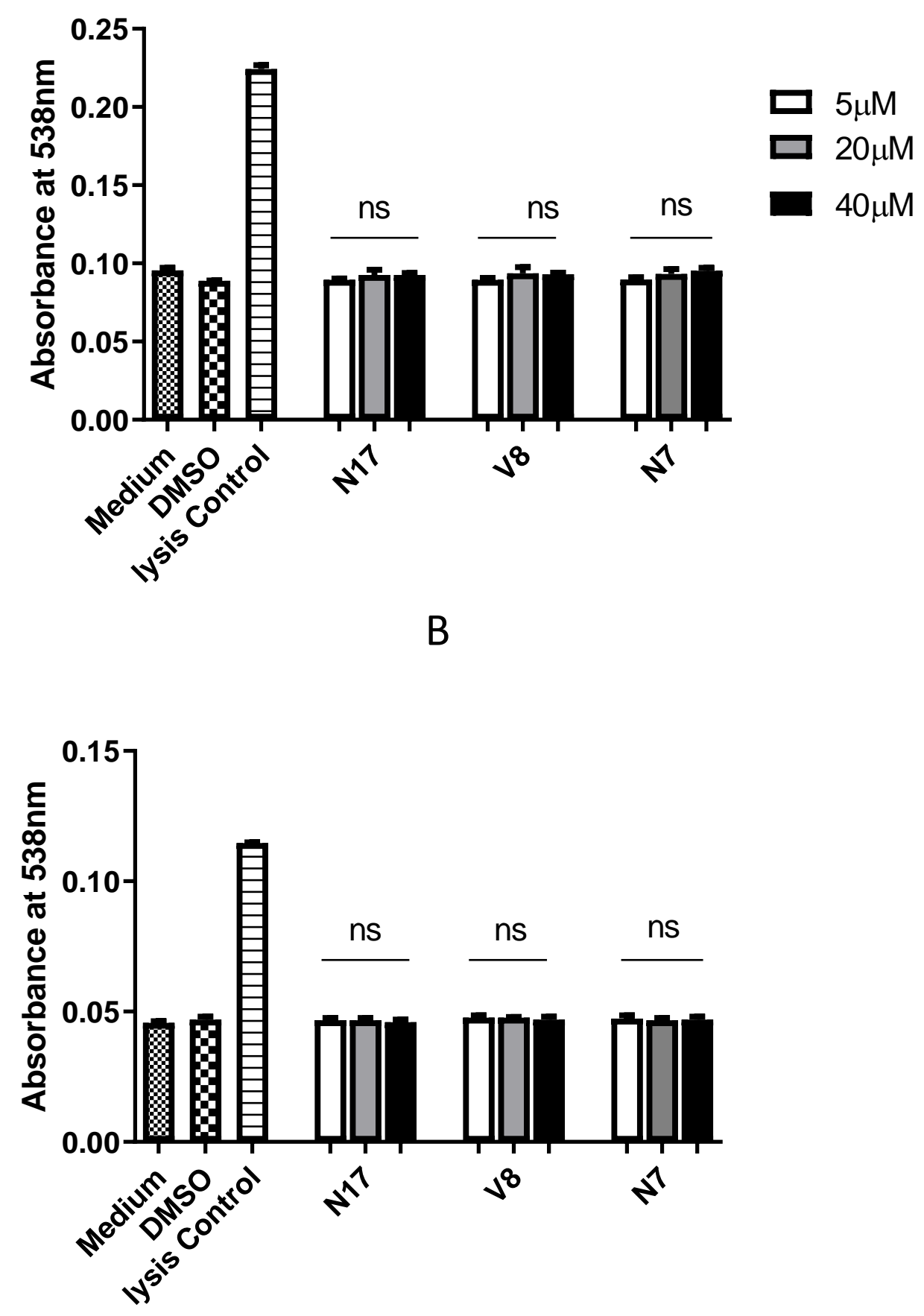

Figure 4.11. Hemolytic assay: Hemolytic activity against sheep (A) and human (B) red blood cells after $4 \mathrm{hr}$ incubation with compounds N7, N17 and V8 at 5, 20, or $40 \mu \mathrm{M}$. ns, not significant. 


\subsection{Discussion}

$P$. gingivalis may contribute to the initiation and progression of periodontitis by functioning as a keystone pathogen that alters host innate immune functions leading to dysbiosis and chronic inflammation $[41,52,152]$. This raises the possibility that therapeutic approaches that are specific for $P$. gingivalis may be effective in controlling periodontal disease. One potential therapeutic target is the interaction of Mfal with streptococcal AgI/II, which may contribute to the initial colonization of the oral cavity by P. gingivalis.

Structural dissection of both AgI/II [134-136] and Mfa1 [168] previously identified specific amino acids and motifs that are required for adherence of $P$. gingivalis with streptococci and facilitated the development of a peptide that inhibits this interaction [135]. However, $P$. gingivalis is a highly proteolytic organism, which would likely limit the application of this peptide for therapeutic purposes. To address this limitation, small molecule peptidomimetics have been recently synthesized and were shown to inhibit $P$. gingivalis adherence $[141,142,161]$. In this study, we sought to identify additional small molecule inhibitors by virtual screening of the ZINC database (https://zinc.docking.org/) $[148,149,169]$ for commercially available compounds that exhibit similarity with the NITVK and VQDLL functional motifs of the streptococcal AgI/II protein. Three lead compounds, N7, N17 and V8, were identified and shown to inhibit $P$. gingivalis/streptococcal adherence in vitro and to reduce $P$. gingivalis virulence in vivo.

Of the three compounds, N17 was the most potent inhibitor of $P$. gingivalis adherence in vitro and exhibited an IC50 of $\sim 18 \mu \mathrm{M}$, similar to the first generation peptidomimetic compounds based on BAR peptide reported by Patil et al. [141] . Preliminary 
experiments using equimolar mixtures of $\mathrm{N} 17$ and $\mathrm{V} 8$ did not indicate significant synergistic activity. One possible explanation for this is that the binding of one compound, e.g., N17, to Mfa1 may sterically hinder the association of V8. In vivo, it has been previously shown that the presence of $S$. gordonii in the murine oral cavity promotes $P$. gingivalis virulence $[135,142]$ and consistent with this, infection of mice with both $S$. gordonii and $P$. gingivalis induced inflammation leading to resorption of alveolar bone. Treatment of infected animals with each of the compounds resulted in a significant reduction in $P$. gingivalis-mediated inflammation and bone loss. Indeed, bone loss in mice treated with compound N17 was not statistically different from shaminfected animals. Since compounds effectively reduce the adherence of $P$. gingivalis to $S$. gordonii, $P$. gingivalis induced IL 17 expression also reduced in gingival tissue in infected mice.

Compounds N17 and V8 exhibited little cytotoxicity against human gingival epithelial cells or human and mouse macrophage cell lines. In contrast, N7 exhibited a significant level of cytotoxicity in each of the cell culture tests that were performed. However, mice that were treated with compound N7 during the infection process did not exhibit any overt signs of distress or toxicity. This could be explained by the difference in the duration of exposure to the compound in the in vitro versus in vivo experiments. Animals that were treated with $\mathrm{N} 7$ were only transiently exposed $(\sim 20 \mathrm{~min})$ to the compound during infection with $P$. gingivalis whereas cell cultures were exposed to N7 for $18 \mathrm{hr}$ prior to the toxicity analyses.

One potential application that we envision for these compounds would be to prevent or reduce colonization of the re-developing oral microbiome by $P$. gingivalis after a patient 
is treated for periodontitis. Typically, the oral microbiome re-forms after treatment and disease recurrence can often occur. We speculate that topical application of these compounds, formulated in a dental varnish or mouth rinse may direct the redevelopment of the microbial community towards a healthy rather than pathogenic biofilm by preventing re-colonization of $P$. gingivalis. Our observation that transient exposure of animals to the compounds significantly reduced $P$. gingivalis virulence provides initial proof of concept that preventing $P$. gingivalis colonization of the oral microbiome may result in positive clinical outcomes. In addition, we previously showed that BAR peptide was also capable of disrupting an established biofilm containing $P$. gingivalis [170], which suggests that N17 and V8 may also have utility in treating existing periodontal infections.

In summary, virtual screening of the ZINC database identified three compounds that inhibited $P$. gingivalis adherence to oral streptococci and represent potential targeted therapeutics against periodontal disease. Two of these exhibited biocompatibility with both human and mouse cells and represent lead compounds that will provide a platform for further modification to improve potency. 


\section{CHAPTER FIVE: SUMMARY}

Periodontal disease is one of the most common oral diseases in the world and up to $47 \%$ of the adult population in the United States suffer from this disease [18]. Managing these diseases is also very expensive and each year, it costs $\$ 15$ billion dollars. Moreover, periodontitis is associated with systemic illness and increases the risk of heart disease, rheumatoid arthritis, diabetes, renal failure and Alzheimer's disease [153, 171]. Porphyromonas gingivalis is strongly associated with chronic adult periodontitis and is an important pathogen that is capable of modulating the host immune response and disrupting normal host/microbe homeostasis [41, 52, 152]. This can lead to the development of a dysbiotic microbial community which can induce uncontrolled inflammation leading to the destruction of tooth-supporting tissues, and ultimately tooth loss $[42,43]$.

The treatment of periodontal disease involves mechanical removal of dental plaque, a combination of antibiotic therapy, surgical removal of infected tissue and tissue regeneration therapy. The concern of antibiotic resistance and invasive treatment often perturb the complex microbial community that requires to maintain healthy gum. Targeted therapeutic approach against major pathogens associated with oral diseases could be an interesting avenue to treat periodontal diseases. Identifying and targeting the essential genes against pathogenic bacteria and blocking the gene function is one approach for targeted therapy. For instance, Stone et al. identified meso-diaminopimelate 
dehydrogenase which catalyzes the formation of M-DAP (diaminopimelate), an intermediate for lysine synthesis that is required for peptidoglycan synthesis as an essential $P$. gingivalis gene and targeting the meso-diaminopimelate with small molecule inhibitors effectively kills $P$. gingivalis cells [165]. Another attractive approach is the delivery of naturally occurring antimicrobial peptides or synthetic peptides in the oral cavity. For instance, Franzman et al. conjugated the $P$. gingivalis $\operatorname{IgG}$ with naturally occurring sheep myeloid antimicrobial peptide (SMAP) that specifically kills $P$. gingivalis in mixed-species biofilm [172]. Mahmoud et al. demonstrated that synthetic BAR peptide released by nanoparticles reduced $P$. gingivalis biofilm formation and prevented the loss of alveolar bone in an animal model of periodontitis [170, 173]. Thus, targeting pathogenic biofilm formation represents a valid approach to develop targeted therapies. Since $P$. gingivalis fimbriae mediate the physical interaction with other organisms and host cells, downregulating the expression of fimbriae, inhibiting fimbrial biogenesis, or targeting specific adhesin-receptor interactions are additional potential approaches for therapy development. For instance, Ho et al. showed that peptides derived from $S$. cristatus ArcA, designated as Streptococcal-derived anti- $P$. gingivalis peptide (SAAP), reduced FimA and Mfa1 expression along with some other virulence genes in $P$. gingivalis and reduced biofilm formation by this organism [174, 175]. Wright et al. screened a small molecule library and identified compounds with 2-aminoimidazole or 2aminobenzimidazole moieties that downregulated FimA and Mfal expression and inhibited biofilm formation of $P$. gingivalis with $S$. gordonii [176]. Alei et al. used a synthetic peptide derived from the $\mathrm{C}$ terminal conserved domain of Mfa1 to block Mfa1 polymerization and inhibited biofilm formation of P. gingivalis with S. gordonii [162]. 
P. gingivalis may initially colonize the oral cavity by adhering to streptococci and this interaction not only facilitates $P$. gingivalis colonization of the oral cavity but increases its virulence $[51,70,72,127,135]$. Therefore, this interaction is an ideal point for intervention. Adherence of $P$. gingivalis to streptococci is driven by two sets of adhesinreceptor interactions but the interaction of the short fimbrial protein Mfa1 of $P$. gingivalis with streptococcal surface antigen AgI/II is crucial [94, 127, 135]. Daep et al. characterized the binding region of $\mathrm{Ag} \mathrm{I} / \mathrm{II}$, designated as BAR, and showed that this region is comprised of two distinct structural motifs, NITVK and VQDLL, which resembled the eukaryotic nuclear receptor box protein-protein interaction domain [134, 136]. Subsequently targeting $P$. gingivalis adherence to streptococci, Daep et al. showed that a synthetic peptide representing BAR significantly reduced $P$. gingivalis-mediated bone loss in a mouse model of periodontitis [135]. More recently, Patil et al. synthesized peptidomimetics based on the BAR peptide which were effective in preventing in vitro community formation [141] and reduced bone loss in the in vivo model [142]. However, no other therapeutic compounds currently exist that specifically target $P$. gingivalis and inhibit its colonization of the oral cavity by preventing its association with oral streptococci. To develop additional more potent therapeutic agents, characterization of the Mfa1 binding site was required in order to better understand the mechanism of this protein-protein interaction at the molecular level.

In this study, I successfully characterized and identified Mfa1 fimbrial residues involved in interactions with $\mathrm{AgI} / \mathrm{II}$ using peptide mapping, in silico docking and mutagenesis approaches. From the peptide mapping studies (Figure 3.1), we showed that the functional region of Mfal resides between residues 225-400 (Figure 3.2). Taking 
advantage of the Mfa1 3D structure [100] and peptidomimetics based on the BAR peptide [141, 142], a putative binding cleft was predicted using Sitemap (Figure 3.3). Integrating the findings from peptide mapping with this in silico prediction, R240, W275 and two amphipathic regions (residues 321-329 and 351-364) were targeted for sitedirected mutagenesis and these studies confirmed the predicted binding cleft by demonstrating that these residues were essential for the interaction (Figure 3.4). Finally, full length $m f a 1$ genes containing mutations at R240 or A357 were constructed and complemented in a $P$. gingivalis Mfa1 deficient strain and analyzed their ability to adhere to $S$. gordonii (Figure 3.5b). The complemented strains were deficient in adherence, thus further validating that these residues comprise part of the binding cleft involved in the interaction with Ag I/II. To rule out the possibility that these mutations may influence the secretion or polymerization of Mfa1 [89, 100-102], cell surface levels of Mfa1 and self polymerization were examined. Neither mutation affected these events (Figure 3.5a and 3.6). Together, our findings suggest that R240, W275, amphipathic helical regions (residues 321-329 and 351-364) are required for the interaction of Mfal with Ag I/II. However, K70 and helical regions 180-194 were also predicted to comprise parts of the binding cleft, so further studies will be required to determine the functional activity of these amino acids in the interaction with $\mathrm{Ag} \mathrm{I} / \mathrm{II}$.

To discover candidate drug-like compounds that target $P$. gingivalis adherence to the streptococcal surface, a virtual screening was performed of commercially available compounds contained in the ZINC databases $[149,169]$ to identify compounds with structural similarity to the NITVK and VQDLL motifs of Ag I/II [146]. Three lead compounds were identified that inhibit in vitro biofilm formation (Figure 4.1 and 4.2). In 
vivo effectiveness was also determined in mice by treating animals with compounds $\mathrm{N} 7$, N17 or V8 at a concentration of $40 \mu \mathrm{M}$. Treatment significantly reduced alveolar bone loss relative to untreated mice (Figure 4.5.). $\mathrm{IC}_{50}$ values for these compounds were $\sim 15 \mu \mathrm{M}$, similar to the first generation BAR peptidomimetics synthesized by Patil et al. [141]. Thus, these compounds represent lead compounds that can be further modified to increase their effectiveness similar to synthetic BAR peptide $\left(\mathrm{IC}_{50} 1.3 \mu \mathrm{M}\right)$ [134]. Furthermore, consistent with a previous study by Mahmoud et al. [173] that targeted the interaction of Mfa1-Ag I/II using BAR peptide encapsulated nanoparticles, treatment with N7, N17 or V8 reduced local IL-17 levels in the gingival tissues (Figure 4.6). Finally, cytotoxic activity of the compounds was evaluated using various human and murine cell lines by measuring levels of LDH release, cellular ATP, cell apoptosis and hemolytic activity. N17 and V8 showed minimal detectable cytotoxic activity, whereas compound N7 was toxic to the cells (Figure 4.8, 9, 10, 11, and Table 4.1, 4.2 and 4.3). However, none of the compounds exhibited toxic activity in the in vivo experiments. An explanation for this may be that mice were only transiently exposed to the compounds during the infection process whereas the cell lines were chronically exposed for 24 hours prior to determining in vitro cytotoxicity. Thus, N17 and V8 represent potential therapeutic agents that may be useful in the treatment or prevention of periodontal diseases. We also recognize that the microbial community in the oral cavity is complex. For example, $F$. nucleatum is often co-local with $P$. gingivalis and co-infection with both organisms has been associated with increased virulence [177, 178], so further studies will be required to determine the efficacy of the candidate compounds in more complex biofilm model. 
In brief, I successfully identified the binding residues of Mfa1 that interact with Ag I/II surface antigen and also identified small molecule inhibitors that are effective in reducing P. gingivalis virulence. Overall, the valuable insight of this protein-protein interaction will facilitate the structural modification of the lead compounds in order to design more potent inhibitors that will reduce $P$. gingivalis colonization and virulence in the oral cavity. It would also be interesting to determine the efficacy of these inhibitors in clinical studies. For example, a Specifically Targeted Antimicrobial Peptide (STAMPs) was developed (designated C16G2) against the cariogenic pathogen S. mutans that is comprised of $16 \mathrm{mer} S$. mutans competence stimulating peptide (CSP) linked to the broad spectrum antimicrobial peptide G2. This STAMP potently killed S. mutans in a mixedspecies community without perturbing the commensal organisms [179, 180]. C16G2 has been formulated in a dental varnish and dental strip and is currently undergoing a Phase 2 clinical trial. Thus, we could hypothesize that formulation of the small molecule inhibitors identified in this study might be effective in a mouth rinse, dental varnish or dental strip to specifically eliminate $P$. gingivalis. A potential limitation of these formulations however, is that they would only transiently deliver the active agent to the oral cavity. Recent studies have examined the use of nanoparticles and nanofibers to increase the concentration and duration of active agents for oral applications $[170,173$, 181]. Indeed, nanoparticles have been widely used for the delivery of preventive drugs, in tooth implantation approaches and for the treatment of oral cancer [182]. We envision the possibility of delivering the small molecule inhibitors using nanoparticles and that nanoparticles-inhibitor conjugates could be formulated in a rinse, varnish or strip to improve the performance of these formulations. 


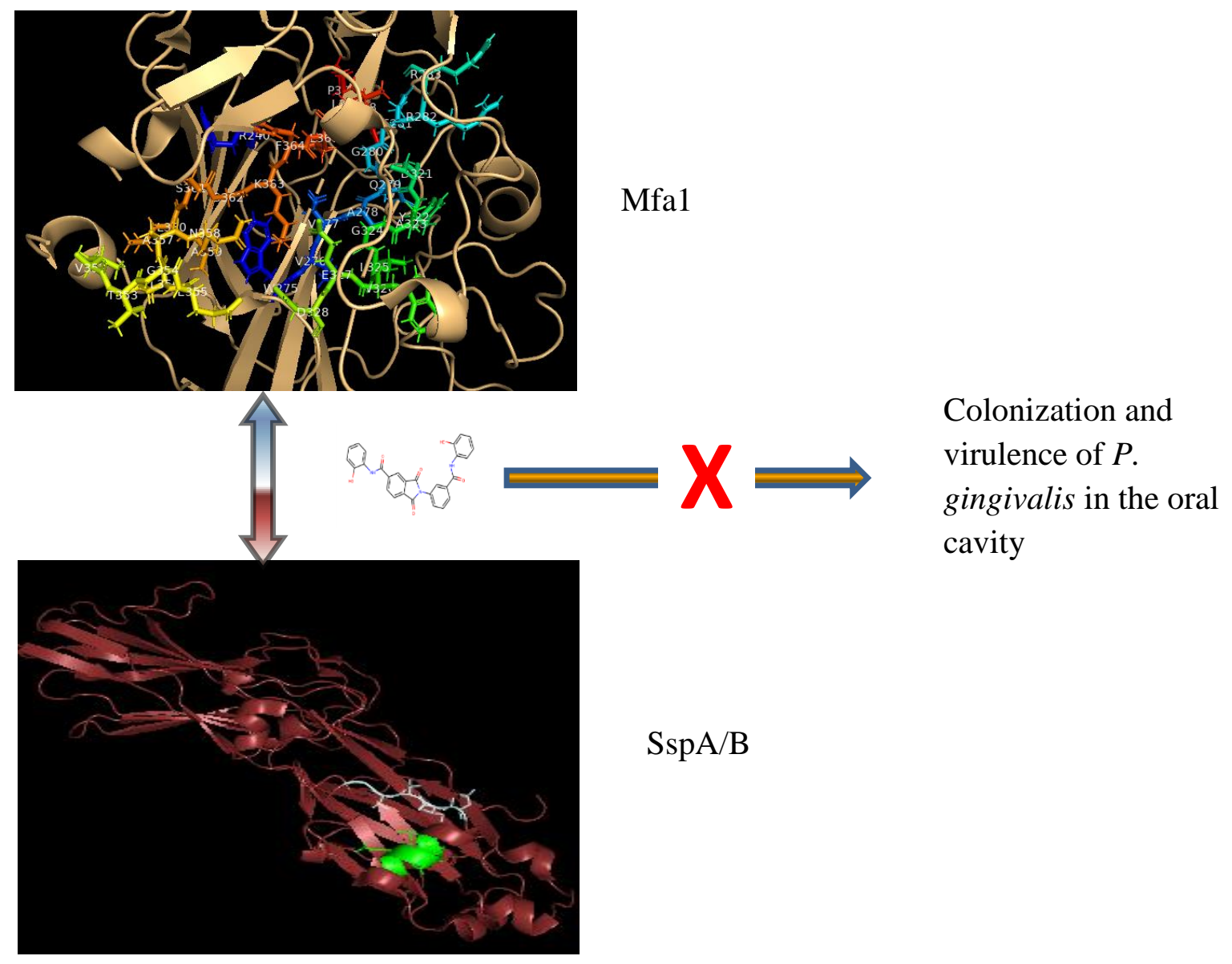

Figure 5. Graphical summary: The Minor fimbriae of $P$. gingivalis 3D structure was solved by Hall et al. (2018). Here we identified the binding antigens of Mfa1 that interact with Ag I/II depicted in rainbow color. Based on NITVK (cyan) and VQDLL (green) motif of SspA/B, lead compounds were identified that reduce P. gingivalis colonization and virulence in animal model of periodontitis. 


\section{CHAPTER SIX: FUTURE DIRECTIONS}

6.1. Co-crystallization of Mfa1 with BAR peptide/peptidomimetics: R240, W275, and the amphipathic regions (residues 321-326, 351-364) were identified as crucial amino acids of the Mfa1 binding cleft, but residue K70 and a putative helical region (residues 180-194) were also predicted as binding cleft residues. Their role in the interaction with Ag I/II needs to be further characterized to better understand the mechanism of this protein-protein interaction. Since the Mfa1 3D structure was recently published [100], it may be possible to co-crystallize Mfa1-BAR peptide or to the Mfa1-peptidomimetics (synthesized by Patil et.al.[141, 161]) to obtain a more complete picture of the binding interface as well as understanding the mechanism of this protein-protein interaction. To achieve this goal, purified Mfal can be conjugated with an equimolar concentration of BAR or ligands, and X-ray crystallography can be performed.

\subsection{Determine the efficacy of the lead compounds in the presence of bridging}

organism: The dental biofilm is a complex and organized microbial structure where other microorganisms such as Fusobacterium nucleatum independently interact with $P$. gingivalis and oral streptococci $[50,183]$. So to be considered as functional therapeutic agents, it will be necessary to determine the efficacy of the lead compounds in dispersing P. gingivalis-streptococcal biofilms in the presence of such organisms. Tan et al. developed a three species biofilm model by introducing the bridging organism $F$. nucleatum in dual-species biofilm [142] and have tested the efficacy of peptidomimetic 
compounds on the dispersion of this mixed-species biofilm. Fortunately, Tan et al. found peptidomimetics effectively inhibit biofilm formation in this three species biofilm model and have also shown these compounds effectively disperse a preformed biofilms [142]. Thus, it is possible to test the efficacy of the lead compounds in inhibition in the three species biofilm model. It will also be interesting to determine the effectiveness of these compounds in the dispersion of preformed dual-species or three species biofilms.

\subsection{Determination the effectiveness of the lead compounds in combined treatment:} NITVK and VQDLL of Ag I/II were identified as crucial for interaction with Mfa1 [134, 136]. Patil et al. [141, 157] synthesized peptidomimetics using a click chemistry approach, taking into consideration both of these motifs which effectively prevent biofilm formation. The lead compounds, N17 and V8 are based on the NITVK and VQDLL motifs respectively, and reduce bone loss in mice model of periodontitis but less effectively than $\mathrm{BAR}$ peptide $\left(\mathrm{IC}_{50}=1.3 \mu \mathrm{M}\right)$ [135]. One possibility is that treatment with a mixture of both N17 and V8 may increase effectiveness since mimics of both motifs will be present. Our preliminary findings (data not shown) suggest that when mice were treated with a combination of these two compounds (each at $5 \mu \mathrm{M}$ ) significantly reduced bone loss in the mice model. However, further studies will be required to determine the effectiveness of these compound mixtures at lower concentrations.

\subsection{Structure-Activity Relationship (SAR) Study of the Lead compounds: SAR is a} powerful tool to refine and improve the potency of active compounds by changing their chemical structure and subsequently assessing their functionality. SAR study can be 
performed using the free tools "Chembench" (https://chembench.mml.unc.edu/) developed by Tropsha Lab at the University of North Carolina at Chapel Hill [184].

6.5. Developing drug delivery vehicles: As discussed in Chapter 5, another challenge of treating periodontal disease is the localized delivery of the active therapeutic agents in the oral cavity because the systemic administration of drugs is ineffective against biofilm in the deeper tissue area. Previous studies suggest that peptide modified nanoparticles effectively disperse a preformed biofilm between $P$. gingivalis and oral streptococci [170], and reduced $P$. gingivalis virulence in the mouse model of periodontitis [173]. Therefore, in collaboration with the Bioengineering Department, it may be possible to develop poly lactic-co-glycolic acid (PLGA) nanoparticles that are surface-modified or that encapsulate the candidate small molecule inhibitors as described by Steinbach et al. [185] and assess their efficacy in dispersing a preformed biofilm dispersion in vitro as well as in vivo efficacy in the animal model system. Some of the advantages of using the PLGA are that it is already FDA approved, widely used as a food additive, relatively safe to humans, easy to synthesize and has inherent antimicrobial effects. The goal will be to engineering nanoparticle with our potential drug-like compounds to generate a platform to effectively deliver the therapeutic agents in the oral cavity. 


\section{REFERENCES}

1. LÖE, H., Periodontal diseases: a brief historical perspective. Periodontology 2000, 1993. 2(1): p. 7-12.

2. Mitsis, F.J., Hippocrates in the golden age: his life, his work and his contributions to dentistry. J Am Coll Dent, 1991. 58(1): p. 26-30.

3. Ong, G., Periodontal disease and tooth loss. Int Dent J, 1998. 48(3 Suppl 1): p. 233-8.

4. Olsen, I. and A.J. van Winkelhoff, Acute focal infections of dental origin. Periodontol 2000, 2014. 65(1): p. 178-89.

5. Tonetti, M.S., et al., Impact of the global burden of periodontal diseases on health, nutrition and wellbeing of mankind: A call for global action. J Clin Periodontol, 2017. 44(5): p. 456-462.

6. Kassebaum, N.J., et al., Global Burden of Severe Tooth Loss: A Systematic Review and Meta-analysis. J Dent Res, 2014. 93(7 Suppl): p. 20s-28s.

7. Jin, L.J., et al., Global burden of oral diseases: emerging concepts, management and interplay with systemic health. Oral Dis, 2016. 22(7): p. 609-19.

8. Nazir, M.A., Prevalence of periodontal disease, its association with systemic diseases and prevention. International journal of health sciences, 2017. 11(2): p. 72-80.

9. $\quad$ Eke, P.I., et al., Prevalence of periodontitis in adults in the United States: 2009 and 2010. J Dent Res, 2012. 91(10): p. 914-20.

10. Eke, P.I., et al., Periodontitis in US Adults: National Health and Nutrition Examination Survey 2009-2014. J Am Dent Assoc, 2018. 149(7): p. 576-588.e6.

11. Johnson, G.K. and M. Hill, Cigarette smoking and the periodontal patient. J Periodontol, 2004. 75(2): p. 196-209.

12. Albandar, J.M., et al., Cigar, pipe, and cigarette smoking as risk factors for periodontal disease and tooth loss. J Periodontol, 2000. 71(12): p. 1874-81.

13. Gautam, D.K., et al., Effect of cigarette smoking on the periodontal health status: A comparative, cross sectional study. Journal of Indian Society of Periodontology, 2011. 15(4): p. 383-387.

14. Preshaw, P.M., et al., Periodontitis and diabetes: a two-way relationship. Diabetologia, 2012. 55(1): p. 21-31.

15. Preshaw, P.M. and S.M. Bissett, Periodontitis: oral complication of diabetes. Endocrinol Metab Clin North Am, 2013. 42(4): p. 849-67.

16. Chapple, I.L.C., R. Genco, and E.F.P.A.A.P.w. on behalf of working group 2 of the joint, Diabetes and periodontal diseases: consensus report of the Joint EFP/AAP Workshop on Periodontitis and Systemic Diseases. Journal of Periodontology, 2013. 84(4S): p. S106-S112.

17. Beikler, T. and T.F. Flemmig, Oral biofilm-associated diseases: trends and implications for quality of life, systemic health and expenditures. Periodontol 2000, 2011. 55(1): p. 87-103.

18. Eke, P.I., et al., Update on Prevalence of Periodontitis in Adults in the United States: NHANES 2009 to 2012. J Periodontol, 2015. 86(5): p. 611-22. 
19. Johannsen, A., et al., Dental plaque, gingival inflammation, and elevated levels of interleukin-6 and cortisol in gingival crevicular fluid from women with stress-related depression and exhaustion. J Periodontol, 2006. 77(8): p. 1403-9.

20. Dolic, M., et al., Psychosocial factors as risk indicators of periodontitis. J Clin Periodontol, 2005. 32(11): p. 1134-40.

21. Merchant, A.T., et al., A prospective study of social support, anger expression and risk of periodontitis in men. J Am Dent Assoc, 2003. 134(12): p. 1591-6.

22. Marcenes, W.S. and A. Sheiham, The relationship between work stress and oral health status. Soc Sci Med, 1992. 35(12): p. 1511-20.

23. Kinane, D.F., P.G. Stathopoulou, and P.N. Papapanou, Periodontal diseases. Nature Reviews Disease Primers, 2017. 3(1): p. 17038.

24. Rheu, G.-B., et al., Risk assessment for clinical attachment loss of periodontal tissue in Korean adults. The journal of advanced prosthodontics, 2011. 3(1): p. 25-32.

25. Albandar, J.M. and T.E. Rams, Global epidemiology of periodontal diseases: an overview. Periodontol 2000, 2002. 29: p. 7-10.

26. Newman, H.N., Focal Infection. Journal of Dental Research, 1996. 75(12): p. 1912-1919.

27. Winning, L. and G.J. Linden, Periodontitis and systemic disease. Bdj Team, 2015. 2: p. 15163.

28. Mattila, K.J., et al., Association between dental health and acute myocardial infarction. British Medical Journal, 1989. 298(6676): p. 779.

29. Tonetti, M.S., T.E. Van Dyke, and E.F.P.A.A.P.w. working group 1 of the joint, Periodontitis and atherosclerotic cardiovascular disease: consensus report of the Joint EFP/AAP Workshop on Periodontitis and Systemic Diseases. Journal of Clinical Periodontology, 2013. 40(s14): p. S24-S29.

30. Sanz, M., K. Kornman, and E.F.P.A.A.P.w. working group 3 of the joint, Periodontitis and adverse pregnancy outcomes: consensus report of the Joint EFP/AAP Workshop on Periodontitis and Systemic Diseases. Journal of Clinical Periodontology, 2013. 40(s14): p. S164-S169.

31. Shen, T.C., et al., Risk of Periodontal Diseases in Patients With Chronic Obstructive Pulmonary Disease: A Nationwide Population-based Cohort Study. Medicine (Baltimore), 2015. 94(46): p. e2047.

32. Paju, S. and F.A. Scannapieco, Oral biofilms, periodontitis, and pulmonary infections. Oral diseases, 2007. 13(6): p. 508-512.

33. Chambrone, L., et al., Periodontitis and chronic kidney disease: a systematic review of the association of diseases and the effect of periodontal treatment on estimated glomerular filtration rate. J Clin Periodontol, 2013. 40(5): p. 443-56.

34. Rodríguez-Lozano, B., et al., Association between severity of periodontitis and clinical activity in rheumatoid arthritis patients: a case-control study. Arthritis Research \& Therapy, 2019. 21(1): p. 27.

35. Sparks Stein, P., et al., Serum antibodies to periodontal pathogens are a risk factor for Alzheimer's disease. Alzheimer's \& Dementia, 2012. 8(3): p. 196-203.

36. Jagannathachary, S. and D. Kamaraj, Obesity and periodontal disease. Journal of Indian Society of Periodontology, 2010. 14(2): p. 96-100.

37. Marchetti, E., et al., Periodontal disease: the influence of metabolic syndrome. Nutrition \& metabolism, 2012. 9(1): p. 88-88. 
38. Fitzpatrick, S.G. and J. Katz, The association between periodontal disease and cancer: a review of the literature. J Dent, 2010. 38(2): p. 83-95.

39. Ohki, T., et al., Detection of periodontal bacteria in thrombi of patients with acute myocardial infarction by polymerase chain reaction. Am Heart J, 2012. 163(2): p. 164-7.

40. Bansal, T., et al., C-Reactive Protein (CRP) and its Association with Periodontal Disease: A Brief Review. Journal of clinical and diagnostic research : JCDR, 2014. 8(7): p. ZE21-ZE24.

41. Hajishengallis, G. and R.J. Lamont, Breaking bad: manipulation of the host response by Porphyromonas gingivalis. Eur J Immunol, 2014. 44(2): p. 328-38.

42. Lamont, R.J. and G. Hajishengallis, Polymicrobial synergy and dysbiosis in inflammatory disease. Trends in molecular medicine, 2015. 21(3): p. 172-183.

43. Hajishengallis, G. and R.J. Lamont, Dancing with the Stars: How Choreographed Bacterial Interactions Dictate Nososymbiocity and Give Rise to Keystone Pathogens, Accessory Pathogens, and Pathobionts. Trends Microbiol, 2016. 24(6): p. 477-489.

44. Dewhirst, F.E., et al., The human oral microbiome. J Bacteriol, 2010. 192(19): p. 5002-17.

45. Kilian, M., et al., The oral microbiome - an update for oral healthcare professionals. British Dental Journal, 2016. 221(10): p. 657-666.

46. Hasan, A. and R.M. Palmer, A clinical guide to periodontology: pathology of periodontal disease. Br Dent J, 2014. 216(8): p. 457-61.

47. $\mathrm{Li}, \mathrm{J}$., et al., Identification of early microbial colonizers in human dental biofilm. J Appl Microbiol, 2004. 97(6): p. 1311-8.

48. Rosan, B. and R.J. Lamont, Dental plaque formation. Microbes and Infection, 2000. 2(13): p. 1599-1607.

49. Mahajan, A., et al., Interspecies communication and periodontal disease. TheScientificWorldJournal, 2013. 2013: p. 765434-765434.

50. Marsh, P.D., A. Moter, and D.A. Devine, Dental plaque biofilms: communities, conflict and control. Periodontol 2000, 2011. 55(1): p. 16-35.

51. Kuboniwa, M. and R.J. Lamont, Subgingival biofilm formation. Periodontology 2000, 2010. 52(1): p. 38-52.

52. Hajishengallis, G., et al., Low-Abundance Biofilm Species Orchestrates Inflammatory Periodontal Disease through the Commensal Microbiota and Complement. Cell Host \& Microbe, 2011. 10(5): p. 497-506.

53. Darveau, R.P., G. Hajishengallis, and M.A. Curtis, Porphyromonas gingivalis as a potential community activist for disease. J Dent Res, 2012. 91(9): p. 816-20.

54. Hajishengallis, G. and R.J. Lamont, Beyond the red complex and into more complexity: the polymicrobial synergy and dysbiosis (PSD) model of periodontal disease etiology. 2012. 27(6): p. 409-419.

55. Cekici, A., et al., Inflammatory and immune pathways in the pathogenesis of periodontal disease. Periodontology 2000, 2014. 64(1): p. 57-80.

56. Nicu, E.A. and B.G. Loos, Polymorphonuclear neutrophils in periodontitis and their possible modulation as a therapeutic approach. Periodontology 2000, 2016. 71(1): p. 140-163.

57. Marcotte, H. and M.C. Lavoie, Oral Microbial Ecology and the Role of Salivary Immunoglobulin A. Microbiology and Molecular Biology Reviews, 1998. 62(1): p. 71. 
58. Zouali, M., The emerging roles of B cells as partners and targets in periodontitis. Autoimmunity, 2017. 50(1): p. 61-70.

59. Wright, C.J., et al., Microbial interactions in building of communities. Molecular oral microbiology, 2013. 28(2): p. 83-101.

60. Zenobia, C. and G. Hajishengallis, Porphyromonas gingivalis virulence factors involved in subversion of leukocytes and microbial dysbiosis. Virulence, 2015. 6(3): p. 236-243.

61. Yang, H.W., Y.F. Huang, and M.Y. Chou, Occurrence of Porphyromonas gingivalis and Tannerella forsythensis in periodontally diseased and healthy subjects. $\mathrm{J}$ Periodontol, 2004. 75(8): p. 1077-83.

62. Kawada, M., et al., Prevalence of Porphyromonas gingivalis in relation to periodontal status assessed by real-time PCR. Oral Microbiol Immunol, 2004. 19(5): p. 289-92.

63. Evans, R.T., et al., Periodontopathic potential of two strains of Porphyromonas gingivalis in gnotobiotic rats. Arch Oral Biol, 1992. 37(10): p. 813-9.

64. Cutler, C.W., J.R. Kalmar, and C.A. Genco, Pathogenic strategies of the oral anaerobe, Porphyromonas gingivalis. Trends Microbiol, 1995. 3(2): p. 45-51.

65. Lamont, R.J. and H.F. Jenkinson, Life below the gum line: pathogenic mechanisms of Porphyromonas gingivalis. Microbiology and molecular biology reviews : MMBR, 1998. 62(4): p. 1244-1263.

66. Bradshaw, D.J., et al., Role of Fusobacterium nucleatum and coaggregation in anaerobe survival in planktonic and biofilm oral microbial communities during aeration. Infection and immunity, 1998. 66(10): p. 4729-4732.

67. Lamont, R.J., S.G. Hersey, and B. Rosan, Characterization of the adherence of Porphyromonas gingivalis to oral streptococci. Oral Microbiol Immunol, 1992. 7(4): p. 193-7.

68. Yamaguchi, T., et al., Preparation and characterization of an Actinomyces naeslundii aggregation factor that mediates coaggregation with Porphyromonas gingivalis. J Periodontal Res, 1998. 33(8): p. 460-8.

69. Takahashi, N., Acid-neutralizing activity during amino acid fermentation by Porphyromonas gingivalis, Prevotella intermedia and Fusobacterium nucleatum. Oral Microbiol Immunol, 2003. 18(2): p. 109-13.

70. Demuth, D.R., et al., Tandem genes encode cell-surface polypeptides SspA and $S s p B$ which mediate adhesion of the oral bacterium Streptococcus gordonii to human and bacterial receptors. Mol Microbiol, 1996. 20(2): p. 403-13.

71. Demuth, D.R., et al., Discrete Protein Determinant Directs the Species-Specific Adherence of Porphyromonas gingivalis to Oral Streptococci. Infection and Immunity, 2001. 69(9): p. 5736-5741.

72. Slots, J. and R.J. Gibbons, Attachment of Bacteroides melaninogenicus subsp. asaccharolyticus to oral surfaces and its possible role in colonization of the mouth and of periodontal pockets. Infection and immunity, 1978. 19(1): p. 254-264.

73. Hamada, S., et al., The importance of fimbriae in the virulence and ecology of some oral bacteria. Oral Microbiol Immunol, 1998. 13(3): p. 129-38.

74. Dickinson, D.P., et al., Molecular cloning and sequencing of the gene encoding the fimbrial subunit protein of Bacteroides gingivalis. J Bacteriol, 1988. 170(4): p. 165865. 
75. Nakagawa, I., et al., Distribution and molecular characterization of Porphyromonas gingivalis carrying a new type of fimA gene. J Clin Microbiol, 2000. 38(5): p. 1909-14.

76. Neiders, M.E., et al., Heterogeneity of virulence among strains of Bacteroides gingivalis. J Periodontal Res, 1989. 24(3): p. 192-8.

77. Nakano, K., et al., Comparison of inflammatory changes caused by Porphyromonas gingivalis with distinct fimA genotypes in a mouse abscess model. Oral Microbiol Immunol, 2004. 19(3): p. 205-9.

78. Amano, A., et al., Variations of Porphyromonas gingivalis fimbriae in relation to microbial pathogenesis. Journal of Periodontal Research, 2004. 39(2): p. 136-142.

79. Nagano, K., et al., FimB Regulates FimA Fimbriation in Porphyromonas gingivalis. Journal of Dental Research, 2010. 89(9): p. 903-908.

80. Yoshimura, F., et al., Surface components of Porphyromonas gingivalis. J Periodontal Res, 2009. 44(1): p. 1-12.

81. Nishiyama, S.I., et al., Involvement of minor components associated with the FimA fimbriae of Porphyromonas gingivalis in adhesive functions. Microbiology, 2007. 153(Pt 6): p. 1916-1925.

82. Enersen, M., K. Nakano, and A. Amano, Porphyromonas gingivalis fimbriae. Journal of oral microbiology, 2013. 5: p. 10.3402/jom.v5i0.20265.

83. Jeong, S.H., et al., Interrupting oral infection of Porphyromonas gingivalis with anti-FimA antibody attenuates bacterial dissemination to the arthritic joint and improves experimental arthritis. Exp Mol Med, 2018. 50(3): p. e460.

84. Zhang, W., et al., Fimbriae of Porphyromonas gingivalis are important for initial invasion of osteoblasts, but not for inhibition of their differentiation and mineralization. $\mathbf{J}$ Periodontol, 2011. 82(6): p. 909-16.

85. Goulbourne, P.A. and R.P. Ellen, Evidence that Porphyromonas (Bacteroides) gingivalis fimbriae function in adhesion to Actinomyces viscosus. J Bacteriol, 1991. 173(17): p. 5266-74.

86. Hashimoto, M., et al., Binding of Porphyromonas gingivalis fimbriae to Treponema denticola dentilisin. FEMS Microbiol Lett, 2003. 226(2): p. 267-71.

87. Brooks, W., et al., Identification of a Streptococcus gordonii SspB domain that mediates adhesion to Porphyromonas gingivalis. Infect Immun, 1997. 65(9): p. 3753-8.

88. Maeda, K., et al., Glyceraldehyde-3-phosphate dehydrogenase of Streptococcus oralis functions as a coadhesin for Porphyromonas gingivalis major fimbriae. Infection and immunity, 2004. 72(3): p. 1341-1348.

89. Xu, Q., et al., A Distinct Type of Pilus from the Human Microbiome. Cell, 2016. 165(3): p. 690-703.

90. How, K.Y., K.P. Song, and K.G. Chan, Porphyromonas gingivalis: An Overview of Periodontopathic Pathogen below the Gum Line. 2016. 7(53).

91. Zeituni, A.E., et al., Targeting of DC-SIGN on human dendritic cells by minor fimbriated Porphyromonas gingivalis strains elicits a distinct effector $T$ cell response. $\mathrm{J}$ Immunol, 2009. 183(9): p. 5694-704.

92. Zeituni, A.E., et al., The native 67-kilodalton minor fimbria of Porphyromonas gingivalis is a novel glycoprotein with DC-SIGN-targeting motifs. J Bacteriol, 2010. 192(16): p. 4103-10. 
93. Amano, A., Bacterial adhesins to host components in periodontitis. Periodontology 2000, 2010. 52(1): p. 12-37.

94. Park, Y., et al., Short Fimbriae of Porphyromonas gingivalis and Their Role in Coadhesion with Streptococcus gordonii. Infection and Immunity, 2005. 73(7): p. 39833989.

95. Lin, X., J. Wu, and H. Xie, Porphyromonas gingivalis minor fimbriae are required for cell-cell interactions. Infection and immunity, 2006. 74(10): p. 6011-6015.

96. Remaut, H., et al., Donor-strand exchange in chaperone-assisted pilus assembly proceeds through a concerted beta strand displacement mechanism. Mol Cell, 2006. 22(6): p. 831-42.

97. Proft, T. and E.N. Baker, Pili in Gram-negative and Gram-positive bacteria structure, assembly and their role in disease. Cell Mol Life Sci, 2009. 66(4): p. 613-35.

98. Waksman, G. and S.J. Hultgren, Structural biology of the chaperone-usher pathway of pilus biogenesis. Nat Rev Microbiol, 2009. 7(11): p. 765-74.

99. Zav'yalov, V., et al., Adhesive organelles of Gram-negative pathogens assembled with the classical chaperone/usher machinery: structure and function from a clinical standpoint. FEMS Microbiol Rev, 2010. 34(3): p. 317-78.

100. Hall, M., et al., Structural and functional characterization of shaft, anchor, and tip proteins of the Mfal fimbria from the periodontal pathogen Porphyromonas gingivalis. Sci Rep, 2018. 8(1): p. 1793.

101. Lee, J.Y., et al., Maturation of the Mfal Fimbriae in the Oral Pathogen Porphyromonas gingivalis. Frontiers in cellular and infection microbiology, 2018. 8: p. 137-137.

102. Shoji, M., et al., Recombinant Porphyromonas gingivalis FimA preproprotein expressed in Escherichia coli is lipidated and the mature or processed recombinant FimA protein forms a short filament in vitro. Can J Microbiol, 2010. 56(11): p. 959-67.

103. Shoji, M., et al., The major structural components of two cell surface filaments of Porphyromonas gingivalis are matured through lipoprotein precursors. Mol Microbiol, 2004. 52(5): p. 1513-25.

104. Kadowaki, T., et al., Arg-gingipain acts as a major processing enzyme for various cell surface proteins in Porphyromonas gingivalis. J Biol Chem, 1998. 273(44): p. 29072-6.

105. Hasegawa, Y., et al., Anchoring and length regulation of Porphyromonas gingivalis Mfal fimbriae by the downstream gene product Mfa2. Microbiology, 2009. 155(Pt 10): p. 3333-3347.

106. Hasegawa, Y., et al., Localization and function of the accessory protein Mfa3 in Porphyromonas gingivalis Mfal fimbriae. Molecular Oral Microbiology, 2013. 28(6): p. 467-480.

107. Ikai, R., et al., Mfa4, an Accessory Protein of Mfal Fimbriae, Modulates Fimbrial Biogenesis, Cell Auto-Aggregation, and Biofilm Formation in Porphyromonas gingivalis. PLOS ONE, 2015. 10(10): p. e0139454.

108. Nyvad, B. and M. Kilian, Microbiology of the early colonization of human enamel and root surfaces in vivo. Scand J Dent Res, 1987. 95(5): p. 369-80.

109. Socransky, S.S., et al., Bacteriological studies of developing supragingival dental plaque. Journal of Periodontal Research, 1977. 12(2): p. 90-106. 
110. Whitmore, S.E. and R.J. Lamont, The pathogenic persona of communityassociated oral streptococci. Molecular microbiology, 2011. 81(2): p. 305-314.

111. Jakubovics, N.S. and P.E. Kolenbrander, The road to ruin: the formation of disease-associated oral biofilms. Oral Dis, 2010. 16(8): p. 729-39.

112. Abranches, J., et al., Biology of Oral Streptococci. Microbiology spectrum, 2018.

6(5): p. 10.1128/microbiolspec.GPP3-0042-2018.

113. Banas, J.A., Virulence properties of Streptococcus mutans. Front Biosci, 2004. 9: p. 1267-77.

114. Burne, R.A. and R.E. Marquis, Alkali production by oral bacteria and protection against dental caries. FEMS Microbiol Lett, 2000. 193(1): p. 1-6.

115. Wang, B.Y. and H.K. Kuramitsu, Interactions between oral bacteria: inhibition of Streptococcus mutans bacteriocin production by Streptococcus gordonii. Appl Environ Microbiol, 2005. 71(1): p. 354-62.

116. Huang, X., et al., A Highly Arginolytic Streptococcus Species That Potently Antagonizes Streptococcus mutans. Appl Environ Microbiol, 2016. 82(7): p. 2187-201.

117. Liu, L., H. Tong, and X. Dong, Function of the pyruvate oxidase-lactate oxidase cascade in interspecies competition between Streptococcus oligofermentans and Streptococcus mutans. Appl Environ Microbiol, 2012. 78(7): p. 2120-7.

118. Tong, H., et al., Streptococcus oligofermentans inhibits Streptococcus mutans through conversion of lactic acid into inhibitory H2O2: a possible counteroffensive strategy for interspecies competition. Mol Microbiol, 2007. 63(3): p. 872-80.

119. Xie, H., et al., Intergeneric communication in dental plaque biofilms. J Bacteriol, 2000. 182(24): p. 7067-9.

120. Kuboniwa, M., et al., Proteomics of Porphyromonas gingivalis within a model oral microbial community. BMC Microbiol, 2009. 9: p. 98.

121. Brown, S.A. and M. Whiteley, A novel exclusion mechanism for carbon resource partitioning in Aggregatibacter actinomycetemcomitans. J Bacteriol, 2007. 189(17): p. 6407-14.

122. Ramsey, M.M., K.P. Rumbaugh, and M. Whiteley, Metabolite cross-feeding enhances virulence in a model polymicrobial infection. PLoS Pathog, 2011. 7(3): p. e1002012.

123. Bamford, C.V., et al., Streptococcus gordonii modulates Candida albicans biofilm formation through intergeneric communication. Infect Immun, 2009. 77(9): p. 3696-704.

124. Ma, J.K., et al., Conservation of the gene encoding streptococcal antigen I/II in oral streptococci. Infection and immunity, 1991. 59(8): p. 2686-2694.

125. Jenkinson, H.F. and D.R. Demuth, Structure, function and immunogenicity of streptococcal antigen I/II polypeptides. Mol Microbiol, 1997. 23(2): p. 183-90.

126. Demuth, D.R., E.E. Golub, and D. Malamud, Streptococcal-host interactions. Structural and functional analysis of a Streptococcus sanguis receptor for a human salivary glycoprotein. J Biol Chem, 1990. 265(13): p. 7120-6.

127. Lamont, R.J., et al., Role of the Streptococcus gordonii SspB protein in the development of Porphyromonas gingivalis biofilms on streptococcal substrates. Microbiology, 2002. 148(Pt 6): p. 1627-36.

128. Hannig, C., et al., The mucosal pellicle - An underestimated factor in oral physiology. Arch Oral Biol, 2017. 80: p. 144-152. 
129. Bensing, B.A., J.A. Lopez, and P.M. Sullam, The Streptococcus gordonii surface proteins GspB and Hsa mediate binding to sialylated carbohydrate epitopes on the platelet membrane glycoprotein Ibalpha. Infect Immun, 2004. 72(11): p. 6528-37.

130. Pancholi, V. and V.A. Fischetti, A major surface protein on group A streptococci is a glyceraldehyde-3-phosphate-dehydrogenase with multiple binding activity. J Exp Med, 1992. 176(2): p. 415-26.

131. McNab, R., et al., Cell surface polypeptide CshA mediates binding of Streptococcus gordonii to other oral bacteria and to immobilized fibronectin. Infect Immun, 1996. 64(10): p. 4204-10.

132. Elliott, D., et al., Prevalence of Csh-like fibrillar surface proteins among mitis group oral streptococci. Oral Microbiol Immunol, 2003. 18(2): p. 114-20.

133. Nagata, H., et al., Identification of the binding domain of Streptococcus oralis glyceraldehyde-3-phosphate dehydrogenase for Porphyromonas gingivalis major fimbriae. Infection and immunity, 2009. 77(11): p. 5130-5138.

134. Daep, C.A., et al., Structural characterization of peptide-mediated inhibition of Porphyromonas gingivalis biofilm formation. Infect Immun, 2006. 74(10): p. 5756-62.

135. Daep, C.A., et al., Structural Dissection and In Vivo Effectiveness of a Peptide Inhibitor of Porphyromonas gingivalis Adherence to Streptococcus gordonii. Infection and Immunity, 2011. 79(1): p. 67-74.

136. Daep, C.A., R.J. Lamont, and D.R. Demuth, Interaction of Porphyromonas gingivalis with Oral Streptococci Requires a Motif That Resembles the Eukaryotic Nuclear Receptor Box Protein-Protein Interaction Domain. Infection and Immunity, 2008. 76(7): p. 3273-3280.

137. Keestra, J.A., et al., Non-surgical periodontal therapy with systemic antibiotics in patients with untreated chronic periodontitis: a systematic review and meta-analysis. $\mathrm{J}$ Periodontal Res, 2015. 50(3): p. 294-314.

138. Rabelo, C.C., et al., Systemic antibiotics in the treatment of aggressive periodontitis. A systematic review and a Bayesian Network meta-analysis. J Clin Periodontol, 2015. 42(7): p. 647-57.

139. Ramfjord, S.P. and R.R. Nissle, The modified widman flap. J Periodontol, 1974. 45(8): p. 601-7.

140. Nyman, S., et al., New attachment following surgical treatment of human periodontal disease. J Clin Periodontol, 1982. 9(4): p. 290-6.

141. Patil, P.C., et al., 1,2,3-Triazole-based inhibitors of Porphyromonas gingivalis adherence to oral streptococci and biofilm formation. Bioorg Med Chem, 2016. 24(21): p. 5410-5417.

142. Tan, J., et al., In Vitro and In Vivo Activity of Peptidomimetic Compounds That Target the Periodontal Pathogen Porphyromonas gingivalis. Antimicrobial agents and chemotherapy, 2018. 62(7): p. e00400-18.

143. Pakula, R. and W. Walczak, On the nature of competence of transformable streptococci. J Gen Microbiol, 1963. 31: p. 125-33.

144. Gardner, R.G., et al., Use of a modified Bacteroides-Prevotella shuttle vector to transfer a reconstructed beta-1,4-D-endoglucanase gene into Bacteroides uniformis and Prevotella ruminicola B(1)4. Appl Environ Microbiol, 1996. 62(1): p. 196-202.

145. Hasegawa, Y., et al., Role of Mfa5 in Expression of Mfal Fimbriae in Porphyromonas gingivalis. Journal of dental research, 2016. 95(11): p. 1291-1297. 
146. Forsgren, N., R.J. Lamont, and K. Persson, Two intramolecular isopeptide bonds are identified in the crystal structure of the Streptococcus gordonii SspB C-terminal domain. J Mol Biol, 2010. 397(3): p. 740-51.

147. Cleves, A.E. and A.N. Jain, Robust Ligand-Based Modeling of the Biological Targets of Known Drugs. Journal of Medicinal Chemistry, 2006. 49(10): p. 2921-2938.

148. Irwin, J.J., et al., ZINC: A Free Tool to Discover Chemistry for Biology. Journal of Chemical Information and Modeling, 2012. 52(7): p. 1757-1768.

149. Sterling, T. and J.J. Irwin, ZINC 15--Ligand Discovery for Everyone. J Chem Inf Model, 2015. 55(11): p. 2324-37.

150. Moffatt-Jauregui, C.E., et al., Establishment and characterization of a telomerase immortalized human gingival epithelial cell line. J Periodontal Res, 2013. 48(6): p. 71321.

151. Olsen, I., J.D. Lambris, and G. Hajishengallis, Porphyromonas gingivalis disturbs host-commensal homeostasis by changing complement function. Journal of oral microbiology, 2017. 9(1): p. 1340085-1340085.

152. Hajishengallis, G., Periodontitis: from microbial immune subversion to systemic inflammation. Nat Rev Immunol, 2015. 15(1): p. 30-44.

153. Kim, J. and S. Amar, Periodontal disease and systemic conditions: a bidirectional relationship. Odontology, 2006. 94(1): p. 10-21.

154. Bingham, C.O., 3rd and M. Moni, Periodontal disease and rheumatoid arthritis: the evidence accumulates for complex pathobiologic interactions. Current opinion in rheumatology, 2013. 25(3): p. 345-353.

155. Kuboniwa, M., et al., Metabolic crosstalk regulates Porphyromonas gingivalis colonization and virulence during oral polymicrobial infection. Nature microbiology, 2017. 2(11): p. 1493-1499.

156. Chung, W.O., D.R. Demuth, and R.J. Lamont, Identification of a Porphyromonas gingivalis receptor for the Streptococcus gordonii SspB protein. Infect Immun, 2000. 68(12): p. 6758-62.

157. Patil, P.C., F.A. Luzzio, and D.R. Demuth, Oxazoles for click chemistry II: synthesis of extended heterocyclic scaffolds. Tetrahedron Lett, 2015. 56(23): p. 30393041.

158. Hamada, N., et al., Isolation and characterization of a minor fimbria from Porphyromonas gingivalis. Infection and Immunity, 1996. 64(11): p. 4788.

159. Sztukowska, M.N., M. Roky, and D.R. Demuth, Peptide and non-peptide mimetics as potential therapeutics targeting oral bacteria and oral biofilms. Mol Oral Microbiol, 2019. 34(5): p. 169-182.

160. Daep, C.A., et al., Selective substitution of amino acids limits proteolytic cleavage and improves the bioactivity of an anti-biofilm peptide that targets the periodontal pathogen, Porphyromonas gingivalis. Peptides, 2010. 31(12): p. 2173-8.

161. Patil, P.C., et al., 'Second-generation' 1,2,3-triazole-based inhibitors of Porphyromonas gingivalis adherence to oral streptococci and biofilm formation. Medchemcomm, 2019. 10(2): p. 268-279.

162. Alaei, S.R., et al., Peptide-Based Inhibitors of Fimbrial Biogenesis in \&lt;span class =\&quot;named-content genus-species\&quot; id=\&quot;named-content$1 \& q u o t ; \& g t ;$ Porphyromonas gingivalis\&lt;/span\&gt. Infection and Immunity, 2019. 87(3): p. e00750-18. 
163. Jepsen, K. and S. Jepsen, Antibiotics/antimicrobials: systemic and local administration in the therapy of mild to moderately advanced periodontitis. Periodontology 2000, 2016. 71(1): p. 82-112.

164. Socransky, S.S., et al., Microbial complexes in subgingival plaque. J Clin Periodontol, 1998. 25(2): p. 134-44.

165. Stone, V.N., et al., Identification of Small-Molecule Inhibitors against Meso-2, 6Diaminopimelate Dehydrogenase from Porphyromonas gingivalis. PloS one, 2015. 10(11): p. e0141126-e0141126.

166. Yu, J.J., et al., The Interleukin-17 Receptor Plays a Gender-Dependent Role in Host Protection against \&lt;em\&gt;Porphyromonas gingivalis\&lt;/em\&gt;-Induced Periodontal Bone Loss. Infection and Immunity, 2008. 76(9): p. 4206.

167. Cheng, W.C., F.J. Hughes, and L.S. Taams, The presence, function and regulation of IL-17 and Th17 cells in periodontitis. J Clin Periodontol, 2014. 41(6): p. 541-9.

168. Roky, M., J.O. Trent, and D.R. Demuth, Identification of functional domains of the minor fimbrial antigen involved in the interaction of Porphyromonas gingivalis with oral streptococci. Molecular Oral Microbiology, 2020. n/a(n/a).

169. Irwin, J.J. and B.K. Shoichet, ZINC--a free database of commercially available compounds for virtual screening. Journal of chemical information and modeling, 2005. 45(1): p. 177-182.

170. Mahmoud, M.Y., D.R. Demuth, and J.M. Steinbach-Rankins, BAR-encapsulated nanoparticles for the inhibition and disruption of Porphyromonas gingivalisStreptococcus gordonii biofilms. J Nanobiotechnology, 2018. 16(1): p. 69.

171. Hegde, R. and K.H. Awan, Effects of periodontal disease on systemic health. Dis Mon, 2019. 65(6): p. 185-192.

172. Franzman, M.R., et al., Targeted antimicrobial activity of a specific IgG-SMAP28 conjugate against Porphyromonas gingivalis in a mixed culture. Int J Antimicrob Agents, 2009. 33(1): p. 14-20.

173. Mahmoud, M.Y., J.M. Steinbach-Rankins, and D.R. Demuth, Functional assessment of peptide-modified PLGA nanoparticles against oral biofilms in a murine model of periodontitis. J Control Release, 2019. 297: p. 3-13.

174. Ho, M.-H., R.J. Lamont, and H. Xie, Identification of Streptococcus cristatus peptides that repress expression of virulence genes in Porphyromonas gingivalis. Scientific reports, 2017. 7(1): p. 1413-1413.

175. Ho, M.-H., R.J. Lamont, and H. Xie, A novel peptidic inhibitor derived from Streptococcus cristatus ArcA attenuates virulence potential of Porphyromonas gingivalis. Scientific reports, 2017. 7(1): p. 16217-16217.

176. Wright, C.J., et al., Disruption of heterotypic community development by Porphyromonas gingivalis with small molecule inhibitors. Molecular oral microbiology, 2014. 29(5): p. 185-193.

177. Whitmore, S.E. and R.J. Lamont, Oral bacteria and cancer. PLoS pathogens, 2014. 10(3): p. e1003933-e1003933.

178. Metzger, Z., et al., Synergistic pathogenicity of Porphyromonas gingivalis and Fusobacterium nucleatum in the mouse subcutaneous chamber model. J Endod, 2009. 35(1): p. 86-94. 
179. Eckert, R., et al., Targeted killing of Streptococcus mutans by a pheromoneguided "smart" antimicrobial peptide. Antimicrobial agents and chemotherapy, 2006. 50(11): p. 3651-3657.

180. Guo, L., et al., Precision-guided antimicrobial peptide as a targeted modulator of human microbial ecology. Proceedings of the National Academy of Sciences of the United States of America, 2015. 112(24): p. 7569-7574.

181. Kalia, P., et al., Peptide-modified nanoparticles inhibit formation of Porphyromonas gingivalis biofilms with Streptococcus gordonii. Int J Nanomedicine, 2017. 12: p. 4553-4562.

182. Priyadarsini, S., S. Mukherjee, and M. Mishra, Nanoparticles used in dentistry: A review. Journal of oral biology and craniofacial research, 2018. 8(1): p. 58-67.

183. Marsh, P.D., Dental plaque as a biofilm and a microbial community implications for health and disease. BMC oral health, 2006. 6 Suppl 1(Suppl 1): p. S14S14.

184. Capuzzi, S.J., et al., Chembench: A Publicly Accessible, Integrated Cheminformatics Portal. Journal of chemical information and modeling, 2017. 57(2): p. 105-108.

185. Steinbach, J.M., et al., Polymer nanoparticles encapsulating siRNA for treatment of HSV-2 genital infection. J Control Release, 2012. 162(1): p. 102-10. 


\title{
CURRICULUM VITAE
}

\author{
Mohammad K. Roky
}

\section{RESEARCH OBJECTIVE}

Microbial Pathogenesis, Host-Pathogen Interactions, Biofilm Infections, Quorum Sensing, Protein Engineering, Small Molecule Drug Discovery, Structure-Based Drug Design, Molecular Microbiology and Microbial Genetics.

\section{EDUCATION}

PhD in Microbiology and Immunology

July 2020

University of Louisville School of Medicine

Louisville, KY

Dissertation: Identification and characterization of functional motifs of short fimbriae of P. gingivalis.

Advisor: Dr. Donald R. Demuth

Master of Science in Microbiology and Immunology

University of Louisville

May 2016

Louisville, KY

Master of Science in Biochemistry and Molecular Biology

January 2012

University of Dhaka

Dhaka, Bangladesh

Thesis: Morphological changes of Vibrio cholerae under starved conditions and on nutritional supplementation.

Bachelor of Science in Biochemistry and Molecular Biology

June 2010

University of Dhaka

Dhaka, Bangladesh 


\section{RESEARCH EXPERIENCE}

Graduate Research Assistant

University of Louisville School of Medicine

August 2014 - July 2020

Louisville, KY

- Identification and characterization of the functional motifs of the short fimbriae (Mfa1) of $P$. gingivalis that interact with oral streptococcal surface antigen $(\mathrm{SspB})$ by expressing truncated Mfa1 peptides, in silico docking and mutagenesis studies. Then, the construction of Mfa1 mutants by site-directed mutagenesis and subsequent complementation in Mfa1 deficient strain to further confirm the identified Mfa1 antigen involve in this protein-protein interaction.

- Discovery of $P$. gingivalis specific small-molecule inhibitor targeting Mfa1-SspB interaction by employing virtual screening on the ZINC database and determination of their efficacy to inhibit biofilm formation in dual-species biofilm model.

- Determination of in vivo effectiveness of the identified small molecule in mice model of periodontitis by their ability to prevent bone loss measured by the dissection microscopy fitted with video imaging marker - also, the determination of IL 17 level in mice gingival tissue by immunofluorescence assay.

- Evaluation of the cytotoxicity of these compounds to various cell lines by performing LDH, ATP and hemolytic assay. Also performed apoptotic assay using flow cytometry to determine the cell death caused by these compounds.

Research Officer

February 2012 - June 2014

International Center for Diarrheal Disease Research,

Dhaka, Bangladesh

- The construction of the mutation in quorum-sensing autoinducers synthase genes CqsA, LuxS, double knock out strains, and complementation to determine the effect of quorum sensing in the resuscitation of Vibrio cholerae from the conditionally viable environmental cells (CVEC) in the environmental water samples which was further confirmed by synthetic autoinducers mediated resuscitation.

- Performed whole genome sequencing and analyzed the Vibrio-Phage (bacteriophages) genome to elucidate the role of CRISPR-Cas mediated bacteriophage predation and co-evolution of Vibrio cholerae.

- Spatiotemporal analysis of microbial abundance in estuarine of the Bay of Bengal to understand the environmental factors contributing to the Vibrio cholerae seasonal outbreak. Water samples were collected along with the river to estuarine at different 
locations and cultured in enriched media for enumeration. Also, the direct extraction of DNA was carried out from the water samples for 16s rRNA sequencing.

Graduate Research Assistant

International Center for Diarrheal Disease Research,

July 2010 - January 2012

Dhaka, Bangladesh

- Observed morphological changes of Vibrio cholerae in response to starvation in minimal media, environmental water and upon nutritional supplementation with bile acids using scanning electron microscopy.

- Construction of transposon mutant of Vibrio polysaccharide (vps) genes by homologous recombination in chitin induced natural competent cells to determine the possible role of these genes to go into Vibrio cholerae CVEC form in the environmental water.

\section{SKILLS AND TECHNIQUES}

- Viral and bacterial genetic manipulation: Cloning, gene deletion, Insertion and substitution mutations, site-directed mutagenesis, random mutagenesis, Gibson assembly.

- DNA transformation: Via conjugation, also transformation in chemical, electro and natural (chitin induced) competent cells of P. gingivalis, E. coli and Vibrio cholerae.

- DNA analysis: Southern blot, Dot blot, PCR, qPCR, RT-PCR

- Protein expression: His and GST tag expression system.

- Protein extraction and purification: Affinity and size exclusion chromatography, SDS-PAGE, Western Blot.

- Microscopy: Confocal (Leica SP8), Phase contrast (Olympus), Tabletop scanning electron microscopy (HITACHI TM 1000) and Dissection Microscopy.

- Mammalian cell culture and maintenance.

- Flow cytometry, ELISA, and Immunofluorescence assay.

- Next-generation sequencing: Illumina Nextseq platform, Velvet sequence assembler.

- Software and programming: Site Map (Binding site prediction), macro modeling, Small molecule docking, and Virtual screening (Shrodinger release 2014), Basic knowledge on $\mathrm{R}$.

- Biophysical assay: Microscale thermophoresis (MST).

- Bioinformatics tools: Blast, Chimera, CRISPR finder, Pymol, AutoDock Vina, Chromas, I-TASSR, Tm align. 


\title{
ACADEMIC LEADERSHIP
}

President, University of Louisville Bangladesh Student Association August 2018 - May 2019

- Organized cultural events.

- Interacted with other student groups.

- Budget preparation.

Mentor, University of Louisville Dept. of Oral Biology and Infectious Diseases August 2015 - May 2017

Mentored a Master's student

- Assisted and advised regarding experimental design and troubleshooting.

- Helped the student in data interpretation and statistical analysis.

Mentor, International Center for Diarrheal Disease Research May 2013 - August 2014 Mentored a Master's student from the University of Dhaka

- Guided the mentee to isolate vibriophages from the environmental water samples.

\author{
AWARDS \\ IPIBS Fellowship, University of Louisville School of Medicine August 2014 - May \\ 2016 \\ Dhaka University Fellowship, University of Dhaka \\ July 2007 - June 2009 \\ Postdoc Preview, University of Michigan \\ April 2020
}

\section{PROFESSIONAL MEMBERSHIP}

- American Society of Microbiology

2019 to present

- International Association for Dental Research 2019 to present

\section{CONFERENCE PRESENTATIONS/INVITED SPEAKER}

Mohammad Roky, Targeting $P$. gingivalis adherence on streptococci as a potential therapeutic intervention. (04/24/2020) Uniformed Services University of Health Sciences, Bethesda, MD (Invited speaker). 
Mohammad Roky, Jinlian Tan, Maryta Sztukowska and Donald R. Demuth. "Identification of small molecules that reduce $P$. gingivalis virulence in vivo". IADR 2020, Washington DC, DC (oral presentation).

Mohammad Roky, Jinlian Tan, and Donald R. Demuth. "Small molecule inhibitors targeting interbacterial adherence." MMPC 2019, University of Toledo, Toledo, OH. (Poster)

Mohammad Roky, Donald R. Demuth. "Functional motifs of the short fimbriae of $P$. gingivalis. ASM 2019, San Francisco, CA. (Poster)

Mohammad Roky, John O. Trent, Donald R. Demuth. "Identification and characterization of the functional domains and motifs of short fimbriae of $P$. gingivalis." Research Louisville 2018, University of Louisville, Louisville, KY. (Poster)

Enrique Rojas, Mohammad Roky, Shah M. Faruque. International Symposium on Microbial Ecology 2014, Seoul, Korea. (Poster)

\section{PUBLICATIONS}

Roky M, Tan J, Sztukowska MN, Trent JO, Donald DR. "Identification of small molecule inhibitors targeting Porphyromonas gingivalis interspecies adherence and determination of their in vitro and in vivo efficacy." (Submitted in Antimicrobial Agents and Chemotherapy)

Roky M, Trent JO, Demuth DR. "Identification of functional domains of the minor fimbrial antigen involved in the interaction of Porphyromonas gingivalis with oral streptococci." Mol Oral Microbiol. 2020;DOI:10.1111/omi.12280

Sztukowska MN, Roky M, Donald DR. Peptide and non-peptide mimetics as potential therapeutics targeting oral bacteria and oral biofilms. Mol Oral Microbiol 2019;34(5):169-182. DOI:10.1111/omi.12267

Naser, I. B., M. M. Hoque, M. A. Nahid, T. M. Tareq, M. K. Rocky and, S. M. Faruque (2017). "Analysis of the CRISPR-Cas system in bacteriophages active on epidemic strains of Vibrio cholerae in Bangladesh." Scientific Reports 7(1): 14880, doi.org/10.1038/s41598-017-14839-2

Bari, S. M., M. K. Roky, M. Mohiuddin, M. Kamruzzaman, J. J. Mekalanos and S. M. Faruque (2013). "Quorum-sensing autoinducers resuscitate dormant Vibrio cholerae in environmental water samples." Proc Natl Acad Sci U S A 110(24): 9926-9931. 